PNNL-13350

\title{
Electric Demand Reduction for the U.S. Navy Public Works Center San Diego, California
}

M. Kintner-Meyer

September 2000

Prepared for the U.S. Department of Energy under Contract DE-AC06-76RLO 1830 


\section{DISCLAIMER}

This report was prepared as an account of work sponsored by an agency of the United States Government. Neither the United States Government nor any agency thereof, nor Battelle Memorial Institute, nor any of their employees, makes any warranty, express or implied, or assumes any legal liability or responsibility for the accuracy, completeness, or usefulness of any information, apparatus, product, or process disclosed, or represents that its use would not infringe privately owned rights. Reference herein to any specific commercial product, process, or service by trade name, trademark, manufacturer, or otherwise does not necessarily constitute or imply its endorsement, recommendation, or favoring by the United States Government or any agency thereof, or Battelle Memorial Institute. The views and opinions of authors expressed herein do not necessarily state or reflect those of the United States Government or any agency thereof.

PACIFIC NORTHWEST NATIONAL LABORATORY operated by

BATTELLE MEMORIAL INSTITUTE for the UNITED STATES DEPARTMENT OF ENERGY under Contract DE-ACO6-76RLO 1830 


\section{Acknowledgements}

LCDR William Scherer, U.S. Navy provided significant contributions to this analysis. In particular, I would like to thank him for his efforts in developing robust cost data representing the Navy's operating and maintenance cost for various ship generators, which were used throughout this analysis. LCDR Scherer's insights into the Navy's operational requirements for operating ship generators were invaluable for this analysis. With his guidance, appropriate load reduction scenarios were selected, which are realistic for future implementation by the Navy.

I would like to thank representatives of Newenergy, Inc., who were engaged in several aspects of this study and who provided electric meter data and essential advice on new market developments in California and opportunities for the Navy to explore. Mr. Derik Viner, Manager of Electricity at Newenergy, Inc., provided technical support and advice in investigating ancillary service opportunities with the California Independent System Operator.

I would also like to thank Mr. John Thomas of the U.S. Navy Public Works Center San Diego, California, who was involved in every aspect of this study and who provided excellent guidance and support for completing the project. Funding was provided by the U.S. Navy Public Works Center San Diego, at the direction of Mr. Thomas. 


\section{Acronyms}

ALMDS Aggregated load meter data server

APX Automated Power Exchange

CAISO California Independent Systems Operator

CALPX California Power Exchange

CPUC California Public Utility Commission

DR

Demand Relief for Summer 2000 Program

ESP Energy service provider

IPP Independent Power Producer

ISO Independent System Operator

NE Newenergy, Inc.

O\&M Operating and Maintenance

PG\&E Pacific Gas and Electric Company

PNNL Pacific Northwest National Laboratory

PWC Public Works Center

PX Power Exchange

SC Scheduling Coordinator

SCADA Supervisory control and data acquisition

SCE Southern California Edison

SDG\&E San Diego Gas and Electric Company

SP15 South of Path 15. Path 15 is the border line between two major congestion zones defined by the CAISO

WSCC Western System Coordinating Council 


\section{Table of Contents}

Acknowledgements ............................................................................................................................................ iii

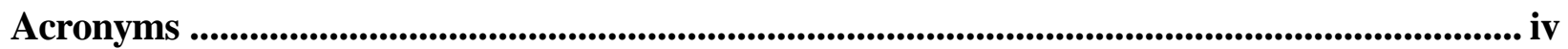

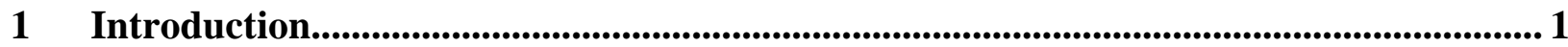

2 Objective ............................................................................................................................ 2

3 Introduction to California's New Electricity Market............................................................. 3

3.1 Two New Major Players in the New Electricity Market .............................................. 3

3.1.1 California Power Exchange ............................................................................... 3

3.1.2 California Independent System Operator (CAISO) .............................................. 4

3.1.3 CAISO Summer 2000 Trial Programs:.................................................................... 5

3.1.4 Navy's Current Electric Power Procurement Arrangement .................................... 7

4 Value Assessment of Electric Curtailment Programs .......................................................... 8

4.1 Value Estimates of Energy-Based Curtailment Program............................................... 9

4.1.1 Background and Definition............................................................................ 9

4.1.2 Conclusions for Energy-Based Curtailment Program.......................................... 12

4.2 Value Estimates for Capacity-Based Curtailment Program........................................... 12

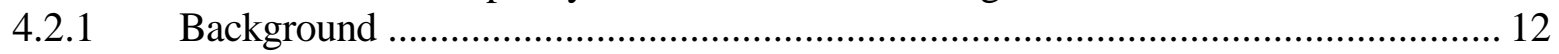

4.2.2 Evaluation of Capacity Value ……………….............................................. 14

4.2.3 Supply Curves of Replacement Reserve Bids .................................................... 16

4.2.4 Discussion on Bidding Strategies .................................................................... 17

4.2.5 Conclusion of the Capacity-Based Curtailment Program..................................... 18

4.3 Value Estimate for Demand Relief Program .......................................................... 19

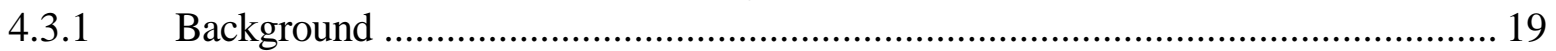

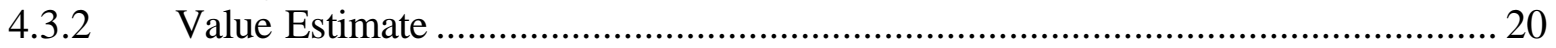

4.4 Value Estimate of Demand Reduction on the Coincident On-Peak Demand Charge of

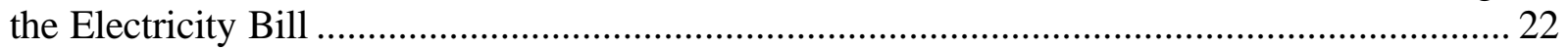

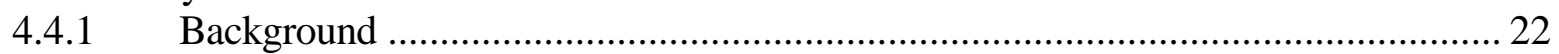

4.4.2 Value Estimate of On-Peak Demand Reduction................................................. 22

5 Comparison of Demand Reduction Programs ................................................................... 25

6 Cost Savings Estimates for CALPX Block Forward Contract ......................................... 27

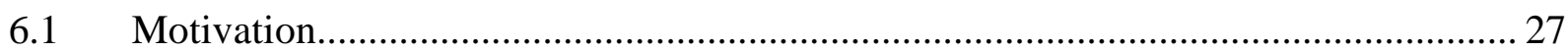

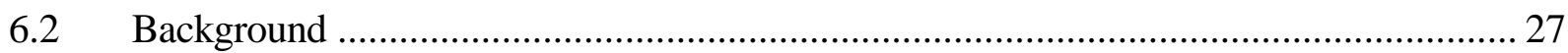

6.3 Design of an Optimal Block Forward Contract ............................................................ 28

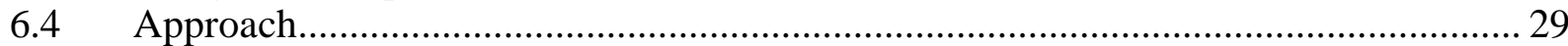

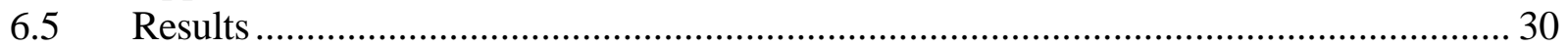




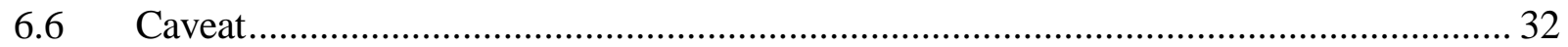

$7 \quad$ Volatility Analysis of the Load........................................................................................ 33

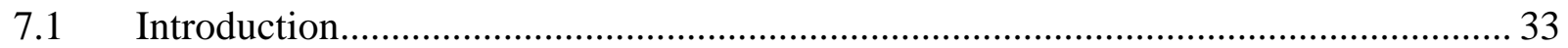

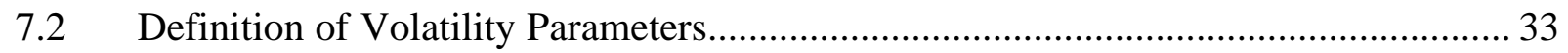

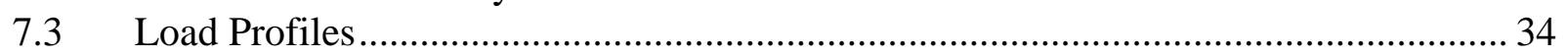

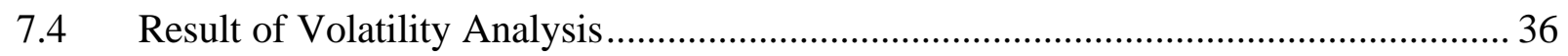

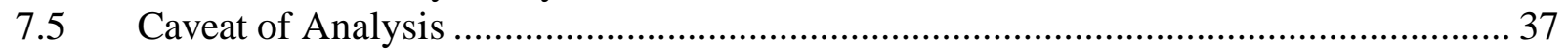

7.6 Non-Compliance Avoidance Strategy ...................................................................... 38

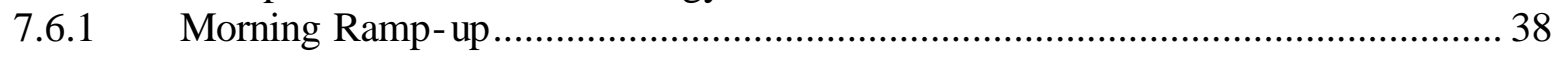

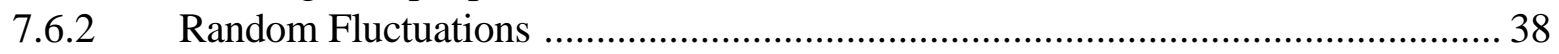

8 Comparison of Direct Access Versus Virtual Direct Access Rates ................................... 40

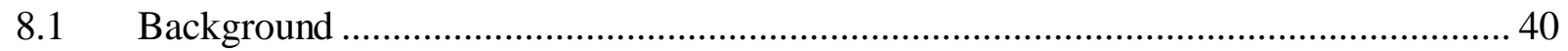

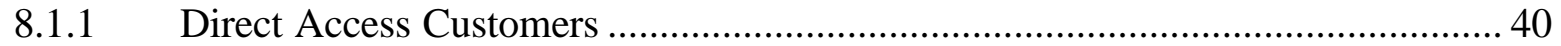

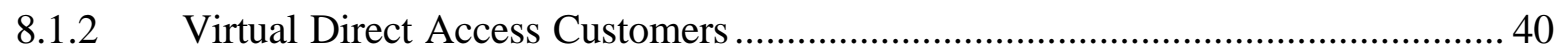

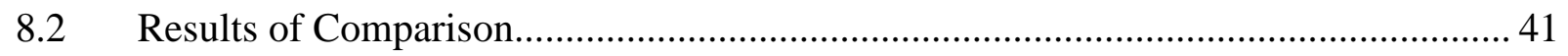

9 Trends and Developments ........................................................................................................... 43

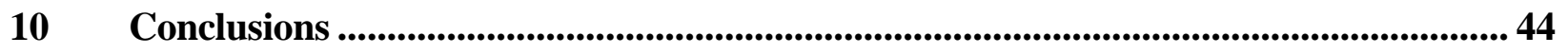

$10.1 \quad$ Energy-Based Load Reduction Program ................................................................ 44

10.2 Capacity-Based Load Reduction Program................................................................... 45

10.3 Demand Relief for Summer 2000 Program ............................................................. 45

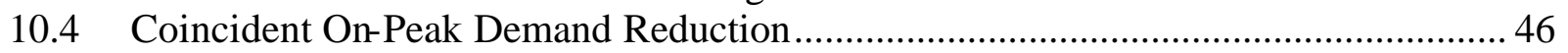

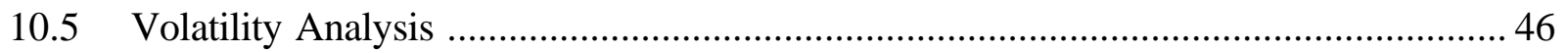

10.6 Block Forward Contracts ............................................................................................. 46

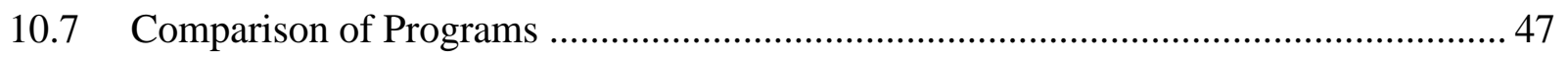

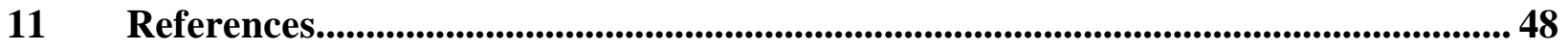

Appendix A: Load Profiles or Selected Navy Accounts ................................... A-1 Appendix B: Statistics of 15-Minute Interval Meter Readings by Day-of-Week........... B-1 


\section{Figures}

Figure 1: Price Duration Curve of CALPX Day-Ahead Price for Zone SP15. ...........................10 Figure 2: Time-of-the-Day Prices for Replacement Reserves (Generation). November 1998

through October 1999 representing 8760 Data Points .....................................................14

Figure 3: Total CAISO Replacement Reserve Market and Market Value of 35 MW of Navy's

Load Reduction Assets for the Period of November 1998 through October 1999................15

Figure 4: Supply Curve for Capacity Value of the Replacement Reserve Market, Based on the

Availability of 35 MW Load Reduction Assets .............................................................16

Figure 5: Supply Curve for Energy Value of the Replacement Reserve Market, Based on the

Availability of 35 MW Load Reduction Assets ........................................................... 17

Figure 6: CAISO Demand Relief Program Call Sequence .......................................................19

Figure 7: Schematic of Procurement Portfolio Consisting of Block Forward and Spot-Market

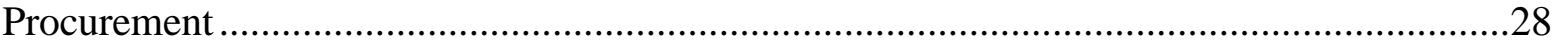

Figure 8 : CALPX Block Forward Prices as of January 13, 2000 ...........................................30

Figure 9: Optimal Block Forward Portfolio for Aggregated Accounts, August 1999.................31

Figure 10: Optimal Block Forward Portfolio for Aggregated Accounts, October 1999. ..............31

Figure 11: Winter Load Profile Using 15-Minute-Interval Data for Selected Accounts...............34

Figure 12: Summer Load Profile Using 15-Minute-Interval Data for Selected Accounts ...........34

Figure 13: Time-of-Day Load Profile for Three Accounts (Period November 1998 to October

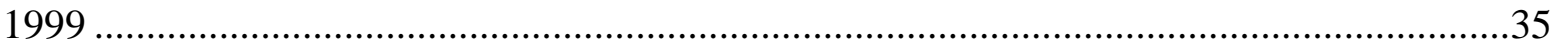

Figure 14: Normalized Probability Distribution Around the Mean of Aggregated Loads Using

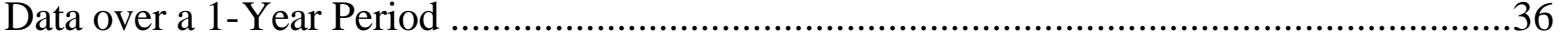

Figure 15: Cumulative Probability Function for Aggregated Accounts .....................................37

Figure 16: Non-Compliance Avoidance Strategy to Protect Against Random Load Fluctuations 39

Figure A-1: 15 Min. Interval Demands, November 1998 .................................................... A-1

Figure A-2: 15 Min. Interval Demands, December 1998 ................................................. A-1

Figure A-3: 15 Min. Interval Demands, January 1999 ........................................................ A-2

Figure A-4: 15 Min. Interval Demands, February 1999 ..................................................... A-2

Figure A-5: 15 Min. Interval Demands, March 1999 ........................................................ A-3

Figure A-6: 15 Min. Interval Demands, April 1999 ....................................................... A-3

Figure A-7: 15 Min. Interval Demands, May 1999 ............................................................... A-4

Figure A-8: 15 Min. Interval Demands, June 1999 ............................................................. A-4

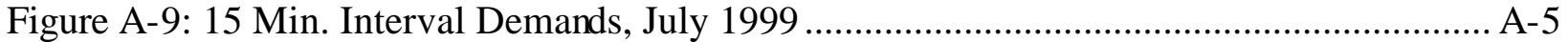

Figure A-10: 15 Min. Interval Demands, August 1999 .................................................... A-5

Figure A-11: 15 Min. Interval Demands, September 1999 ............................................. A-6

Figure A-12: 15 Min. Interval Demands, October 1999 ..................................................... A-6 


\section{Tables}

Table 1: Major Features of the CAISO Summer 2000 Trial Programs ............................................6

Table 2: Availability and Operating Cost Assumptions of Navy's Load Management Assets .....10

Table 3: Hours of Operation in Energy-Based Curtailment Program for Period November 1998

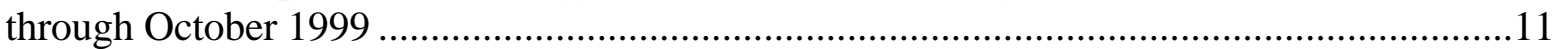

Table 4: Economic Value of Energy-Base Curtailment Program for Period November 1998 through October 1999 .......................................................................................................12

Table 5: Energy Value of the Demand Relief Program during Times When Load Relief Was Dispatched. (Note: Load Relief Events are only Listed through August 31, 2000. Program Continues until October 15, 2000)............................................................................. 21

Table 6: Total Value Estimate for the Demand Relief Program Using Energy Value for Period

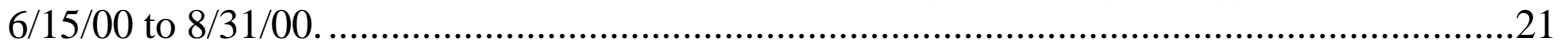

Table 7: Value Estimate for Demand Reduction......................................................................23

Table 1: Summary of the Economic Value of Programs Assessed in this Study .........................25

Table 9: Summary of Cost Comparison Between Two Procurement Strategies for Aggregated Accounts (Naval Station, North Island, Point Loma) ………….............................................32

Table 10: Results of Cost Comparison in Commodity Procurement between Direct Access and

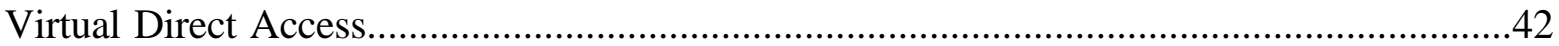

Table 11: Summary of Assessed Programs …………….......................................................4 


\section{Introduction}

As the largest U.S. Naval fleet concentration area on the West Coast, San Diego is homeport for 58 surface ships. Every U.S. Navy ship has the capability of activating their generators to produce electrical power. Yet when in port, most ships receive electric services from the shore distribution system because, generally, on-shore electric power is the least cost alternative and it facilitates maintenance of the ship's electrical power generating equipment.

As of July 1, 1999, the Public Works Center (PWC) San Diego, as the operating agent for the Navy, contracted with Newenergy, Inc. (NE) to provide electric services to the Navy Station, including the ships in port. This new service arrangement utilizes an electric rate structure that is based on the open market. Therefore, electricity prices are determined by market forces and are expected to be more volatile than in the past. This new electric service contract is in effect until March 2002.

PWC is interested in investigating the economic value of operating a ship's generators during high electricity price periods. The economic value is predicated on the trade-off between the operating cost incurred by the Navy for operating the ship generators and the net profit associated with NE's sale of the electric power on the spot market. Furthermore, the ship's generators can be used as a means to achieve predicted load curtailments. Load curtailment assets can then be marketed to the California Independent System Operator (CAISO) as an ancillary service. This would require that either the PWC or NE, as an agent for PWC, would bid the load curtailment assets into an appropriate CAISO's ancillary service market. The cost saving opportunities and the associated notification and verification requirements imposed by the CAISO will be discussed and investigated.

This analysis has been performed by Pacific Northwest National Laboratory (PNNL) ${ }^{1}$ using operating cost for the operation of a common set of ship generators. These costs were provided by LCDR William Scherer, who also provided the necessary insights into operational requirements and notification constraints for starting, operating, and stopping on-board generator capacity.

\footnotetext{
${ }^{1}$ Operated for the U.S. Department of Energy under Contract DE-AC06-76RLO 1830.
} 


\section{Objective}

The overall goal of this project is to evaluate the cost savings opportunities using the significant load management assets available at the U.S. Navy Base in San Diego, California, when disconnecting Navy ships from the on-shore electric power supply and, operating the ships with on-board generation. In particular, this project has the following objectives:

1. Analyze the cost savings opportunities of the load management assets in an energybased load curtailment program. This program is based on the premise that cost can be potentially reduced when high-cost electric energy is displaced by lower cost generation on the Navy's ships while in port.

2. Analyze the cost savings opportunities in a capacity-based load curtailment program. This program involves bidding load reduction assets into the California Independent System Operator's ancillary markets. Operational requirements for participating in this program will be discussed, as well as issues related to compliance and verification of contracted load curtailments imposed by the Independent System Operator.

3. Analyze the economic value for the Navy in participating in the competitive CAISO Demand Relief Program. This program is part of the CAISO Summer 2000 Market Participating Load Trial Program. The program encourages single and aggregated curtailable loads of $1 \mathrm{MW}$ or greater to provide load relief at the CAISO notification. Program participants are committed to curtail up to 30 hours per month. In return, the participants receive two payments from the CAISO: (1) a capacity reservation payment and (2) an energy payment.

4. Analyze the cost savings opportunities of the load management assets as they reduce the coincident on-peak demand charge component of the local utility (San Diego Gas $\&$ Electric) charges.

5. Analyze cost savings opportunities of block forward contracts, which are a risk management tool to minimize the risk exposure when procuring power on the spot market. A block forward contract is a financial instrument and as such, can be purchased independent of any load reduction or curtailment programs and can provide value regardless of load manage ment capabilities. The PWC requested this additional analysis for informational purposes to gauge the economic value of this financial instrument for the Navy in San Diego. 


\section{Introduction to California's New Electricity Market}

This section provides some general overview of the California's new electricity market, which is intended to help the reader to understand better the cost savings mechanics discussed in this report.

On March 31, 1998, California's electric power industry began a 4-year phased-in restructuring process that affected all customer classes of investor owned utility companies (Pacific Gas and Electric Company (PG\&E), Southern California Edison (SCE), and San Diego Gas \& Electric (SDG\&E)) [AB 1890, 1996]. As a result, customers of these utility companies obtained the choice to buy electricity from either their current electric utility or from alternative suppliers.

At the same time, beginning March 31, 1998, the operation of the three investor-owned utilities' electric transmission facilities was transferred into management by the California Independent System Operator (CAISO). As a not-for-profit corporation, the CAISO ensures that all electricity producers have an equal opportunity to transmit electric power through the California power grid to their customers.

For the transition period, ending March 2002, the three investor-owned utilities are required to buy and sell their electric generation through the California Power Exchange (CALPX). The CALPX is a not-for profit public benefit corporation that conducts the auctions for wholesale electricity demand and supply. Other market participants, such as independent power producers (IPP), municipal utilities, load aggregators and others, have the option to buy and sell through the CALPX or any other power exchange or negotiate contracts directly with generators and end-users.

\subsection{Two New Major Players in the New Electricity Market}

There are several new players in the California's restructure electricity market. The major new players are the CALPX and the CAISO, whose functions are described below.

\subsubsection{California Power Exchange}

The primary purpose of the CALPX is to provide an efficient and competitive short-term wholesale spot electricity market by performing several auctions for the supply and demand of electricity. There are two major market auctions: (1) the hourly Day-Ahead auction and the (2) hourly Day-Of auction. The three investor-owned utilities must buy and sell all the electricity through the CALPX. Combined, the three investor-owned utilities represent approximately $80 \%$ of California's electricity demand [CALPX PRIMER, 1999]. Recently (June 1999), the CALPX added new service offerings responding to new market needs. These services include a Block-Forward Contract auction, which provides market participants with a longer-term trading instrument to hedge hourly price risks. This Block-Forward market enables both buyers and sellers to avoid exposure to the volatility of electricity prices during peak usage periods, while 
continuing to reap the market liquidity offered by the CALPX. Other power exchanges are feasible under the new market structure. The most notable is the Automated Power Exchange (APX), as a competitor to the CALPX.

Besides its responsibility to conduct competitive short-term wholesale spot markets, the CALPX also serves as a Scheduling Coordinator (SC), which involves the submission of balanced demand and supply schedules for successful bidders to the CAISO. The Scheduling Coordinator performs settlement functions with the CAISO and its market participants. Settlement is the financial transaction process for all sales of electricity. The CALPX collects and disperses monies based on settlements and all transaction costs incurred with the CAISO and the CALPX.

Wholesale electricity trading and sales can be performed either in the CALPX or as bilateral agreement passed through other Scheduling Coordinators. New Energy, the Navy's energy service provider, is a Schedule Coordinator. All trades must be scheduled with the CAISO.

\subsubsection{California Independent System Operator (CAISO)}

The CAISO's mandate is to ensure open access to the transmission grid and to maintain reliable supply of electricity in California. It is responsible for following functions:

- coordination of day-ahead and hour-ahead schedules from all Schedule Coordinators. This involves transmission congestion management. If transmission congestion exists, CAISO adjusts schedules to eliminate congestion.

- performing markets for ancillary services, necessary to maintain grid reliability

- control of dispatch of generation

- performing realtime balancing of load and generation in the imbalance energy market.

The scheduling function consist of the following steps [Gomez et al., 1999]:

- CAISO receives balanced schedules by Scheduling Coordinators along with adjustment bids, which reflect the generators bids for adjustments to avoid transmission congestion. This information is provided on a generator level.

- CAISO performs congestion analysis given the detailed generation and load information. It adjusts the schedule (this means in all cases so far an adjustment of the generation) to avoid transmission congestion.

- The adjusted schedules are the basis for the zonal market-clearing price, which the CAISO communicates back to the Scheduling Coordinators.

The CAISO buys ancillary services and imbalance energy competitively. They are to conduct real-time imbalance resolution. The following services are considered ancillary services. They are listed in ascending sequence of notification time. 
1. Regulation service, provided by generator under CAISO control. Generator's unloaded capacity can be loaded, or loaded capacity can be unloaded, in response to the automated generation control signals from the CAISO's energy management system control computer.

2. Spinning reserve, provided by generators that are in unloaded synchronized operation. Generator is controlled by CAISO and must be able to be loaded in 10 minutes.

3. Non-spinning reserve, prime mover is not in operating mode. Generation capacity must be established within 10 minutes of CAISO notification.

4. Replacement reserves, prime mover is not in operating mode. Generation must be established within 60 minutes of CAISO notification.

The CAISO does NOT restrict the above services to be supplied by generation capacity. Load reduction capacities could equally be bid into the ancillary markets. Traditionally, generators have been participating in the ancillary markets with only a few load reduction capacity bids for the replacement reserves.

Suppliers of these services bid quantities and prices for each type of service into an hourly auction. In addition, the CAISO non-competitively procures reactive power for voltage support and black-start generation capability. These services are highly locationspecific and thus, cannot be competitively bid.

Real-time imbalances occur when metered generation and consumption deviate from those determined in the submitted schedules. To adjust power generation so that generation meets load in real-time, CAISO utilizes the supplemental energy bids from the generators. The last unit dispatched for resolving imbalances sets the real-time marketclearing price. The real-time market-clearing price is determined every 10 minutes.

\subsubsection{CAISO Summer 2000 Trial Programs:}

In late 1999, the CAISO elicited suggestions from California's stakeholders and interested parties to discuss the framework of a trial program to be launched in the summer of 2000. The goal of the trial program was to improve the demand responsiveness of the California demand sector to mitigate the power adequacy issues anticipated for the summer of 2000. In the winter of 2000, the CAISO held several workshops and teleconference calls to discuss with stakeholders scope and structure of a set of programs. Early on in the discussions, the Market Participating Load Program emerged as one of the trial programs. Later in the spring of 2000, continued discussions resulted in an additional program, called, Demand Relief Program. Participants to both programs were required to bid into a competitive market conducted by the CAISO. The requests for proposal went out in March 2000. The trial programs were designed to be in effect from June 15, 2000 through October 15, 2000. Table 1 below contrasts some of the features and requirements of each program. 
Table 1: Major Features of the CAISO Summer 2000 Trial Programs ${ }^{2}$

\begin{tabular}{|c|c|}
\hline Market Participating Load Program & Demand Relief Program \\
\hline $\begin{array}{l}\text { Objective: } \\
\text { To allow end-use customers to aggregate } \\
\text { and participate in CAISO ancillary services } \\
\text { and supplemental energy markets. }\end{array}$ & $\begin{array}{l}\text { Objective: } \\
\text { To provide a market for end-use customers } \\
\text { load curtailment to prevent or minimize the } \\
\text { need to trigger utility non-firm interruptible } \\
\text { programs or involuntary load shedding } \\
\text { (brown outs) }\end{array}$ \\
\hline $\begin{array}{l}\text { Single or aggregated loads capable of } \\
\text { reducing electric demand by at least } 1 \mathrm{MW} \\
\text { may participate }\end{array}$ & $\begin{array}{l}\text { Single or aggregated loads capable of } \\
\text { curtailing electric demand by at least } 1 \\
\text { MW may participate }\end{array}$ \\
\hline $\begin{array}{l}\text { End-use customers may not be participants } \\
\text { in utility interruptible programs. }\end{array}$ & $\begin{array}{l}\text { End-user customers also covered under } \\
\text { utility interruptible program may } \\
\text { participate (subject to public utility } \\
\text { commission approval and adjustment of } \\
\text { payments) }\end{array}$ \\
\hline $\begin{array}{l}\text { Participation requires successful bid in the } \\
\text { day-ahead and hour-ahead markets for: } \\
\text { - Non-spinning reserves } \\
\text { - Replacement reserves } \\
\text { - Real-time supplemental energy }\end{array}$ & $\begin{array}{l}\text { Competitive award after one-time request } \\
\text { form proposal for the demand relief } \\
\text { program for } 4 \text {-month period (June } 15 \text { - } \\
\text { October } 15,2000 \text { ) }\end{array}$ \\
\hline $\begin{array}{l}\text { Participants must provide metering and } \\
\text { telemetry in accordance with CAISO } \\
\text { standards }\end{array}$ & $\begin{array}{l}\text { Simple interval metering approved by } \\
\text { California Public Utility Commission } \\
\text { (CPUC) }\end{array}$ \\
\hline $\begin{array}{l}\text { Load is dispatched as done for generators. } \\
\text { Notification periods are: } \\
\text { - Non-spinning reserves: } 10 \text { minutes } \\
\text { - Replacement reserves: } 60 \text { minutes } \\
\text { - Supplemental energy: } 60 \text { minutes }\end{array}$ & $\begin{array}{l}\text { Total interruption time is limited to } 30 \\
\text { hours/month. CAISO may dispatch load } \\
\text { only after a Stage } 1 \text { Electric Emergency } \\
\text { and just before Stage } 2 \text { is called. }{ }^{3} \text {. } \\
\text { Notification period is } 30 \text { minutes. }\end{array}$ \\
\hline $\begin{array}{l}\text { Payments are for: } \\
\text { - Capacity/load reduction capability } \\
\text { according to ancillary markets } \\
\text { regardless of whether or not } \\
\text { dispatched } \\
\text { - Energy payments according to real } \\
\text { time energy markets when } \\
\text { dispatched }\end{array}$ & $\begin{array}{l}\text { Payments are for: } \\
\text { Capacity/load reduction capability } \\
\text { according to award for a month } \\
\text { regardless of whether or not } \\
\text { dispatched } \\
\text { - Energy payments according to real } \\
\text { time energy markets when } \\
\text { dispatched }\end{array}$ \\
\hline Penalty for non-compliance & penalties for non-compliance. \\
\hline
\end{tabular}

\footnotetext{
${ }^{2}$ Table compiled from CAISO publication [CAISO DR, 2000], [CAISO PL, 2000], and [CAISO, 2000]

${ }^{3}$ In Stage 1 Electric Emergency, reserves fall below $7 \%$ of total available capacity. In Stage 2, reserves fall below $5 \%$ of total available capacity.
} 


\subsubsection{Navy's Current Electric Power Procurement Arrangement}

The Navy in San Diego has several "Direct Access Customers" accounts with San Diego Gas \& Electric Company (SDG\&E), the local utility company. The Direct Access Customers classification means that the Navy procures the electric energy as a commodity through an energy service provider other than the local utility company. The energy service provider is Newenergy, Inc. San Diego Gas \& Electric Company charges the Navy for its delivery services. The bill for a Direct Access Customer is calculated as if the Navy is a bundled service customer who receives energy supply and delivery services from SDG\&E. This bill is then credited by the amount of the CALPX commodity component (called CALPX credit), which represents the value of the CALPX commodity markets.

The major Navy accounts analyzed in this report (Naval Base, North Island, and Point Loma) are serviced by SDG\&E under the time-of-use schedule, A6-TOU [A6-TOU, 1999].

The electricity bill details the charges in the following main components:

1. Fees and surcharges

2. CALPX credit

3. Energy charges for peak, semi, off-peak $\mathrm{kWh}$ consumption

4. Coincident on-peak demand charge

5. Non-coincident demand charge (relatively small, less than $1 / 10$ of coincident on-peak demand charge)

The value estimates discussed in this report affect individual components of the electricity bill depending on the load curtailment program. The major components of the bill are the CALPX credit and, during the summer season, the coincident on-peak demand charge. 


\section{Value Assessment of Electric Curtailment Programs}

The Navy's load reduction assets have distinct economic values that can provide financial rewards under the current market conditions in California. Value assessments for four load curtailment programs are discussed in this report. Each assessment is based on a common set of electric load curtailment assumptions. The following four programs are discussed:

1. Energy-based curtailment program: The value of this program is based on the avoided consumption of electric energy during periods of high prices. Because the majority of the wholesale trading is performed by the CALPX in the hourly Day-Ahead auction, the relevant price of electric energy is the day-ahead price, determined and published by the California Power Exchange.

2. Capacity-based curtailment program: The value of the capacity-based program is expressed in the ability to reduce electric power demands to maintain electric grid reliability. Load reduction capabilities are bid into the CAISO ancillary service market. If the bid is awarded, the CAISO will request dispatch of load reduction during times when the grid requires it for maintaining safety and reliability of the grid. The payments for ancillary services have a capacity and energy component. Those payments depend on the market-clearing price of the capacity and energy provided.

3. Demand relief for the summer 2000 program: This program is administered by the CAISO as a trial program for the period June 15 through October 15, 2000. The value estimate includes two components: (1) a capacity reservation payment, which is independent on the frequency of load curtailment and (2) an energy payment applicable during periods with load is curtailed.

4. Coincident on-peak demand charge reduction program: This value is based on the ability to reduce the monthly demand charge of the San Diego Gas and Electric's rate schedule. The demand charge is computed each month as the product of the rate expressed in $\$ / \mathrm{kW}$ times the electric demand recorded over a 15 -min interval, when the SDG\&E system-wide peak occurs.

The value propositions of the load curtailment programs listed above are additive, implying that they all could be utilized in combination with each other. For instance, a market participant has successfully bid into the ancillary market and receives capacity payments for this service. When a load curtailment is called by the CAISO, at the time of the SDG\&E's system peak, the market participant reduces its energy charge for consumed $\mathrm{kWh}$ in addition to an additional benefit in the form of a coincident on-peak demand charge reduction in the local utility bill.

This report describes the characteristics and economic value of the following four programs: (1) energy-based curtailment, (2) capacity-based curtailment, (3) demand relief program for the Summer 2000 Program, and (4) the demand reduction program for 
reducing the SDG\&E demand charge component. Analysis tools for the demand reduction program are already implemented at the San Diego Navy. The energy-based and capacity-based curtailment programs are currently not implemented. They only exist as a conceptional framework for the value estimation as discussed with PWC, Newenergy, the Navy, and PNNL. It should be noted and stressed that this report provides only a value estimation of the curtailment programs as a first assessment for further exploration into contract modification or amendments of the existing contract between Newenergy, Inc. and the Navy. A cost savings estimate would be the natural extension of the value assessment after the terms of the economic benefits are established.

\subsection{Value Estimates of Energy-Based Curtailment Program}

\subsubsection{Background and Definition}

An energy-based curtailment program is a fictitious program that capitalizes on the value of electric energy displaced by the operation of the ship generators.

The underlying premise of this program is that there is an economic value to reduce the electric energy consumption during periods when the market value of electricity is greater than the cost for self-generation. The financial incentive is determined by the difference between the spot-market price of electricity and the cost of self-generation. The appropriate price index for the spot-market value of electric energy commodity in California is the California Power Exchange day-ahead price. The majority (> 80\%) of the entire California electric power wholesale is transacted in the day-ahead market at the California Power Exchange [CALPX, 1999].

The economic value of an energy-based curtailment program can then be determined by the following formula:

Value $=\sum_{t=1}^{8760}\left(\right.$ PXDayAheadZonalPrice $_{t}-$ Operating Cost $\left._{t}\right) \bullet$ Energy $_{t}$

for all hours $t$ when PXDayAheadZonalPrice ${ }_{t}>$ OperatingCost ${ }_{t}$.

where:

Value The annual estimated economic value of operating ship generators. Value is estimated for the period from November 1998 through October 1999.

PXDayAheadZonalPrice ${ }_{t} \quad$ California Power Exchange day-ahead market price of electric power for zone South of Path 15 (SP15) in hour $t$ expressed in [\$/MWh]. The zonal price is derived from the CALPX day-ahead price and adjusted by the CAISO for resolving potential congestion in the transmission system. 
OperatingCost $_{t} \quad$ Operating and maintenance cost for performing load reduction in hour $t$ expressed in [\$/MWh]. This includes the fuel and labor cost. The depreciation of the generator asset is negligible compared to the operating and maintenance cost and is, therefore, ignored.

Energy $_{t} \quad$ Electric energy produced in hour $t$ expressed in [MWh]. The energy produced replaces the electric energy purchased from an energy provider.

The following assumptions are used for the value estimates. They are summarized in Table 2.

Table 2: Availability and Operating Cost Assumptions of Navy's Load Management Assets

\begin{tabular}{|l|l|l|l|l|}
\hline Cost of Operation & Capacity & Prime mover & Location/Account & Notes \\
\hline $\begin{array}{l}45[\$ / \mathrm{MWh}] \text { or } \\
4.5[\phi / \mathrm{kWh}]\end{array}$ & $15 \mathrm{MW}$ & Reciprocating & Naval Station & $\begin{array}{l}\text { Estimated ship generator } \\
\text { capacity: 1 MW. }\end{array}$ \\
\cline { 2 - 5 } & $5 \mathrm{MW}$ & Reciprocating & North Island & Aircraft carrier capacity 5 MW \\
\hline $\begin{array}{l}90[\$ / \mathrm{MWh}] \text { or } \\
9.0[\phi / \mathrm{kWh}]\end{array}$ & $15 \mathrm{MW}$ & Gas turbine & Naval Station & \\
\hline Total & $\mathbf{3 5}$ & & & \\
\hline
\end{tabular}

Figure 1 shows the price duration curve for the relevant zonal CALPX day-ahead price for the period November 1998 to October 1999. As can be seen from this figure, there are less than 500 hours during which the wholesale price of electricity exceeds 45 [\$/MWh] or $4.5[\mathrm{c} / \mathrm{kWh}$, the lowest cost for ship generator operation. As the analysis shows, the opportunities to capitalize on the high-priced electricity market values are small because of the limited high-price occurrence throughout the year.

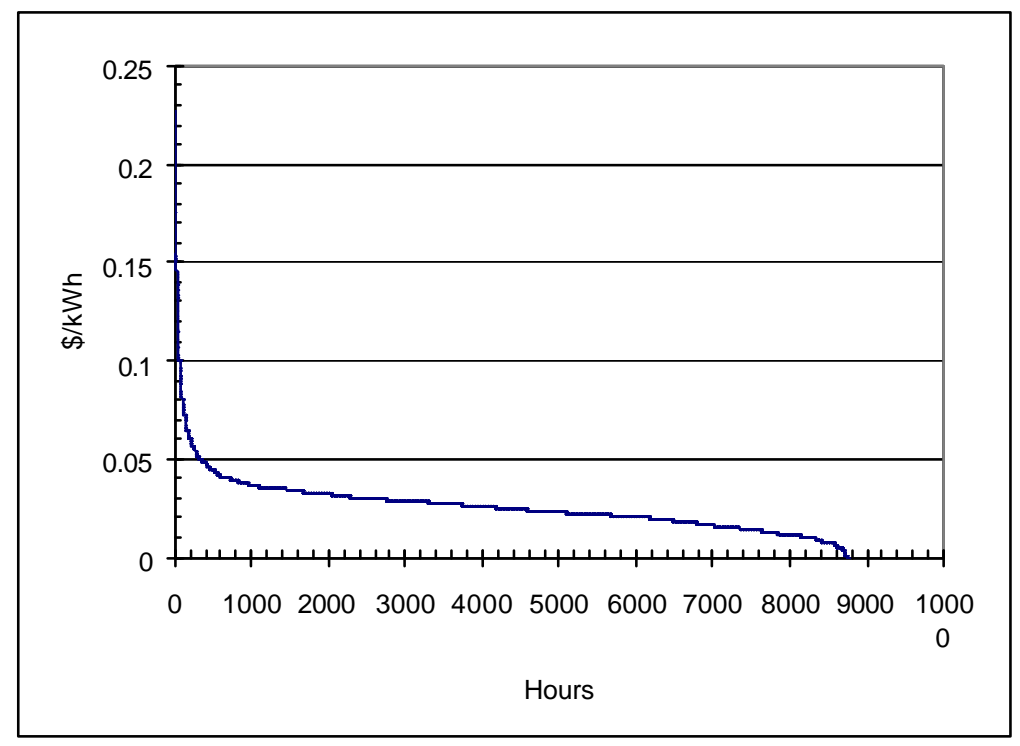

Figure 1: Price Duration Curve of CALPX Day-Ahead Price for Zone SP15. 
We estimated the potential value and hours of operation, during which PXDayAheadZonalPrice ${ }_{t}>$ Operating Cost and, furthermore, grouped the ho urs into time blocks defined by SDG\&E's time-of-use schedule as:

- peak summer: $11 \mathrm{am}-6 \mathrm{pm}$ weekdays winter: $5 \mathrm{pm}-8 \mathrm{pm}$ weekdays

- semi-peak

- off-peak

- 9am to 5pm summer: 6am-11am weekdays summer: 6pm-10pm weekdays

summer: 10pm-6am weekdays summer: weekends\&holidays

summer: 9am - 5pm weekdays This schedule emulates the regular Navy working schedule in the San Diego port. The motivation for the definition of this schedule is based on the fact that ship generators must be manned during operation and that it is unreasonable to ask ship staff to stay on the ship after regular working hours to operate the generator.

- 24 hours all hours during the year.

The results of the estimated hours of Operation and potential economic value are shown in Table 3 and Table 4.

Table 3: Hours of Operation in Energy-Based Curtailment Program for Period November 1998 through October 1999

\begin{tabular}{|c|c|c|c|c|c|c|c|}
\hline $\begin{array}{l}\text { Location/ } \\
\text { Account }\end{array}$ & MW & $\begin{array}{c}\text { Operating } \\
\text { Cost } \\
{[\mathrm{c} / \mathrm{kWh}]} \\
\end{array}$ & $\begin{array}{c}\begin{array}{c}\# \text { of } \\
\text { peak } \\
\text { hours }\end{array} \\
\end{array}$ & $\begin{array}{l}\text { \# of semi- } \\
\text { peak hours }\end{array}$ & $\begin{array}{c}\text { \# of off- } \\
\text { peak hours }\end{array}$ & $\begin{array}{c}\text { \# of } \\
\text { hours } \\
9-5 \\
\end{array}$ & $\begin{array}{c}\text { \# of hours } \\
\text { over } \\
24 \mathrm{~h} \\
\end{array}$ \\
\hline $\begin{array}{l}\text { Naval } \\
\text { Station }\end{array}$ & 15 & 4.5 & 225 & 155 & 89 & 159 & 469 \\
\hline $\begin{array}{l}\text { Naval Station } \\
\& \text { North Island }\end{array}$ & 20 & 9.0 & 55 & 19 & 4 & 39 & 78 \\
\hline Total & 35 & na & 280 & 174 & 93 & 198 & 547 \\
\hline
\end{tabular}


Table 4: Economic Value of Energy-Base Curtailment Program for Period November 1998 through October 1999

\begin{tabular}{|l|r|r|r|r|r|r|r|}
\hline $\begin{array}{c}\text { Location/ } \\
\text { Account }\end{array}$ & $\begin{array}{c}\text { Value } \\
\text { peak }\end{array}$ & $\begin{array}{c}\text { Value } \\
\text { semi-peak }\end{array}$ & $\begin{array}{c}\text { Value } \\
\text { off-peak }\end{array}$ & $\begin{array}{c}\text { Value } \\
\mathbf{9 - 5}\end{array}$ & $\begin{array}{c}\text { Value } \\
\mathbf{2 4} \text { hours }\end{array}$ & $\begin{array}{c}\text { \$/MWh } \\
\mathbf{2 4} \text { hours }\end{array}$ & $\begin{array}{c}\text { \$/MWh } \\
\mathbf{9 - 5}\end{array}$ \\
\hline NavalStation & $\$ 138,000$ & $\$ 60,000$ & $\$ 27,000$ & $\$ 98,000$ & $\$ 225,000$ & 32 & 41 \\
\hline $\begin{array}{l}\text { Naval Station } \\
\text { \& North Island }\end{array}$ & $\$ 37,000$ & $\$ 6,500$ & $\$ 2,500$ & $\$ 27,500$ & $\$ 46,000$ & 29 & 35 \\
\hline Total & $\mathbf{\$ 1 7 5 , 0 0 0}$ & $\mathbf{\$ 6 6 , 5 0 0}$ & $\mathbf{\$ 2 9 , 5 0 0}$ & $\mathbf{\$ 1 2 5 , 5 0 0}$ & $\mathbf{\$ 2 7 1 , 0 0 0}$ & $\mathbf{3 1}$ & $\mathbf{4 0}$ \\
\hline
\end{tabular}

\subsubsection{Conclusions for Energy-Based Curtailment Program}

The following conclusions can be drawn from the energy-based curtailment program:

- The total value of curtailed energy over a period of 1 year (November 1998 through October 1999) is $\$ 271,000$. This is achieved by operating $20 \mathrm{MW}$ at $4.5[\phi / \mathrm{kWh}]$ for 469 hours and $15 \mathrm{MW}$ at $9.0[\mathrm{c} / \mathrm{kWh}]$ for 78 hours.

- A realistic time window for implementation of this curtailment program is the 9-5 working schedule. The total potential value is then reduced to $\$ 125,500$ with 159 hours of $15 \mathrm{MW}$ reciprocating energy operation and 39 hours of the gas turbine generator operation.

- By limiting the curtailment program to a 9-5 schedule, more than 50\% of the total potential value was lost. This is predominantly because high price hours persisted during the early evening hours, past $5 \mathrm{pm}$.

- The average economic incentive for a curtailment during the 9-5 schedule was 40 [ $\$ / \mathrm{MWh}]$ or $4[\phi / \mathrm{kWh}]$. This translates into an average economic incentive of $\$ 40$ per hour for each ship that operates its generator. For the 24-hour schedule, the average incentive was reduced to $\$ 31$ per hour for each ship participating in the program.

\subsection{Value Estimates for Capacity-Based Curtailment Program}

\subsubsection{Background}

The capacity-based curtailment program is based on the premise that there exists a capacity value associated with the Navy's load reduction assets that can be marketed and sold into an existing market. The appropriate market is the California Independent System Operator's replacement reserve market, which is one of several ancillary service markets administered by the CAISO to ensure and maintain reliability of the electric transmission system in California and to provide coordinating functions as part of the Western System Coordinating Council (WSCC). 
The CAISO receives replacement reserve bids from both generators and participating loads (or negative capacity). The CAISO established a detail bidding protocol that describes the format in which a bid must be submitted to the CAISO and the sequence in which the bid and bid notification must occur [CAISO BID, 1999]. There are stringent verification procedures imposed by the CAISO for market participants, which require communication links between the participants' meters and the CAISO. Via these communication lines, the CAISO verifies the contracted load reduction levels and the response time measures as the period between the curtailment notification and the participants load reduction.

In the spring of 2000, the CAISO elicited suggestions from energy service companies, utilities, and other stakeholders, for a pilot program with the primary goal to encourage more price responsiveness by the demand sector. An increased demand responsiveness has the potential to improve the overall market efficiency and may avoid the existing price caps on electric power imposed by the CAISO [CAISO PL, 2000]. The primary novelty in this pilot program is to test the viability of aggregated load participation. While formerly individual loads could participate in the replacement reserve market, now load aggregators and energy service companies can submit load curtailment bids to the CAISO from an aggregated load. The verification requirements are then imposed to the energy service companies' meter server, which represents a quasi realtime central point of contact for the participating loads. This allows the energy service companies not only to attract smaller participants to this market but also provides opportunities to share the risk for non-compliance among a portfolio of customers.

The following describes the major characteristics of both the pilot program and the established replacement reserve program:

- Notification time between CAISO issuing contracted load curtailment and participant's response is $60 \mathrm{~min}$.

- Participant receives a capacity payment - if bid is accepted - for being in the pool of loads that can be called up for curtailment. Capacity payments are made regardless of whether or not a curtailment call is made. The payment is made at the market clearing price of the capacity bid.

- Participants receive an energy payment for the duration of the load curtailment. This off-sets the operating cost during curtailment. Energy payments are made at the market clearing price of the energy bid.

- Meter reading connectivity must be established between the aggregated loads and CAISO or between individual loads and the CAISO. Aggregated loads are represented by the aggregated load meter data server (ALMDS), a meter data acquisition and processing system capable of passing meter data to the CAISO supervisory control and data acquisition (SCADA) system for means of telemetry. The CAISO telemetry must be available on a scan rate no less frequent than 1 minute from the ALMDS to the CAISO. Each individual meter behind the ALMDS must be 
read no less frequently than once per 5-minute interval and the aggregated demand must be updated after each individual meter scan. [CAISO PL, 2000].

- Compliance is tested. The relevant time period for compliance testing is 1 hour, the settlement period of CAISO markets. A meter reading $E_{o}$ is taken at the time of notification. A participating load is in compliance if the average demand after the notification time is below the contracted load reduction based on the initial meter reading $E_{o}$. In cases of non-compliance, CAISO will reward partial compliance, which is pro-rated based on the actual reduction versus that the contracted demand reduction.

\subsubsection{Evaluation of Capacity Value}

Figure 2 shows the historical magnitude of the market clearing prices for the capacity bid of the replacement reserve markets. The CAISO distinguishes between generation reserves and load curtailment reserves in this market. However, from a valuation point of view, the CAISO treats them equally. As a consequence, the market clearing price for both are equal. Because of a limited number of load curtailment participants (about two or three), the data shown in Figure 2 are representative of the generation reserves. The market clearing prices for the generation replacement reserves are used for the value estimation in this study.

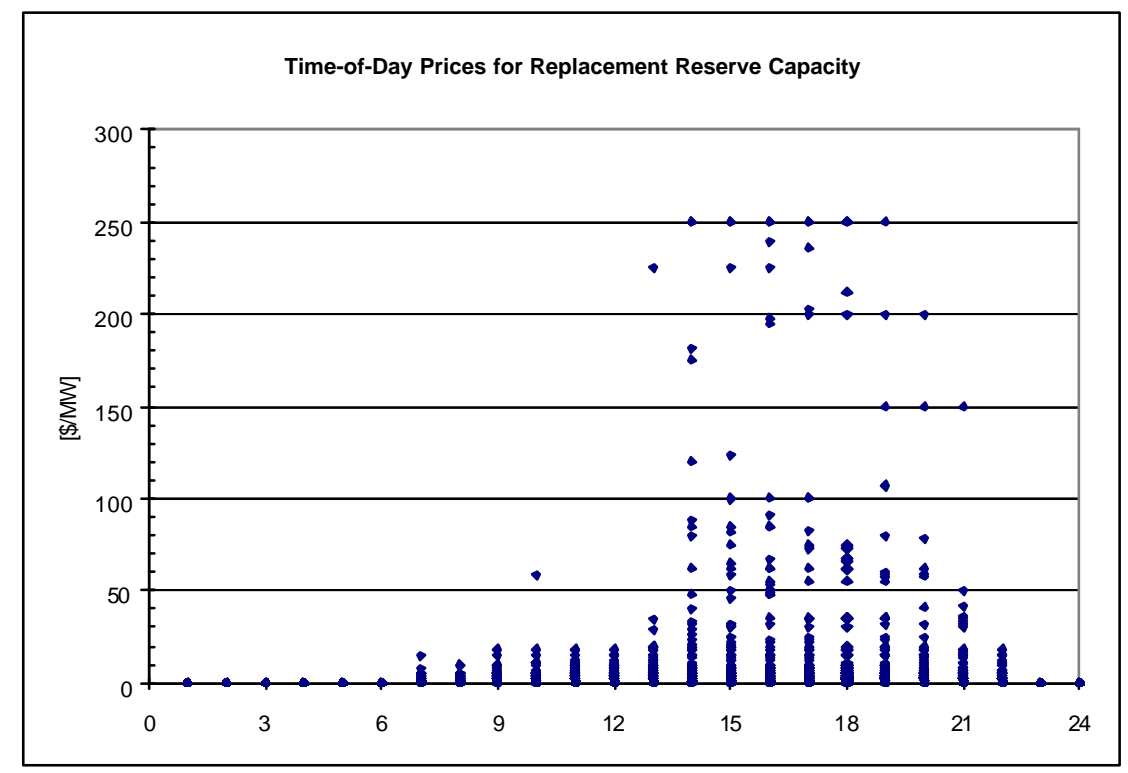

Figure 2: Time-of-the-Day Prices for Replacement Reserves (Generation). November 1998 through October 1999 representing 8760 Data Points

Figure 2 indicates a concentration of high-priced market clearing prices for replacement reserves in the afternoon and evening hours (14:00 to 20:00), which is based on the tighter supply of reserves during hours of highest load in the California transmission 
system. The CAISO imposed a price cap of $250 \$ / \mathrm{MWh}$ in 1999 , which is reached six times over the 1 year period.

Figure 3 shows the total value of the replacement reserves as a function of time-of-day. The total value is determined by multiplying the hourly price ( $\$ \mathrm{MWh}$ ) with the corresponding MWh of reserve generation dispatched by the CAISO for each hour. The dispatched replacement reserves are relatively constant at about 550 MW during a 7:00 to 22:00 hour period and negligible during the remaining hours. As expected, the value is high during the 14:00 to 20:00 hour time period because of the hourly price distribution. The total market value of the replacement reserve generation market for the time period November 1998 through October 1999 was \$5.4 million.

Using the available load reduction assets assumptions of $35 \mathrm{MW}$, as defined in the previous section and summarized in Table 2, a total potential value for the Navy of $\$ 700,000$ is calculated over a 24 -hour period and $\$ 392,000$ over a limited 9-5 schedule.

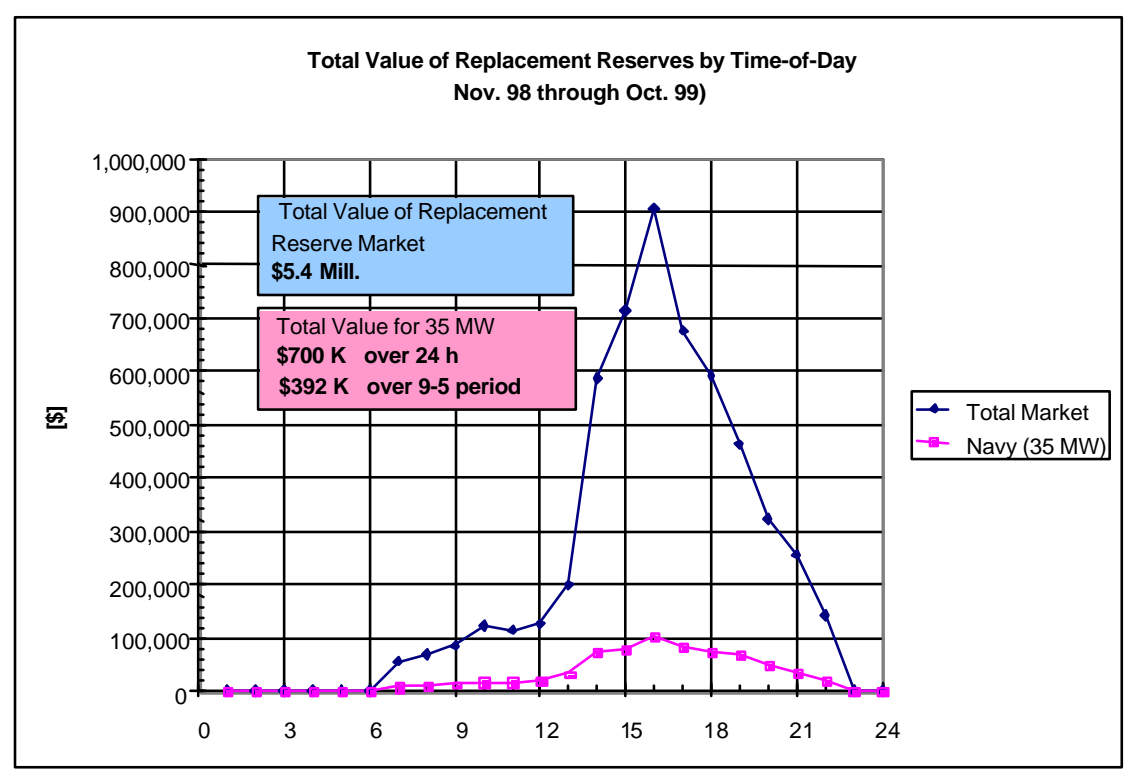

Figure 3: Total CAISO Replacement Reserve Market and Market Value of $35 \mathrm{MW}$ of Navy's Load Reduction Assets for the Period of November 1998 through October 1999 


\subsubsection{Supply Curves of Replacement Reserve Bids}

Any potential financial reward in the replacement reserve markets depends on a successful bid of the Navy's load reduction assets. There is a revenue stream directly associated with the successful bid into the pool of replacement reserves capacity. This revenue is received for the entire duration during which the Navy's load reduction assets are committed to the replacement reserve pool without necessarily being dispatched. If and when dispatched by the CAISO, the replacement reserve capacity receives an additional revenue stream only for the period of dispatch. This second revenue stream is a cost item associated with the operation and relates to the cost of achieving the load curtailment.

Figure 4 and Figure 5 provide estimates on the bid-price dependency on the overall potential value. Figure 4 shows the capacity value curves for the Navy's 35 MW load reduction capability as a function of the bid-prices. The curves estimate the capacity value that can be captured by choosing a certain bid-price. For instance, if a market participant had set a bid-price to zero, it would have been in the replacement reserve pool at all times and received a payment for each hour corresponding to the market clearing price of that hour. This defines the upper limit of the potential revenue stream and is estimated to be about $\$ 700,000$, for the 24-hour availability scenario, and $\$ 392,000$ for the limited 9-5 schedule. Any other bid-price greater than zero eliminates hours of commitment and, therefore, reduces the total value. If the bid-price is chosen high, the bid would only be successful for a limited number of hours. The highest acceptable bidprice is $250 \$ / \mathrm{MW}$, which corresponds to the imposed price cap.

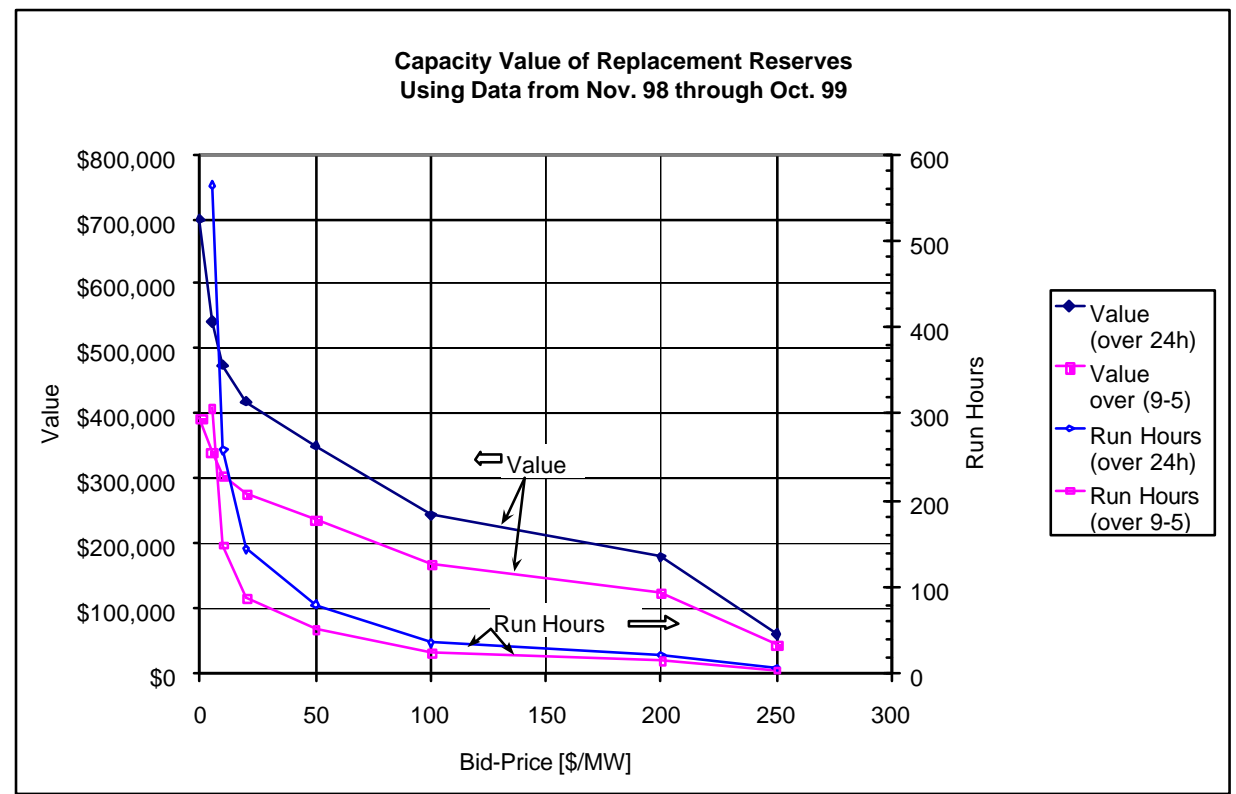

Figure 4: Supply Curve for Capacity Value of the Replacement Reserve Market, Based on the Availability of 35 MW Load Reduction Assets 
Figure 5 shows the energy value and the associated runtime of the ship generators as a function of the energy-bid. The energy-bid, as shown in Figure 5, has been adjusted to represent a cost above the operating cost of the ship generators, i.e. the net revenues. The appropriate operating costs are summarized in Table 2.

The maximum energy value is $\$ 709,000$ for the 24-hour availability scenario and $\$ 394,000$ for the 9-5 limited schedule. The combined total value of the replacement reserve market is the sum of the capacity and energy values. It is $\$ 1,499,000$ for the 24hour availability and $\$ 786,000$ for the 9-5 schedule, respectively.

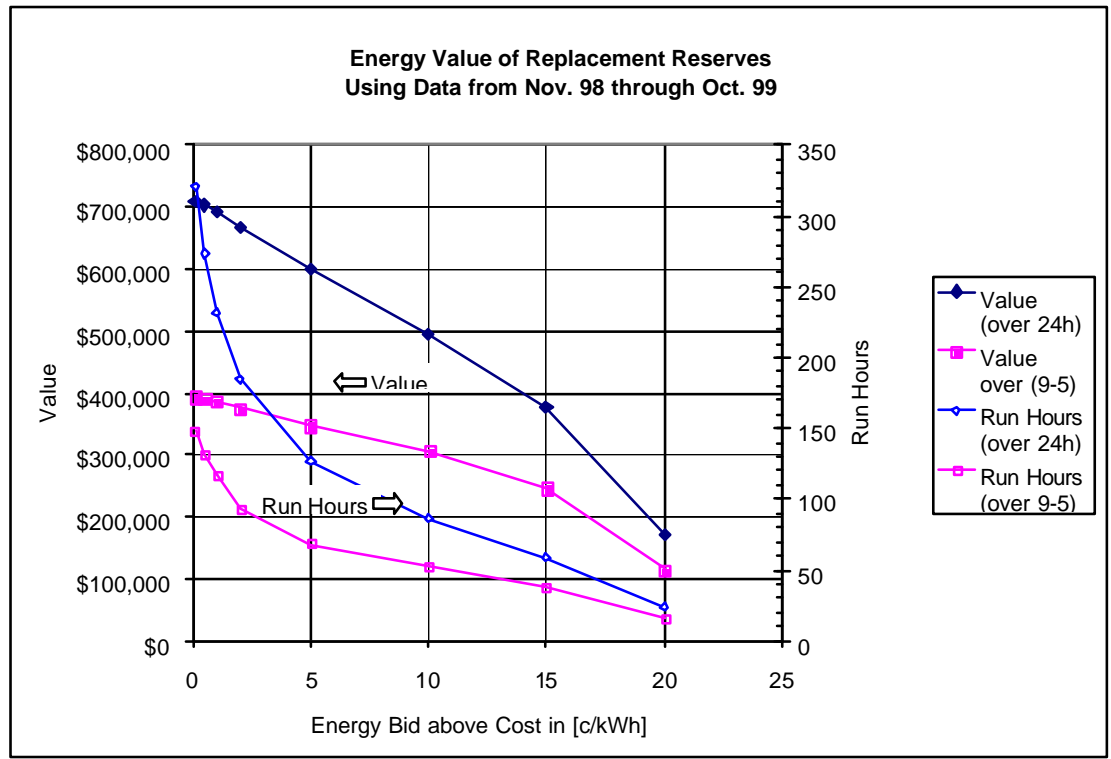

Figure 5: Supply Curve for Energy Value of the Replacement Reserve Market, Based on the Availability of 35 MW Load Reduction Assets

\subsubsection{Discussion on Bidding Strategies}

Figure 4 and Figure 5 can be used for developing a bidding strategy. There are two major questions whose answers determine the bidding strategy:

1. What is the availability of the load reduction assets? The availability determines the capacity and time period for the bid and, if accepted, the capacity and hours of commitment for potential load reduction dispatch.

2. How many hours of load curtailment dispatch are desirable? The energy bid determines the ranking order in which the CAISO dispatches all reserve capacity. By submitting a high energy bid, the chances of being called for load dispatch are reduced.

The load reduction availability is defined as an hourly capacity that is available to assist in a load reduction measure. The availability should be selected according to the expected presence of the ship in port and the ship's operational constraints to participate in the load 
reduction program. The energy bid provides a means to affect the likelihood of being called by the CAISO to dispatch the load reduction.

One strategy is to maximize the availability to capitalize on the capacity payments and to minimize likelihood of load dispatch. For this strategy, the capacity bid should be low and the energy bid must be high.

To achieve maximum profits, the capacity and energy value must be maximized. This requires maximal runtime of the ship's generators, which can be achieved by a low energy bid. It should be noted that a low bid should still recover the generator's own cost. A low bid in this sense is defined as a low profit bid.

Furthermore, it should be noted that the bidding process is highly dynamic and that one's bid has impacts on determining the market clearing price and, potentially how other participants bid. Therefore, the intent of this discussion is to describe only some fundamentals of the bidding process. The actual bidding strategy should be discussed and refined by experts employed by the Navy's the energy service provider.

\subsubsection{Conclusion of the Capacity-Based Curtailment Program}

The following conclusions are provided for evaluating the capacity-based program:

- The capacity-based program involves participation in the replacement reserve markets of the CAISO. A recently offered pilot program provides the opportunity to offer the Navy's load reduction assets to the CAISO markets through an energy service provider, who will function as a broker on behalf of the Navy. This would simplify the operational and administrational requirements for the Navy and shift them to the energy provider.

- There are two revenue streams available through the capacity-based program consisting of a capacity payment and an energy payment. The maximum combined value of the replacement reserve market is $\$ 1,499,000$ for the 24-hour availability of $35 \mathrm{MW}$ of ship generator capacity. When reduced to a limited 9-5 schedule, the maximal combined value is $\$ 786,000$.

- The capacity-based program requires a bidding strategy and constant attention by monitoring the bidding performance. There are two major parameters that determine the revenue streams resulting from this program. The Navy needs to determine the hours and capacity to be bid into the replacement reserve pool first. If bid is accepted, the Navy will receive payments for being in the reserve pool with the commitment to be available for load curtailment dispatch by the CAISO. The frequency of the actual load curtailment dispatch is influenced by the energy bid. A high energy bid will reduce the probability, a low bid will increase the probability of dispatch. The CAISO determines dispatch based on the need for replacement reserves for maintaining safety and reliability of the California electric grid. 
- The notification period for replacement reserves is 60 minutes. Within 60 minutes, the contracted (by means of bid acceptance) load reduction must be achieved. In case of non-compliance, the CAISO imposes penalties.

\subsection{Value Estimate for Demand Relief Program}

\subsubsection{Background}

In late spring of 2000, the CAISO supplemented the Summer 2000 Market Participation Load Trial Program announced on February 29, 2000 by offering - what it calls "Demand Relief for Summer 2000" (DR) Program. As the part of the trial program the DR program was offered for a 4-month period (June 15 through October 15, 2000). The most significant differentiation of the DR from the other load trial programs is the DR program is awarded for a duration of 1 month, whereas the other programs are bid in a day-ahead auction as part of the ancillary markets. In addition, there is a notification period of 30 minutes, which lies between the 60 minutes requirement of the replacement reserve program and the 10 minutes stipulated for the non-spinning reserves. ${ }^{4}$ The DR program is invoked just before a stage 2 emergency is declared by the CAISO. Figure 6 shows the emergency stages and call sequence for the program. More detail on the program is listed in Table 1.

The CAISO had hoped to attract up to $1000 \mathrm{MW}$ of load participation on a competitive bases. The actual contracted load for the DR program will likely to be significantly less than the $1000 \mathrm{MW}$ limit. In discussions with a representative of NewEnergy, Inc., the contracted load was cited to be less than $200 \mathrm{MW}$ on average for the 4-month period.

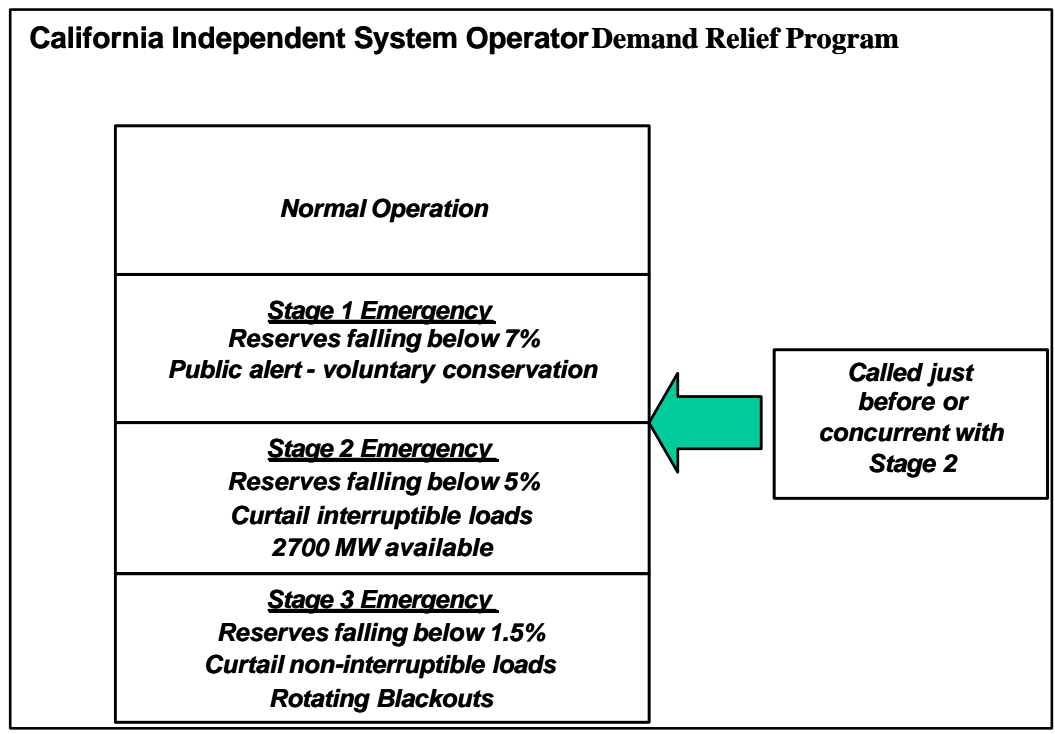

Note: 2700 MW load under utility interruptible rates

Figure 6: CAISO Demand Relief Program Call Sequence

\footnotetext{
${ }^{4}$ Article 5, Delivery of committed capacity of Pro Forma Demand Relief Agreement [CAISO DR, 2000].
} 


\subsubsection{Value Estimate}

The participants of this program receive two payment streams: (1) a capacity reservation payment and (2) an energy payment when load is curtailed. The capacity reservation payment equals the bid award. It can be lowered in cases of partial non-compliance. In the worst case, it is zero for full non-compliance. Bid awards are proprietary information, therefore, they are not available. Unofficial estimates by market experts place the capacity payments in a range between $\$ 25,000$ and $\$ 40,000$ per MW of curtailable load for a month ${ }^{5}$. High bids are assumed to be as high as $\$ 100,000$ per MW per month. The program requires the participants to make the load available up to 30 hours of CAISO invoked curtailment. Capacity reservation payments are made independent of curtailment frequency once approved by the CAISO.

Using similar assumptions as for the capacity and energy based program, we can estimate the capacity value of $35 \mathrm{MW}$ committed to this DR program. Assuming a successful bid for the 4-month period (June 15 to October 15, 2000) and the low capacity reservation value of $\$ 25,000 / \mathrm{MW} / \mathrm{month}$, the total value is $\$ 3,500,000\left(35 \mathrm{MW}^{*} \$ 25,000 / \mathrm{MW} / \mathrm{month}\right.$ $* 4$ months). Using the high value of $\$ 40,000 / \mathrm{MW} /$ month, the total value is $\$ 5,600,000$.

In addition to the capacity reservation payments, participants will receive energy payments during the period of curtailment. The payments are computed using the contracted curtailment and the market prices of the real-time energy market.

As of end of August 2000, the CAISO invoked the DR program for a total of 58 hours and 48 minutes [CAISO, 2000]. The curtailment periods and the corresponding average real-time energy prices are listed in Table 5. As can be seen in the average real-time market column of Table 5, the markets are at, or very near, the price caps imposed by the CAISO. Effective July 1, 2000, the price cap in the realtime energy and ancillary markets were reduced from the former \$750/MWh to \$500/MWh [CAISO, 2000]. Effective August 7, 2000, the price cap was further reduced from \$500/MWh to \$250/MWh and will remain at this level until October 15, 2000 [CEC CAP, 2000].

To evaluate the potential energy revenue stream, the operating cost for the power production by the on-board generators, as shown in Table 2, is subtracted from the energy payments. Table 5 shows the potential revenue for each day of the load curtailment.

\footnotetext{
${ }^{5}$ Unofficial estimate was provided by Derik Viner of NewEnergy, Inc.
} 
Table 5: Energy Value of the Demand Relief Program during Times When Load Relief Was Dispatched. (Note: Load Relief Events are only Listed through August 31, 2000. Program Continues until October 15, 2000).

\begin{tabular}{|r|r|r|r|r|r|}
\hline \multicolumn{1}{|c|}{ Date } & Start & \multicolumn{1}{c|}{ End } & \multicolumn{1}{c|}{$\begin{array}{c}\text { Duration } \\
\text { Hours:minutes }\end{array}$} & $\begin{array}{c}\text { Average real-time } \\
\text { energy market } \\
\text { [\$/MWh] }\end{array}$ & $\begin{array}{c}\text { Energy revenue } \\
\text { (energy payments - } \\
\text { operating cost })\end{array}$ \\
\hline $6 / 26 / 00$ & $16: 30$ & $18: 15$ & $1: 45$ & 750 & $\$ 42,000$ \\
\hline $6 / 27 / 00$ & $12: 00$ & $19: 00$ & $7: 00$ & 750 & $\$ 168,000$ \\
\hline $6 / 28 / 00$ & $14: 00$ & $18: 45$ & $4: 45$ & 750 & $\$ 114,000$ \\
\hline $7 / 19 / 00$ & $15: 31$ & $19: 00$ & $3: 29$ & 464 & $\$ 48,300$ \\
\hline $7 / 24 / 00$ & $15: 00$ & $17: 00$ & $2: 00$ & 500 & $\$ 30,500$ \\
\hline $7 / 25 / 00$ & $16: 11$ & $19: 00$ & $2: 49$ & 407 & $\$ 33,200$ \\
\hline $7 / 31 / 00$ & $12: 00$ & $19: 00$ & $7: 00$ & 500 & $\$ 106,700$ \\
\hline $8 / 1 / 00$ & $12: 00$ & $18: 00$ & $6: 00$ & 500 & $\$ 91,500$ \\
\hline $8 / 2 / 00$ & $12: 00$ & $18: 00$ & $6: 00$ & 499 & $\$ 91,300$ \\
\hline $8 / 3 / 00$ & $14: 00$ & $18: 00$ & $4: 00$ & 500 & $\$ 61,000$ \\
\hline $8 / 11 / 00$ & $15: 00$ & $17: 00$ & $2: 00$ & 250 & $\$ 13,000$ \\
\hline $8 / 14 / 00$ & $14: 30$ & $19: 00$ & $4: 30$ & 250 & $\$ 29,300$ \\
\hline $8 / 15 / 00$ & $14: 30$ & $17: 30$ & $3: 00$ & 250 & $\$ 19,500$ \\
\hline $8 / 16 / 00$ & $14: 30$ & $16: 30$ & $2: 00$ & 250 & $\$ 13,000$ \\
\hline $8 / 17 / 00$ & $15: 00$ & $17: 30$ & $2: 30$ & 250 & $\$ 16,300$ \\
\hline Total & & & $\mathbf{5 8 : 4 8}$ & & $\$ \mathbf{8 7 7 , 6 0 0}$ \\
\hline
\end{tabular}

A total of 58 hours and 48 minutes of load dispatch was recorded as of August 31, 2000, with 13.5 hours in June, 15.3 hours in July and 30 hours in August. Using a simply average scheme, yields an average of $19.6 \mathrm{~h}$ per month. Using this monthly average for the load dispatch hours and the price cap for the real-time energy market, we project the energy revenue for the remainder of the DR program (September 1 through October 15, 2000). This projection yields an energy revenue of $\$ 255,192(19.6 \mathrm{~h} / \mathrm{month} * 2$ month *35 MW * (\$250/MWh-\$64/MWh).

The total value estimates combining the capacity reservation payments for the entire 4month period, and the energy revenues are listed in Table 6. The normalized total projected value is determined by dividing the total projected value by the generation of 35 MW over a period of 98 hours, assuming 39.2 hours for the remainder of the program through October 15, 2000 in addition to the 58.8 hours (58 hours, 48 minutes) of actual load dispatch.

Table 6: Total Value Estimate for the Demand Relief Program Using Energy Value for Period $6 / 15 / 00$ to $8 / 31 / 00$.

\begin{tabular}{|l|c|c|c|c|c|}
\hline & Capacity Value & $\begin{array}{c}\text { Energy Value } \\
(6 / 15 / 00- \\
8 / 31 / 00)\end{array}$ & $\begin{array}{c}\text { Projected } \\
\text { Energy } \\
\text { Value } \\
(6 / 15 / 00- \\
10 / 15 / 00\end{array}$ & $\begin{array}{c}\text { Total } \\
\text { Projected } \\
\text { Value } \\
(6 / 15 / 00- \\
8 / 31 / 00)\end{array}$ & $\begin{array}{c}\text { Normalized } \\
\text { Total } \\
\text { Projected } \\
\text { Value } \\
\text { [S/MWh] }\end{array}$ \\
\hline $\begin{array}{l}\text { Low capacity } \\
\text { value estimate }\end{array}$ & $\$ 3,500,000$ & $\$ 877,600$ & $\$ 1,132,800$ & $\$ 4,632,800$ & $\$ 1,351$ \\
\hline $\begin{array}{l}\text { High capacity } \\
\text { value estimate }\end{array}$ & $\$ 5,600,000$ & $\$ 877,600$ & $\$ 1,132,800$ & $\$ 6,732,800$ & $\$ 1,963$ \\
\hline
\end{tabular}




\subsection{Value Estimate of Demand Reduction on the Coincident On-Peak Demand Charge of the Electricity Bill}

\subsubsection{Background}

Previously, the Pacific Northwest National Laboratory has developed a forecasting tool that predicts the electric load peak in the SDG\&E service territory. The objective of this forecasting tool is to assist in making decisions for reducing the Navy's electric demand during the utility's system peak to reduce the coincident on-peak demand charge of the Navy's electricity bill. The coincident on-peak demand component of the electricity bill contributes to between $40 \%$ and $60 \%$ of the total electricity during the summer period (May 1 through September 30).

In this section, we will discuss the impacts that a $35 \mathrm{MW}$ load reduction has on the coincident on-peak demand charge. Similar assumptions used in the previous value estimates will be applied here. The load reduction will be achieved by the utilizing onboard generators at cost detailed in Table 2 . The weighted average of the operating cost for the generator mix of the $35 \mathrm{MW}$ capacity is $\$ 64 / \mathrm{MWh}$. The value estimate of the onpeak demand charge reduction is performed only during the 5-month summer period (May 1 through September 30) because SDG\&E, as a summer peaking utility, sets high demand charges during the summer months. The contribution of the coincident demand charge during the rest of the year is less significant. The demand charge component is generally in the range of $6 \%$ to $10 \%$ during the spring, fall, and winter.

\subsubsection{Value Estimate of On-Peak Demand Reduction}

The forecasting tool determines the day of the month and the time of the day, when the SDG\&E system peak is likely to occur. To provide sufficient safety margin so that any potential demand reductions dispatch coincide with the system peak, a 3-hour curtailment window is placed around the forecasted system peak. The 3-hour curtailment window is an arbitrarily set period that strikes a balance between too small and too large a period around the forecasted system peak. A short curtailment window may result in missing the actual system peak by a few minutes rendering the entire curtailment worthless. A large curtailment window, on the other hand, may cause unnecessary inconvenience by the sailors operating the ship generators.

Given that a demand reduction dispatch lasts 3 hours, the operating cost for the $35 \mathrm{MW}$ generator capacity can be calculated as $\$ 64 / \mathrm{MWh} * 35 \mathrm{MW} * 4 \mathrm{~h}=\$ 6,720$. The desirable cost savings target for the dispatch is a reduction in the demand charge, valued as the product of the peak demand charge times the demand reduction. For the summer period, the current demand charge for the applicable electric rate (Schedule A6-TOU) of the Navy accounts is $\$ 8.19 / \mathrm{kW}$ for the 15 minute interval demand measured at the Navy's electrical meters at the time when the SDG\&E's system peak occurred [A6-TOU, 1999]. The system peak is determined once a month. Applying this demand charge to the 35 MW of demand reduction would then yield a value of $\$ 286,650$ per month. 
In addition to the cost savings potential resulting from a reduction in the demand charge, there could be an economic value by replacing the high-priced electric energy during onpeak periods with on-board generation. To assess the economics for the generation, we use the PX credit during the on-peak period (11 am through $6 \mathrm{pm}$ ) for the summer months May 1 through September 30 and compare the credit with the Navy's cost for generation. The PX credit represents the commodity price the Navy is charged by its energy service provider. The PX credit is determined by using the hourly prices of SDG\&E's procurement portfolio weighted by the load profile of the A6-TOU load group.

To capture the uncertainty in the system peak forecast, the tool may suggest two or more dispatch calls during a course of a month. This means that two or more dispatches are necessary to achieve the desirable cost savings in the coincident on-peak demand charge. The tool allows the user to adjust parameters that affect the frequency of a dispatch call over period of 1 month. This adjustment is based in the risk strategy that balances the risk to miss the monthly system peak versus calling too many dispatches. Table 7 shows the value estimates as a function of dispatch calls for the summer months of 1999. The PX credits are evaluated for the on-peak period during the summer of 1999.

Table 7: Value Estimate for Demand Reduction

\begin{tabular}{|c|c|c|c|c|c|c|}
\hline $\begin{array}{c}\text { Summer } \\
\text { Month of } \\
1999\end{array}$ & $\begin{array}{c}\text { Value of } \\
\text { Demand } \\
\text { reduction } \\
{[\$]}\end{array}$ & $\begin{array}{c}\text { Average PX } \\
\text { credit during } \\
\text { on-peak } \\
{[\$ / M W h]}\end{array}$ & $\begin{array}{c}\text { No of } \\
\text { dispatch } \\
\text { calls }\end{array}$ & $\begin{array}{c}\text { Net energy } \\
\text { benefits } \\
{[\$]}\end{array}$ & $\begin{array}{c}\text { Total value } \\
{[\$]}\end{array}$ & $\begin{array}{c}\text { Normalized } \\
\text { total value } \\
{[\$ / M W h]}\end{array}$ \\
\hline \multirow{4}{*}{ May } & \multirow{4}{*}{286,650} & \multirow{4}{*}{73.77} & 1 & 1,026 & 287,676 & 2,740 \\
\hline & & & 2 & 2,052 & 288,702 & 1,375 \\
\hline & & & 3 & 3,078 & 289,728 & 920 \\
\hline & & & 4 & 4,103 & 290,753 & 692 \\
\hline \multirow{4}{*}{ June } & \multirow{4}{*}{286,650} & \multirow{4}{*}{46.28} & 1 & $-1,861$ & 284,789 & 2,712 \\
\hline & & & 2 & $-3,721$ & 282,929 & 1,347 \\
\hline & & & 3 & $-5,582$ & 281,068 & 892 \\
\hline & & & 4 & $-7,443$ & 279,207 & 665 \\
\hline \multirow{4}{*}{ July } & \multirow{4}{*}{286,650} & \multirow{4}{*}{61.10} & 1 & -305 & 286,346 & 2,727 \\
\hline & & & 2 & -609 & 286,041 & 1,362 \\
\hline & & & 3 & -914 & 285,737 & 907 \\
\hline & & & 4 & $-1,218$ & 285,432 & 680 \\
\hline \multirow{4}{*}{ August } & \multirow{4}{*}{286,650} & \multirow{4}{*}{46.71} & 1 & $-1,816$ & 284,834 & 2,713 \\
\hline & & & 2 & $-3,632$ & 283,018 & 1,348 \\
\hline & & & 3 & $-5,448$ & 281,202 & 893 \\
\hline & & & 4 & $-7,264$ & 279,386 & 665 \\
\hline \multirow{4}{*}{ September } & \multirow{4}{*}{286,650} & \multirow{4}{*}{60.79} & 1 & -337 & 286,313 & 2,727 \\
\hline & & & 2 & -674 & 285,976 & 1,362 \\
\hline & & & 3 & $-1,011$ & 285,639 & 907 \\
\hline & & & 4 & $-1,348$ & 285,302 & 679 \\
\hline \multirow{4}{*}{$\begin{array}{c}\text { Total } \\
\text { summer }\end{array}$} & \multirow{4}{*}{$1,433,250$} & & 1 & $-3,292$ & $1,429,958$ & 2,724 \\
\hline & & & 2 & $-6,585$ & $1,426,665$ & 1,359 \\
\hline & & & 3 & $-\mathbf{9 , 8 7 7}$ & $1,423,373$ & 904 \\
\hline & & & 4 & $-13,169$ & $1,420,081$ & 676 \\
\hline
\end{tabular}

Note: The operating cost for Navy's generation is $\$ 64 / \mathrm{MWh}$. Normalized total value for the total summer is evaluated as monthly weighted average. 
Table 7 indicates a total value of about $\$ 1.4$ million for the demand reduction in the demand charge component of the electricity bill. The table also indicates that the operating cost for the Navy's generation cannot be fully offset by the avoided procurement of electric energy for the summer months in 1999. However, resulting cost burdens are relatively insignificant, amounting to about $\$ 13,000$ for conservatively assuming four dispatch calls per month for a successful coincident demand reduction. This suggests that the economic gains of demand reduction measures are not sensitive to the number of dispatch calls, as long as the inconvenience factor to realize the demand reduction is not monetized.

The per-MWh-value of the demand charge reduction is significant. Given a demand charge of $\$ 8.19 / \mathrm{kW}$ or $\$ 8,190 / \mathrm{MW}$ and a 3 hour dispatch period for every MW reduced, a value of $\$ 2,730 / \mathrm{MWh}(\$ 8,190 / \mathrm{MW} / 3 \mathrm{~h})$ is achieved. 


\section{Comparison of Demand Reduction Programs}

This section compares the results of each program assessed in this study. The major economic characteristics of each program are summarized in Table 8. The normalized total value provides a measure of the economics per unit of load displacement. Because a power requirement of a surface ship (the aircraft carrier excluded) is about $1 \mathrm{MW}$, a MWh displacement is approximately equivalent to a disconnect of one surface ship for 1 hour ${ }^{6}$. Thus the normalized total value can be used as a measure of economic benefit per ship per hour.

It should be mentioned that the total run hours for the energy-based and capacity-based programs are determined for periods when the market prices (CALPX and CAISO) exceed the operating cost for generation of the ship generators. The relatively large number of run hours for the energy-based and capacity-based programs, compared to the demand relief and demand charge reduction program, are caused by two factors. First, load dispatch in the demand relief program and the demand charge reduction program is only exercised during a few hours during the course of one month when the California power grid is under very short supply conditions or when SDG\&E system peak occurs. Furthermore, the demand relief and the demand charge reduction program are only summer programs. The energy- and capacity-based programs are available all year round and, therefore, accumulate more run hours over the 12-month period.

Table 8: Summary of the Economic Value of Programs Assessed in this Study

\begin{tabular}{|c|c|c|c|c|}
\hline $\begin{array}{l}\text { Program } \\
\text { (Time frame for value } \\
\text { estimate) }\end{array}$ & Assumption & Total Value & $\begin{array}{l}\text { Total Run } \\
\text { Hours }\end{array}$ & $\begin{array}{l}\text { Normalized } \\
\text { Total Value } \\
{[\$ / \mathrm{MWh}]} \\
\end{array}$ \\
\hline \multirow{2}{*}{$\begin{array}{l}\text { Energy-based curtailment } \\
\text { program }\end{array}$} & $24 \mathrm{~h}$ availability & $\$ 217,000$ & $547 \mathrm{~h}$ & 11 \\
\hline & 9-5 availability & $\$ 125,000$ & $198 \mathrm{~h}$ & 18 \\
\hline \multirow{2}{*}{$\begin{array}{l}\text { Capacity-based curtailment } \\
\text { program }\end{array}$} & $24 \mathrm{~h}$ availability & $\$ 1,499,00$ & $320 \mathrm{~h}$ & 134 \\
\hline & 9-5 availability & $\$ 786,000$ & $148 \mathrm{~h}$ & 152 \\
\hline \multirow{2}{*}{$\begin{array}{l}\text { Demand relief program } \\
\text { (June } 15,00 \text { - Oct } 15,00 \text { ) }\end{array}$} & $\begin{array}{l}\text { Low estimate of } \\
\text { capacity value }\end{array}$ & $\$ 4,632,000$ & \multirow[b]{2}{*}{$98 \mathrm{~h}$ (projected) } & 1,351 \\
\hline & $\begin{array}{l}\text { High estimate of } \\
\text { capacity value }\end{array}$ & $\$ 6,732,000$ & & 1,963 \\
\hline \multirow{2}{*}{$\begin{array}{l}\text { Demand charge reduction } \\
\text { program (SDG\&E) } \\
\text { (May } 1,99-\text { Sep. } 30,99 \text { ) }\end{array}$} & Optimistic & \multirow[t]{2}{*}{$\$ 1,430,000$} & $\begin{array}{c}15 \mathrm{~h} \\
\text { (one dispatch } \\
\text { call/month of } 3 \mathrm{~h} \\
\text { each) } \\
\end{array}$ & 2,724 \\
\hline & Pessimistic & & $\begin{array}{c}60 \mathrm{~h} \\
\text { (four dispatches/ } \\
\text { month of } 3 \mathrm{~h} \text { each) }\end{array}$ & 659 \\
\hline
\end{tabular}

\footnotetext{
${ }^{6}$ According to discussions with LCDR William Scherer. Aircraft carrier requires about $5 \mathrm{MW}$.
} 
It should also be mentioned that the value estimates of the demand relief program are based on summer 2000 market data, whereas the capacity- and energy-based curtailment programs use data for the period November 1998 through October 1999. Because of the most recent price run ups of the electric power markets in California during the summer of 2000, any summer 2000 program compared to a program based on the previous year data would look favorable. Furthermore, the level of the price cap in the ancillary services markets underwent several changes during the period from November 1998 through August 2000, causing a distortion in the value comparisons. For example, for the replacement reserve markets, the price cap changed from $\$ 250 / \mathrm{MW}$ in 1999 to $\$ 750 / \mathrm{MW}$ in 2000 to a lower level of $\$ 500 / \mathrm{MW}$ on July 1, 2000 and finally down to \$250/MW on August 7, 2000.

A fair comparison would be to redefine energy- and capacity-based curtailment programs to the same time period as was established for the demand relief program. Because of resource constraints this analysis was not performed.

The following general qualitative differences should be noted:

1. The energy-based curtailment program exhibits the lowest value. It requires the longest run time of the ship generators and, thus, the longest commitment by the ship staff. As a result of the lowest total value and the greatest run time of ship generators the per MWh value is the lowest.

2. The capacity-based curtailment program capitalizes on the capacity and energy value of the power markets. It achieves a per MWh value by an order of magnitude greater than that for the energy-based curtailment program

3. The demand relief program exhibits the highest total value and an order of magnitude improvement of the per-MWh value compared to the capacity-based curtailment program. This result is attributable to the overall high prices during the summer of 2000, which may or may not be representative for the future. However, the capitalization of only the highest priced periods for only a few hours during the summer months makes this program attractive on a per-MWh basis.

The coincident on-peak demand charge reduction is valued at a fixed-demand charge rate set by the SDG\&E rate schedule $(\$ 8.19 / \mathrm{kW})$. The per-MWh value can be the highest of all program analyzed under optimistic assumptions. However, under more realistic assumptions (see Table 7) the value may be comparable to that of the demand relief program. 


\section{Cost Savings Estimates for CALPX Block Forward Contract}

\subsection{Motivation}

The motivation to conduct a cost savings analysis of block forward contracts emerged in a meeting with PWC, Navy, PNNL, and Newenergy, Inc. representatives in which various curtailment options were discussed. A block forward contract is a risk management tool to minimize the risk exposure when procuring power on the spot market. A block forward contract is a financial instrument that can be purchased independent of any load reduction or curtailment programs and, thus, can provide value regardless of load management capabilities.

The PWC requested this additional analysis for informational purposes to gauge the economic value of this financial instrument for the Navy in San Diego.

\subsection{Background}

The CALPX recently offered a new market for forward contracts in response to a market need for a financial instrument that provides risk management options to protect against high-price periods. Since June of 1999, the CALPX began trading block forward contracts [CALPX BF, 1999]. A block forward is a block of electric energy defined by the following three parameters:

- Height: The height determines the MWh of electric energy. It is traded at the CALPX in increments of $1 \mathrm{MWh}$.

- Width: The width specifies the length of the daily block in hours. It is traded at a constant length of 16 hours per day, starting at 6:00 and ending at 22:00 hour. The block is only traded for weekdays, except holidays.

- Duration: Duration of the contract for which the daily height and width is valid. The duration is 1-calendar-month.

The fixed duration and large MWh increments are designed for large sales and purchases of wholesale electricity. This contract structure may not necessarily be suitable for the end-use customers, largely because of the fixed width contract constraint. In discussions with the Navy's energy provider, Newenergy, Inc. entertained the opportunity to offer more flexibility to the block forward contract whereby the width can be determined by the Navy and the MWh increments are reduced to a smaller, yet unspecified increment ${ }^{7}$. The price for the more flexible block forward contract would then be indexed on the CALPX block forward contract plus some yet to be determined transaction fee. Each month, prior to the delivery of the block forward, the Navy would need to determine the height and width that is constant over the duration of that month. The remainder of the Navy's electric energy requirements would be purchased through the existing contract

\footnotetext{
${ }^{7}$ Discussion with Derik Viner of Newenergy, January 6, 2000.
} 
vehicle (see Figure 7). To offer flexibility to the Navy, Newenergy, Inc. would need to procure forward contracts either through the CALPX or through bilateral contracts with generators.

Because of this flexibility in the block forward contract design, the Navy felt sufficiently interested to investigate and explore the cost savings opportunities using this instrument rather than to be exposed to the market volatility of the CALPX day-ahead prices.

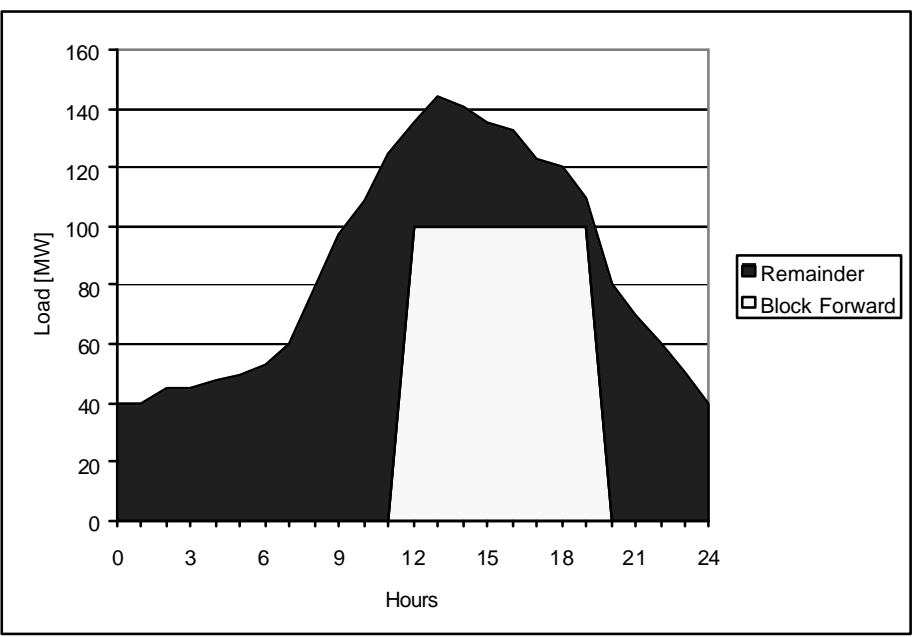

Figure 7: Schematic of Procurement Portfolio Consisting of Block Forward and SpotMarket Procurement

\subsection{Design of an Optimal Block Forward Contract}

The objective of this particular analysis is to estimate the cost savings potential by protecting against high price spikes using a block forward instrument. The analysis is based on a cost comparison of an optimal procurement portfolio consisting of block forward contracts and spot market purchases versus a simple spot market portfolio. Because of the very recent trading of block forward contracts, no sufficient historic data are available to perform a 1-year comparison between the cost of an optimal portfolio position with that of the existing procurement contracts with Newenergy, Inc (see Section 3.1.4). Furthermore, an integrated analysis incorporating both financial instruments and the Navy's load management exceeds the scope of this analysis.

The design of an optimal block forward contract is based on the following assumptions:

1. The electric energy for the Navy is provided using a procurement portfolio consisting of the following two components: (1) block forward contract, and (2) spot market electricity indexed by the CALPX zonal day-ahead price for SP15.

2. Last year's hourly load profiles are a sufficient proxy for future load profiles.

3. The load profile used consists of hourly electric energy consumption aggregated for the following three accounts: (1) Naval Station, (2) North Island, (3) Point Loma. 
4. Last year's CALPX hourly day-ahead prices are sufficient proxy for future electric hourly day-ahead prices.

Assumption four is probably the weakest assumption because the CALPX hourly dayahead prices are expected to be more highly correlated by the weather than is the aggregate energy consumption of the Navy. Furthermore, there are random unavailability of critical generation and transmission capacity in the California power system that may contribute to a sharp rise of day-ahead prices, which may not be captured in last year's price data.

However, in the absence of any prediction tools for day-ahead price and consumption trajectories, the assumptions above provide sufficient means of estimated past cost savings potentials. It remains uncertain as to how applicable last year's cost savings estimates are for the future, because the commodity markets, and particularly, the block forward market, is very new, and therefore, is still evolving to a mature market.

\subsection{Approach}

The estimates of cost savings potential are based on an linear optimization technique that selects the cost-optimal procurement portfolio by minimizing the cost of procuring electric energy subject to a set of constraints. The cost savings are then determined by comparing the monthly cost of electricity using the spot market prices with that of the optimal procurement portfolio.

The minimization problem is formulated over a period of 1 month to comply with the terms of a generic contract duration. It can be expressed in the following form:

Minimize

$Z=\sum_{i=1}^{\text {month }}\left[\left(P_{B F} \cdot E_{B F, t}\right)+\left(P_{S M, t} \cdot E_{S M, t}\right)\right] \cdot \Delta t$

subject to the following constraints:

$\begin{array}{ll}E_{B F, t}=E_{B F, t+1}=E_{B F, t+2}=\ldots \ldots=E_{B F, t+i} & \text { for all } i=1, \ldots 720 \\ E_{t o t a l, t}=E_{B F, t 1}+E_{S M, t} & \text { for all } t=1, \ldots 720\end{array}$

where

$P_{B F} \quad$ traded price for block forward contract for a particular month, in $\$ / \mathrm{MWh}$

$P_{S M, t} \quad$ CALPX spot market price (day-ahead price) at hour $t$, in $\$ / \mathrm{MWh}$

$E_{B F, t}$ height of block forward contracted electric power at hour $t$, in MW

$E_{S M, t}$ height of spot market procured electric power at hour $t$, in MW

$E_{\text {total }, t}$ total load at hour $t$, in MW

$\Delta t \quad$ time unit of 1 hour 
Constraint Equation (3) expresses equal height of all hourly block forward heights within a calendar month. Constraint Equation (4) defines that the energy procurement portfolio must meet the hourly loads.

The linear minimization was performed using a linear optimization solver Minos [Minos, 1993].

\subsection{Results}

Figure 8 shows the CALPX traded block forward prices by month of delivery, as of January 13, 2000. Summer months are more actively traded, with trades occurring 6 months prior to delivery. The spring months, April and May 2000, were not traded in January 2000 at all because of a lack of attractiveness.

For the analysis, a mean value of the block forward prices is used.

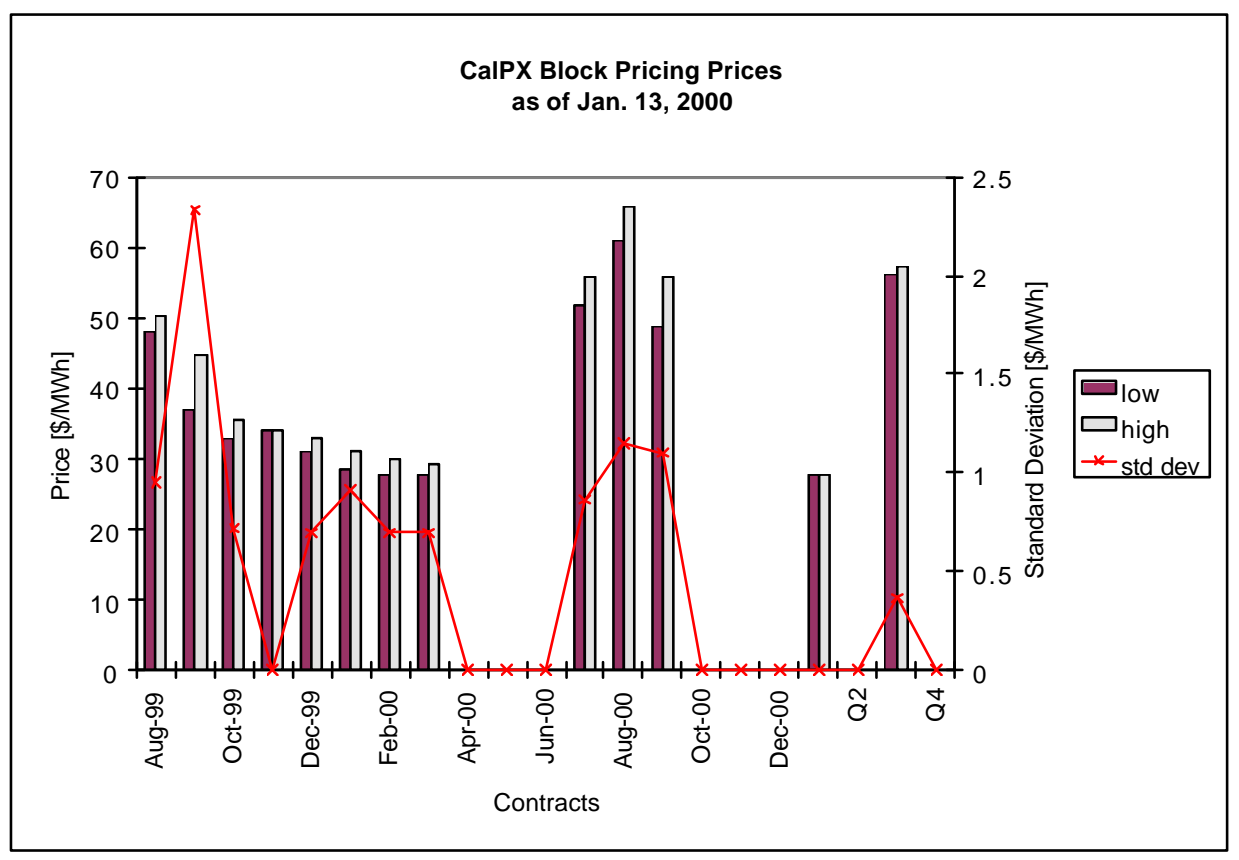

Figure 8 : CALPX Block Forward Prices as of January 13, 2000. 
Results of the optimal procurement portfolio are shown for selected months of 1999 in Figure 9 and Figure 10.

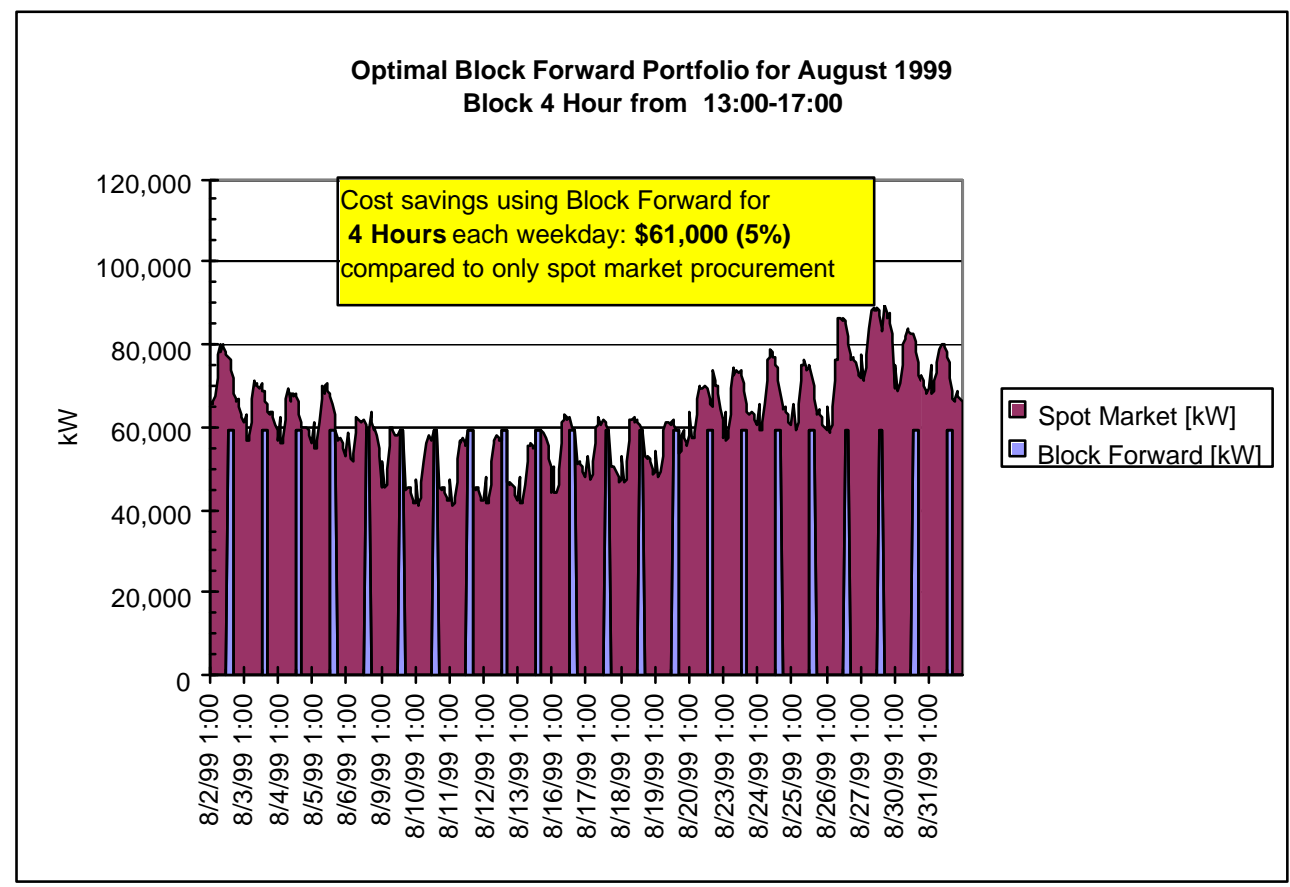

Figure 9: Optimal Block Forward Portfolio for Aggregated Accounts, August 1999.

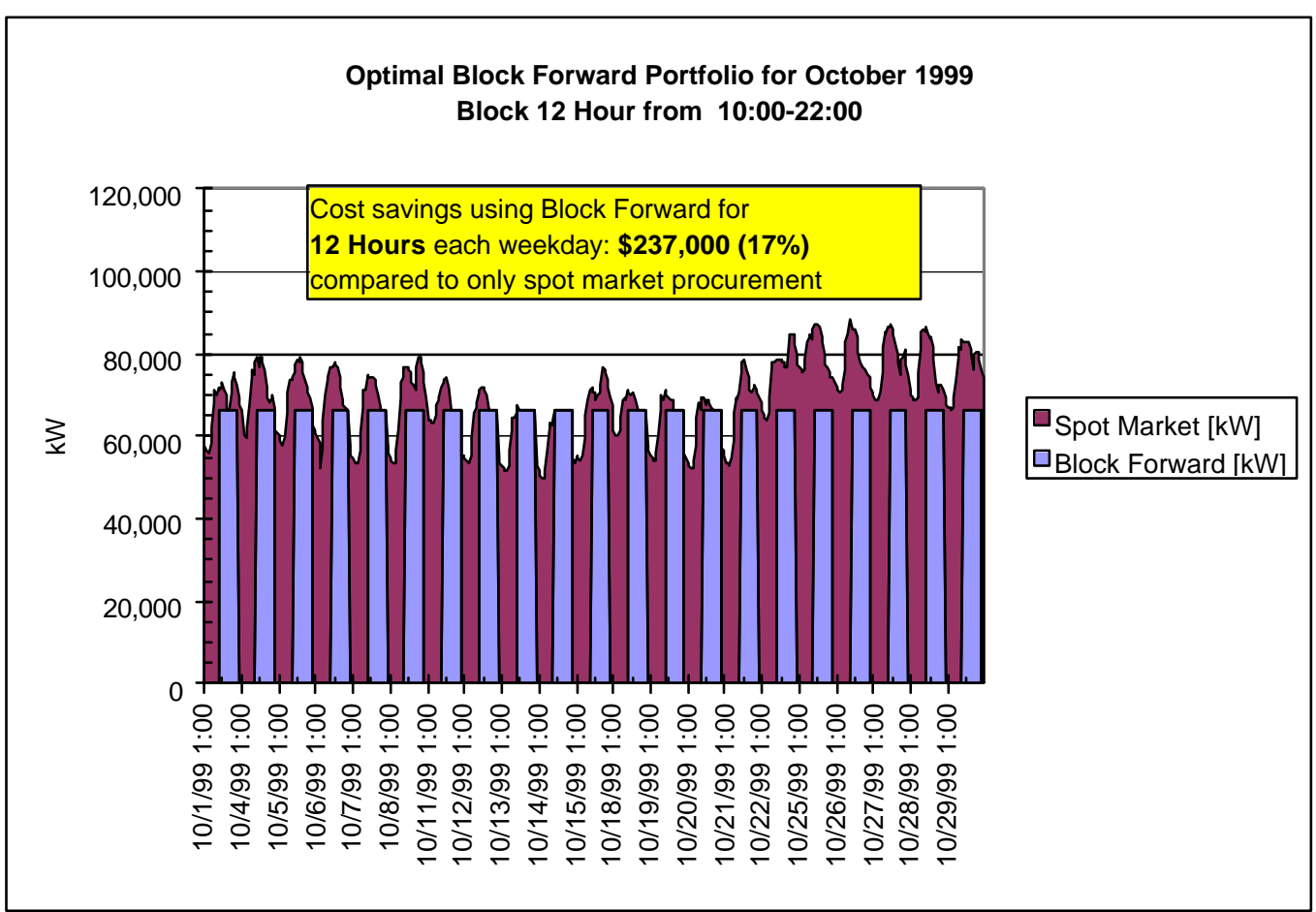

Figure 10: Optimal Block Forward Portfolio for Aggregated Accounts, October 1999. 
Table 9 provides a summary of the cost comparisons.

Table 9: Summary of Cost Comparison Between Two Procurement Strategies for Aggregated Accounts (Naval Station, North Island, Point Loma)

\begin{tabular}{|c|c|c|c|}
\hline & $\begin{array}{l}\text { Optimal Procurem. } \\
\text { Port. (Opti) }\end{array}$ & $\begin{array}{l}\text { Spot Market } \\
\text { (SM) }\end{array}$ & $\begin{array}{c}\text { Difference } \\
\text { (Opti-SM) } \\
\text { [\% Diff] }\end{array}$ \\
\hline & in $\$ 1000$ & in $\$ 1000$ & in $\$ 1000$ \\
\hline June 99 & $\$ 932$ & $\$ 1,051$ & $\begin{array}{r}\$ 119 \\
{[11 \%]}\end{array}$ \\
\hline July 99 & $\$ 1,131$ & $\$ 1,153$ & $\begin{array}{r}\$ 22 \\
{[2 \%]} \\
\end{array}$ \\
\hline Aug. 99 & $\$ 1,133$ & $\$ 1,194$ & $\begin{array}{r}\$ 61 \\
{[5 \%]}\end{array}$ \\
\hline Sept. 99 & $\$ 1,180$ & $\$ 1,203$ & $\begin{array}{r}\$ 23 \\
{[2 \%]}\end{array}$ \\
\hline Oct. 99 & $\$ 1,159$ & $\$ 1,397$ & $\begin{array}{r}\$ 237 \\
{[17 \%]}\end{array}$ \\
\hline Nov. 99 & $\$ 870$ & $\$ 891$ & $\begin{array}{r}\$ 21 \\
{[2 \%]}\end{array}$ \\
\hline Dec. 99 & $\$ 1,144$ & $\$ 1,220$ & $\begin{array}{r}\$ 76 \\
{[6 \%]}\end{array}$ \\
\hline Total & $\$ 8,549$ & $\$ 9,109$ & $\begin{array}{l}\$ 560 \\
{[7 \%]}\end{array}$ \\
\hline
\end{tabular}

The cost comparison indicates a moderate $7 \%$ cost reduction potential over a period from June 99 to December 99. As shown for the month of October 99, the cost savings could be as high as $17 \%$ providing significant one-time savings opportunities.

\subsection{Caveat}

It should be pointed out that the cost savings estimates are performed for past months with perfect knowledge of hourly load profile and price data. It is difficult to judge how these cost savings estimates will hold for future procurement strategies. The largest uncertainty in judging the potential usefulness of block forward contracts for the Navy is associated with the difficulty to predict the load for the Naval Station and the North Island accounts. More research needs to be done to investigate how uncertainties in the load prediction could affect the outcome of the optimal procurement portfolio design and on the 'bottom' line. 


\section{Volatility Analysis of the Load}

\subsection{Introduction}

The volatility analysis of the San Diego Navy electric load attempts to assess the risk of being non-compliant with certain California Independent System Operator ancillary (CAISO) markets rules. In particular, the capacity-based curtailment program defined in Section 4.2 requires verifiable documentation of a load reduction by the CAISO through direct or semi-direct real-time meter reading of the Navy's revenue meters.

Because it is conceivable that major loads can be connected or disconnected as Navy ships arrive at the pier, it is imperative to understand the overall volatility of the loads from hour to hour.

\subsection{Definition of Volatility Parameters}

Data input for the volatility analysis are 15-minute-interval revenue meter readings as provided by the Newenergy, Inc., the energy service provider (ESP).

The load volatility is characterized by the following parameters:

- Mean of 15 min electric energy readings over 1 hour (RHM)

- Difference of RHM over a 15-minute time step ( $\triangle \mathrm{RHM})$

- Difference in electric energy $(\mathrm{kWh})$ over a 15 -minute time step $\left(\Delta \mathrm{E}_{15}\right)$

- Difference in electric energy $(\mathrm{kWh})$ over four 15 - minute time steps $\left(\Delta \mathrm{E}_{60}\right)$.

Statistics for volatility parameters are determined for each day of the week separately to identify any potential load characteristics that are day-specific. The following statistical parameters are evaluated:

- Maximum value

- Minimum value

- Mean

- Standard deviation.

The statistics of 15 min electric energy readings are shown for each day of the week in Applendix B. 


\subsection{Load Profiles}

Figure 11 shows a winter load profile for the following three separate accounts: North Island, Naval Station and Point Loma. Figure 12 presents the corresponding load profile for a summer month.

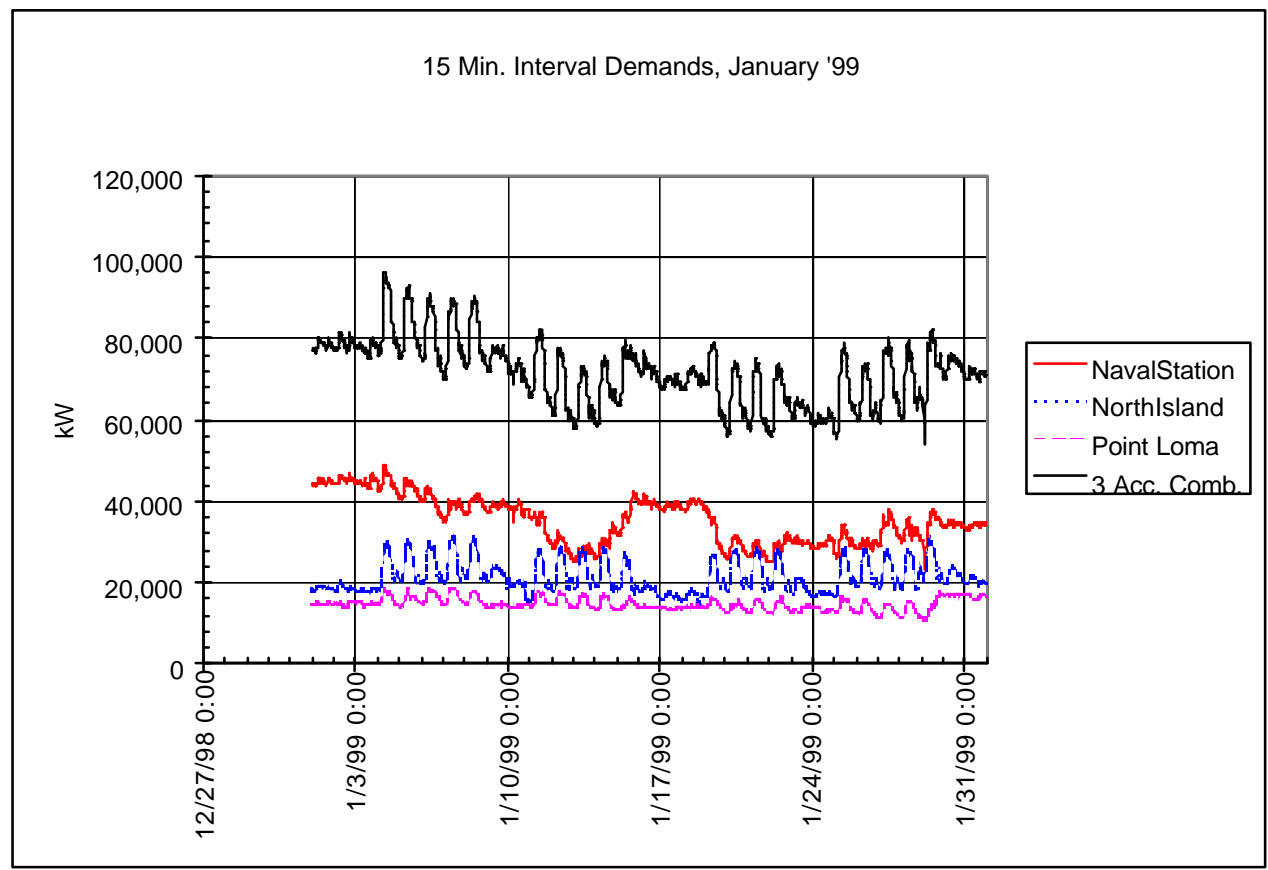

Figure 11: Winter Load Profile Using 15-Minute-Interval Data for Selected Accounts

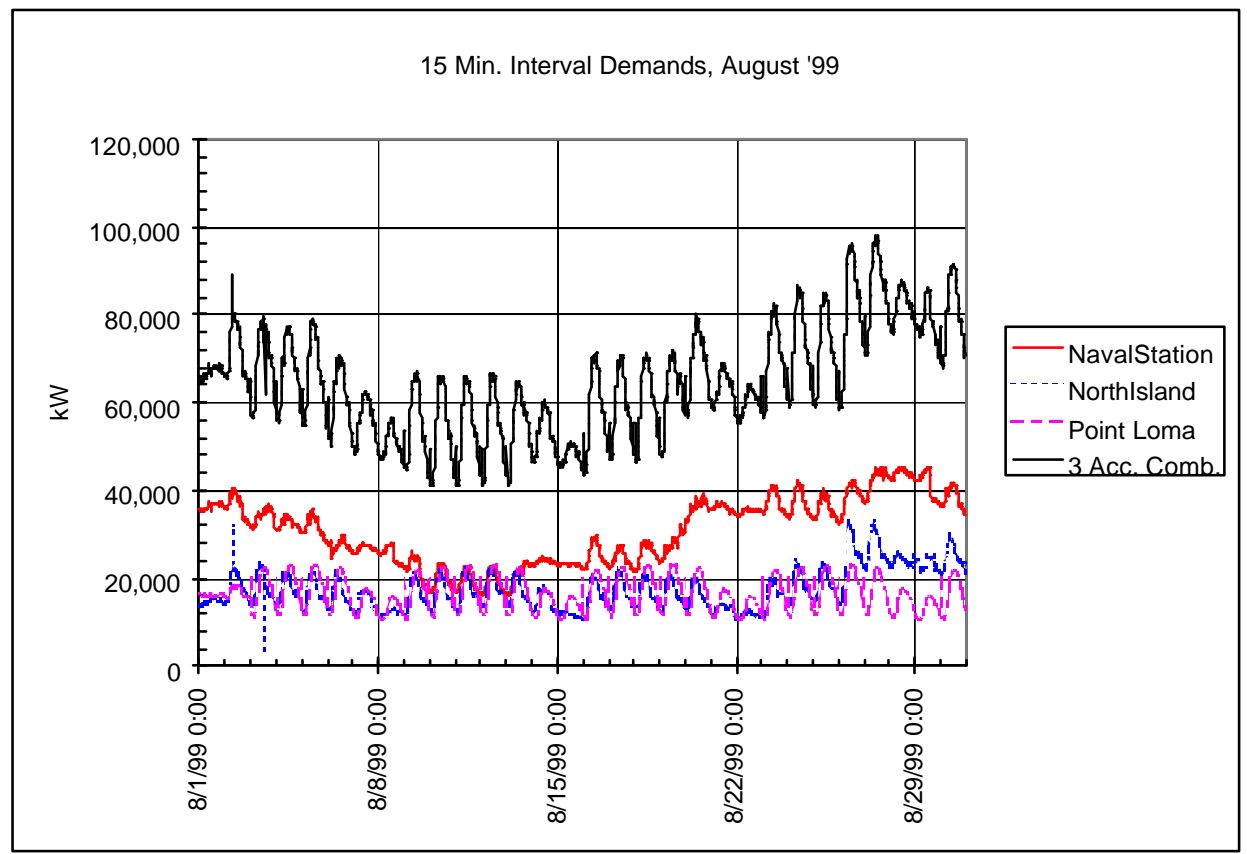

Figure 12: Summer Load Profile Using 15-Minute-Interval Data for Selected Accounts 
The load profiles for the three selected accounts show similar characteristics. The profile for the Naval Station is mainly determined by the number of surface ships it serves. Both North Island and Point Loma accounts show characteristic day and night fluctuations attributable to day shift operations. The day/night fluctuation is more pronounced in the summer time for Point Loma, which may be attributable to the additional air-conditioning and cooling operations. Further load profiles for the period of November 98 through October 99 can be found in Appendix A.

The combined time-of-day load profile for all three accounts is shown in Figure 13

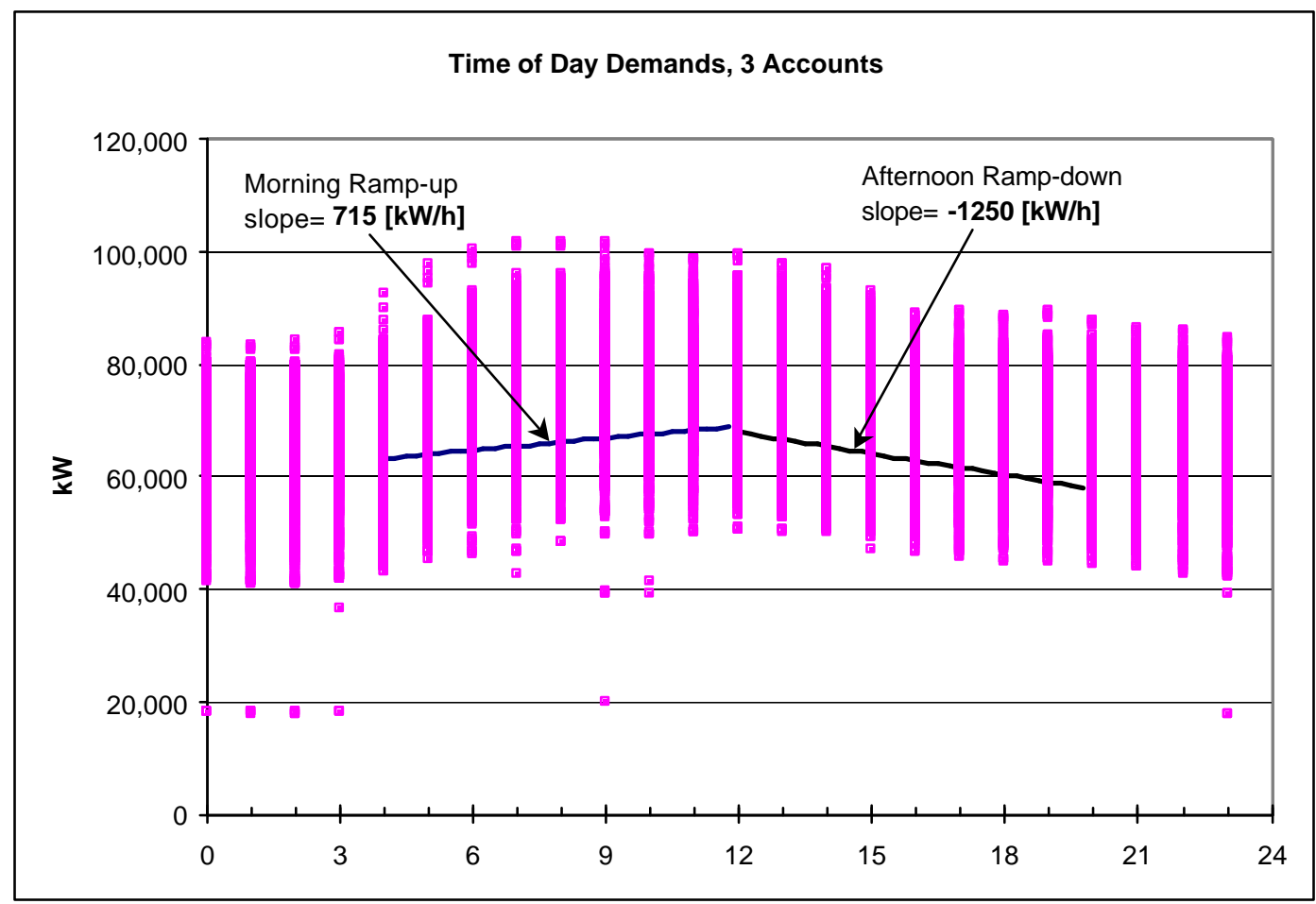

Figure 13: Time-of-Day Load Profile for Three Accounts (Period November 1998 to October 1999

The three accounts in the aggregate indicate a morning ramp-up followed by an afternoon ramp-down, which is expected to be attributable to the work activities on base. The slope of the morning ramp-up was defined for the period from 4:00 to 12:00 hour and determined by linear regression using $15 \mathrm{~min}$. interval data from November 1, 1998 through October 31, 1999. The afternoon ramp-down is defined for the period starting at 12:15 through 20:15 hour.

The significance of the ramping characteristics comes into play when contemplating the demand reduction strategies, which may last for several hours. It is important to compensate for the up-sloping trend when designing load reduction targets to avoid exceeding the target value. For instance, if at 8:00 hour the load is $65 \mathrm{MW}$ and demand is to be dropped to maintain $60 \mathrm{MW}$ or less for a 4-hour period, then $7.86 \mathrm{MW}$ (65-60MW 
$+0.715 \mathrm{MWh} / \mathrm{h} * 4 \mathrm{~h}$ ) are to be dropped initially to compensate for the anticipated load increase in the morning. Alternatively, $5 \mathrm{MW}$ are dropped at 8:00 hour followed by additional incremental demand reduction totaling up to $2.86 \mathrm{MW}$ to limit the load at or below $60 \mathrm{MW}$.

\subsection{Result of Volatility Analysis}

Volatility in the electric load of the aggregated accounts can be significant and needs to be considered in establishing operational load targets for load curtailment or load reduction programs. Random loads such as connecting new surface ships to the distribution grid, may occur during curtailment periods, for which sufficient load reduction reserves need to be available. It is important to understand the randomness of load fluctuation to design sufficient reserves in the load curtailment program that protect against non-compliance with the contracted curtailment program targets.

Figure 14 presents a probability distribution function of load fluctuation around its mean value for the aggregated accounts over a 1-year period using 15-min interval data.

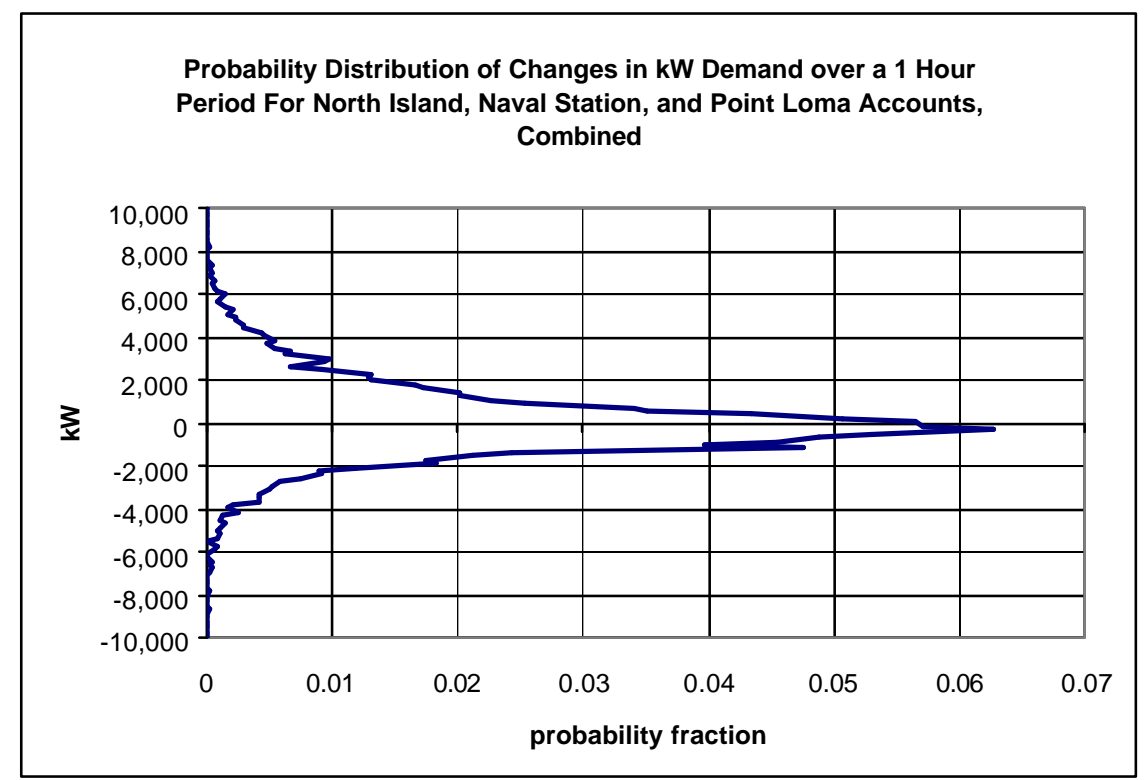

Figure 14: Normalized Probability Distribution Around the Mean of Aggregated Loads Using Data over a 1-Year Period

The probability of the load to be at its mean value is about $8 \%(0.08)$. Positive $\mathrm{kW}$ values indicate loads above the mean load. Analogously, negative $\mathrm{kW}$ values indicate loads below the mean. The area under the probability distribution function constitutes the cumulative probability and when integrated from $-\infty$ to $+\infty$, yields $100 \%$ or 1 .

Figure 15 presents the integral or cumulative probability function. This figure shows a probability of $58 \%$ that the load will be at or below its mean value. Likewise, there is a probability of $90 \%$ that the load will be at or below $2200 \mathrm{~kW}$ above the mean value. To 
avoid non-compliance, we could state that there is a $10 \%$ probability that the load would exceed $2200 \mathrm{~kW}$ above its mean value. This cumulative probability function can be used to set non-compliance avoidance reserves. The table in Figure 15 provides a set of probability or risk scenarios. For instance, a low risk position would be to set the noncompliance avoidance reserve at $5,370 \mathrm{~kW}$. This would reduce the risk to exceed the demand reduction target to a probability of $1 \%$.

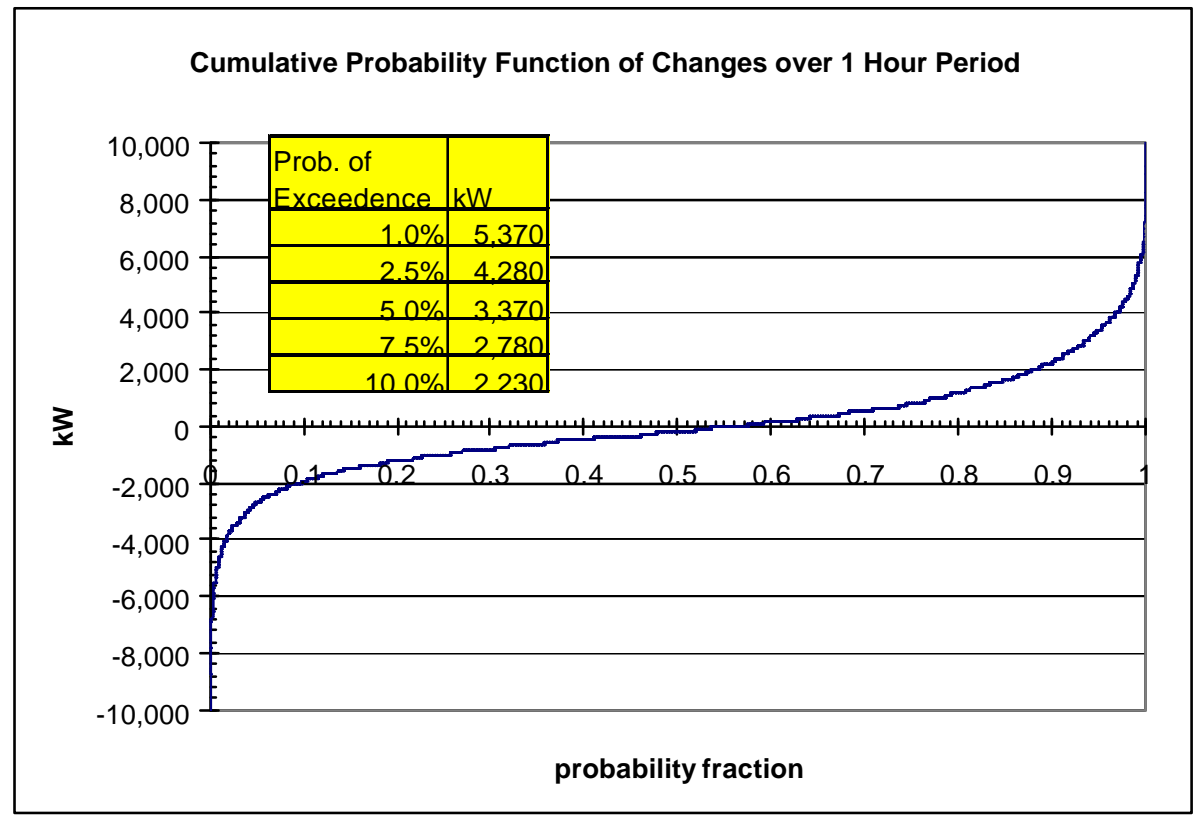

Figure 15: Cumulative Probability Function for Aggregated Accounts

\subsection{Caveat of Analysis}

The statistical analysis was based on the 15-min load data over a period of 1 year. As a consequence, the results are applicable over the entire range of load levels measured over the 1-year period. A potential correlation of the volatility with respect to load level has not been performed. It is, therefore, unclear at this time as to whether the volatility increases or decreases at high loads when a curtailment call by the CAISO is most likely. It could be argued that the diversity of the load increases at higher loads resulting in less volatility, alternatively, major loads such as ships may be connected or disconnected during the day when the loads are generally high and, therefore, increase the volatility.

It is recommended to further investigate the load dependency on the volatility if and when the Navy decides to engage in specific ancillary service markets. The results above are intended to provide a general discussion on non-compliance avoidance reserves to illuminate an important issue associated with "playing" in ancillary services markets. 


\subsection{Non-Compliance Avoidance Strategy}

There are two mechanisms that could bring any load curtailment into non-compliance. They are: 1) morning ramp-up of the average load and 2) random fluctuations of the load. The strategy to effectively counter these load mechanisms is to implement load reduction reserves, which are additional load reduction levels beyond the contracted curtailment levels. They need to be applied collectively to avoid non-compliance.

\subsubsection{Morning Ramp-up}

As seen in Figure 13, there is a morning ramp-up of $715 \mathrm{kWh}$ per hour ending at noon. Conversely, there is an afternoon ramp-down of $1250 \mathrm{kWh}$ per hour. To protect against this load increase during the morning, a reserve of $715 \mathrm{~kW}$ of additional demand reduction for each hour during the curtailment must be applied. For curtailment periods longer than 1 hour, the reserve can either be applied at the beginning of the curtailment, as one reserve block that accounts for the entire load increase over the curtailment period, or it can be phased in for each hour. It should be noted that most curtailments occur during the system peaks in the afternoon, when the average load is decreasing. This load decrease will assist in avoiding non-compliance by increasing the avoidance reserves for each hour in the afternoon.

Use of a negative reduction reserve to account for the decrease in the anticipated average load in the afternoon hours is not recommended. Rather, it is suggested that the afternoon ramp-down be used to decrease the risk position against random load increases, a phenomenon described in the next section.

\subsubsection{Random Fluctuations}

Figure 16 shows how to apply the load volatility statistics in the non-compliance avoidance strategy. Assume that a notification for a contracted load reduction of $\mathrm{X}$ has occurred at time $\mathrm{T}_{0}$, and the Navy is required to reduce the load from its current level of $\mathrm{P}_{0}$ to $\mathrm{P}_{\text {red }}$ by time $\mathrm{T}_{1}$. Further, assume that at no time during the curtailment period can the load exceed $\mathrm{P}_{\text {red. }}$. The non-compliance protection requires a load reduction below the $\mathrm{P}_{\text {red }}$ level to a new load demand of $\mathrm{P}_{\text {safe. }}$. The difference between $\mathrm{P}_{\text {red }}$ and $\mathrm{P}_{\text {safe }}$ is then the noncompliance avoidance reserve and is sized dependent on the Navy's risk position according to the table in Figure 15. 


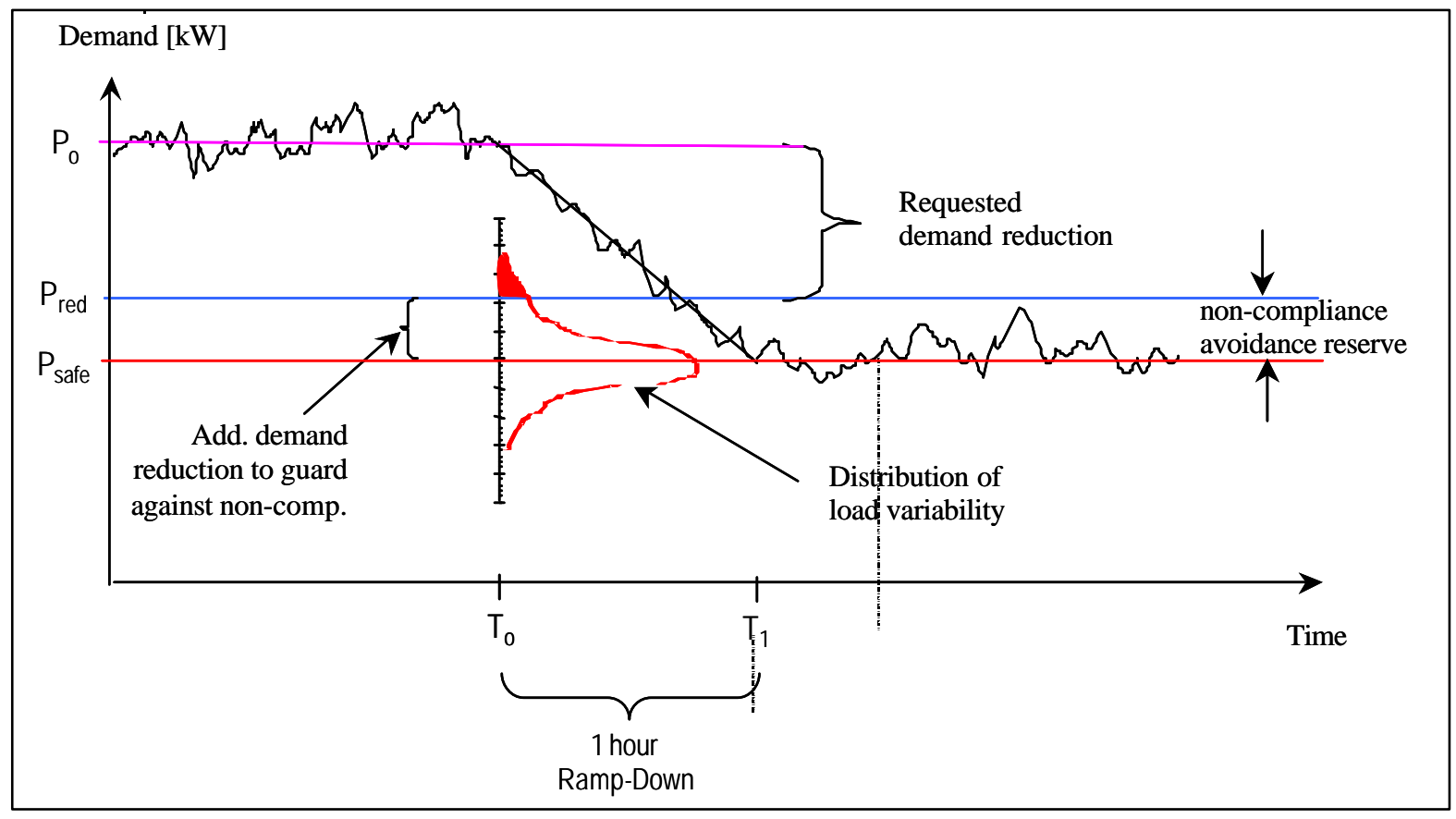

Figure 16: Non-Compliance Avoidance Strategy to Protect Against Random Load Fluctuations 


\section{Comparison of Direct Access Versus Virtual Direct Access Rates}

\subsection{Background}

The Navy in San Diego was interested in evaluating a hypothetical scenario in which the Navy would procure the market-based commodity of electric energy from the local utility (SDG\&E) rather than from Newenergy, Inc. In this scenario, the Navy accounts would change from a currently direct access customer to a virtual direct access customer. The following definitions of the two account options will clarify the difference between the two.

\subsubsection{Direct Access Customers}

Direct access customers purchase energy from an energy service provider and continue to receive delivery services from SDG\&E. The bill for a direct access customer will be calculated as if it were a SDG\&E bundled service customer, then crediting the bill by the amount of the PX component (commodity). The credit is based on the weighted averaging scheme that determines the average PX component over a specified period of time weighted by the load profile of the aggregated load of customers, who are on the same rate schedule.

The cost of the commodity is then billed by the energy service provider (Newenergy, Inc.). Newenergy bills the Navy applying a discount on the PX credit ${ }^{8}$.

\subsubsection{Virtual Direct Access Customers}

Virtual direct access customers receive supply and delivery services solely from SDG\&E. The bill for a virtual direct access customer will be calculated as if it were a SDG\&E bundled service customer, then crediting the bill by the amount of the PX component, then adding the hourly PX component, which is determined by multiplying the hourly energy used in the billing period by the hourly cost of energy from the PX [A6-TOU, 1999].

The difference between the two options is that in the direct access case, the volatility of the hourly PX prices is mitigated by the load diversity of all members in the same rate class. For example, if the Navy had a very pointed load profile with a dominant peak in the afternoon when PX prices are high, and the other members of the rate class exhibited a relatively flat load profile, then the full impact of the high prices would be mitigated or dampened by the lower average price. In this case, the Navy may be better off to be a

8 Contract between New Energy Ventures and Defense Energy Support Center, Ft. Belvoir, VA. Requisition number: SC0600-98-0077 Amend 1-4, May 12, 1998. 
direct access customer. Conversely, if the Navy's load profile is flat but the other load class members show a distinct peak during high price periods, then the Navy would be better off as a virtual direct access customer.

\subsection{Results of Comparison}

On its website, SDG\&E posts weekly PX credit information as well as hourly PX prices for the virtual direct access customers ${ }^{9}$. The hourly PX prices applicable for virtual direct access customers are called SDG\&E specific PX prices, and they include PX prices from the day-ahead and day-off markets in a distribution that is proportional to the SDG\&E procurement portfolio of these two markets. In addition, the PX prices include an uplift charge, which accounts for the incurred cost of the real-time markets, and a cost multiplier called distribution loss factor to account for the losses in the delivery of electric energy. The PX credits are posted on a weekly basis at the same site.

Table 10 shows the results of a cost comparison between the two commodity procurement options, using the weekly PX credits, the hourly SDG\&E specific PX prices, and the Navy's load profiles. The Navy receives a discount from Newenergy, Inc. applied to the PX credit, which is shown in Table 10 in the Direct Access column. The discount is account specific and shown in the table.

For the period November 1, 1998 through October 1, 1999, the virtual direct access option would have been about $\$ 414,000$ more expensive than the current direct access option with Newenergy, Inc. Without the Newenergy, Inc. discount, the virtual direct access would have still been more expensive by about $\$ 41,000$. This suggests that the other load class members have an aggregated load profile that is less pointed during the high-price periods compared to that of the Navy. It is difficult to derive general recommendations given these results because the number of members of the load class is changing and the impacts of this change on the aggregated load profile are difficult to assess.

\footnotetext{
${ }^{9}$ SDG\&E specific PX prices are found at http://www.sdge.com/EIC/html/loss_factors.htm
} 
Table 10: Results of Cost Comparison in Commodity Procurement between Direct Access and Virtual Direct Access

\begin{tabular}{|c|c|c|c|c|c|c|c|c|c|c|c|c|}
\hline \multirow[b]{2}{*}{ Month } & \multicolumn{3}{|c|}{$\begin{array}{c}\text { Naval Station Account } \\
1.70 \% \text { discount }\end{array}$} & \multicolumn{3}{|c|}{$\begin{array}{l}\text { North Island Account } \\
1.70 \% \text { discount }\end{array}$} & \multicolumn{3}{|c|}{$\begin{array}{l}\text { Pt. Loma Account } \\
1.87 \% \text { discount }\end{array}$} & \multicolumn{3}{|c|}{ Aggregated Account } \\
\hline & MWh & $\begin{array}{l}\text { Direct } \\
\text { Access } \\
{[\$ 1000]} \\
\end{array}$ & $\begin{array}{c}\text { Virtual } \\
\text { DA } \\
{[\$ 1000]} \\
\end{array}$ & MWh & $\begin{array}{l}\text { Direct } \\
\text { Access } \\
{[\$ 1000]}\end{array}$ & $\begin{array}{c}\text { Virtual } \\
\text { DA } \\
{[\$ 1000]} \\
\end{array}$ & MWh & $\begin{array}{l}\text { Direct } \\
\text { Access } \\
{[\$ 1000]}\end{array}$ & $\begin{array}{c}\text { Virtual } \\
\text { DA } \\
{[\$ 1000]} \\
\end{array}$ & $\begin{array}{c}\text { Direct } \\
\text { Access } \\
{[\$ 1000]} \\
\end{array}$ & $\begin{array}{c}\text { Virtual } \\
\text { DA } \\
{[\$ 1000]} \\
\end{array}$ & $\begin{array}{c}\text { Difference } \\
{[} \\
{[\$ 1000]} \\
\end{array}$ \\
\hline Nov-98 & 25,904 & $\$ 985$ & $\$ 768$ & 15,231 & $\$ 579$ & $\$ 468$ & 9,866 & $\$ 375$ & $\$ 299$ & $\$ 1,939$ & $\$ 1,534$ & $\$ 405$ \\
\hline Dec-98 & 31,080 & $\$ 964$ & $\$ 996$ & 16,981 & $\$ 536$ & $\$ 548$ & 11,433 & $\$ 357$ & $\$ 365$ & $\$ 1,857$ & $\$ 1,909$ & $-\$ 52$ \\
\hline Jan-99 & 23,846 & $\$ 714$ & $\$ 650$ & 15,219 & $\$ 464$ & $\$ 416$ & 10,353 & $\$ 312$ & $\$ 281$ & $\$ 1,491$ & $\$ 1,347$ & $\$ 144$ \\
\hline Feb-99 & 20,158 & $\$ 463$ & $\$ 460$ & 16,144 & $\$ 377$ & $\$ 374$ & 10,033 & $\$ 232$ & $\$ 23$ & $\$ 1,072$ & $\$ 1,064$ & $\$ 9$ \\
\hline Mar-99 & 20,486 & $\$ 454$ & $\$ 475$ & 18,795 & $\$ 421$ & $\$ 439$ & 9,200 & $\$ 205$ & $\$ 213$ & $\$ 1,080$ & 1,128 & $-\$ 48$ \\
\hline Apr-99 & 20,154 & $\$ 498$ & $\$ 518$ & 16,235 & $\$ 408$ & $\$ 426$ & 10,913 & $\$ 272$ & $\$ 282$ & $\$ 1,178$ & 1,226 & $-\$ 47$ \\
\hline May-99 & 26,378 & $\$ 1,557$ & $\$ 1,672$ & 15,632 & $\$ 927$ & $\$ 967$ & 11,152 & $\$ 654$ & $\$ 745$ & $\$ 3,138$ & $\$ 3,385$ & $-\$ 246$ \\
\hline Jun-99 & 27,521 & $\$ 915$ & $\$ 992$ & 15,721 & $\$ 533$ & $\$ 600$ & 10,116 & $\$ 333$ & $\$ 361$ & $\$ 1,781$ & $\$ 1,953$ & $-\$ 171$ \\
\hline Jul-99 & 25,528 & $\$ 906$ & $\$ 955$ & 14,815 & $\$ 546$ & $\$ 575$ & 12,468 & $\$ 449$ & $\$ 478$ & $\$ 1,901$ & $\$ 2,007$ & $-\$ 106$ \\
\hline Aug-99 & 21,231 & $\$ 722$ & $\$ 846$ & 12,360 & $\$ 427$ & $\$ 498$ & 9,084 & $\$ 307$ & $\$ 341$ & $\$ 1,456$ & $\$ 1,685$ & $-\$ 229$ \\
\hline $\begin{array}{l}\text { Sep-99 } \\
\end{array}$ & 26,995 & $\$ 1,004$ & $\$ 954$ & 19,669 & $\$ 749$ & $\$ 710$ & 9,841 & $\$ 369$ & $\$ 354$ & $\$ 2,122$ & $\$ 2,018$ & $\$ 104$ \\
\hline Oct-99 & 25,092 & $\$ 1,110$ & $\$ 1,208$ & 13,719 & $\$ 618$ & $\$ 664$ & 7,916 & $\$ 353$ & $\$ 385$ & $\$ 2,082$ & $\$ 2,256$ & $-\$ 174$ \\
\hline Total & 294,373 & $\$ 10,294$ & $\$ 10,493$ & 190,519 & $\$ 6,587$ & $\$ 6,683$ & 122,375 & $\$ 4,216$ & $\$ 4,335$ & $\$ 21,098$ & $\$ 21,511$ & $-\$ 414$ \\
\hline
\end{tabular}




\section{Trends and Developments}

In the summer of 2000, power markets in California experienced significant increases over the previous summer in the overall wholesale prices of electricity and ancillary services. Legislative actions by the state of California and an investigation by the Federal Energy Regulatory Commission into undue market influences followed in response. Although no conclusions have yet been reached as to what factors contributed to the alarming price increases over the summer of 2000, fundamental market conditions of tight power supplies and a very inelastic demand sector, that is, where demand responds very little to changing prices, are the underlying causes. The power supply has been tightening over the last several years, with peak demand growing by 5,500 MW between 1996 and 1999. During that same period, net generation increased only slightly by 672 MW [EOB 2000]. This trend is expected to continue with a booming California economy. Significant new capacity is not expected to be online until 2002 or 2003, based on filed applications for siting approval with the California Energy Commission [CEC, 1990].

Last summer, California's investor-owned and other utilities submitted to the California Public Utilities Commission requests for immediate implementation of energy efficiency and demand responsiveness programs. If approved, it is still questionable whether the energy efficiency programs can be implemented quickly enough to have an effective impact on peak demand in the summer of 2001.

The CAISO is currently undergoing an evaluation of the Summer 2000 Participating Load Trial Program in preparation for program revision of the Summer 2001 program. It is anticipated that workshops will be held to discuss lessons learned from the Summer 2000 program, which will then provide input for the revision of the 2001 program.

While over the long term new capacity will be brought online and thus mitigate the tight power supply markets in California, the short term outlook does not project any structural changes in the demand and supply conditions of the electricity markets for California. Given this situation, it is likely that CAISO trial programs and utility energy efficiency programs will continue. This also means that the marketability of the Navy's load management assets into CAISO markets is likely to continue for the next few years until the new capacity will be available. 


\section{Conclusions}

This analysis investigated cost savings opportunities for the Navy in San Diego, California by utilizing the ships' generator capacity to reduce the Navy's on-shore electric energy consumption during periods of high-cost energy. The analysis was motivated by the underlying premise that a reduced procurement of electric energy during periods when the spot market price of electricity is high, could create opportunities to resell the 'freed-up' electric energy back into the market or would allow the Navy or its energy provider to market the reduced demands such that ultimately a net benefit for the Navy would be generated.

Four separate load reduction programs were evaluated with regards to their potential cost savings opportunities for the Navy: (1) an energy-based load reduction program, (2) a capacity-based load reduction program, (3) the demand relief for summer 2000 program, and (4) the coincident on-peak demand reduction program. The results of the analysis are summarized for each program individually below.

\subsection{Energy-Based Load Reduction Program}

The economic value of operating an arbitrary but reasonable number of ship generators at those times when the hourly day-ahead prices at the California Power Exchange exceeded the Navy's own operating cost for the ship generators was evaluated. The economic value was determined over a period of 1 year (November 1998 through October 1999) assuming the availability of $20 \mathrm{MW}$ of generator capacity at $4.5[\mathrm{c} / \mathrm{kWh}]$ and $15 \mathrm{MW}$ of generator capacity at $9[\phi / \mathrm{kWh}]$. The $20 \mathrm{MW}$ capacity was assumed to be comprised of 15 surface ships with a reciprocating engine generator of $1 \mathrm{MW}$ capacity per ship and one aircraft carrier with a $5 \mathrm{MW}$ capacity. The $15 \mathrm{MW}$ capacity was assumed to be the aggregated capacity of 15 surface ships each equipped with a gas turbine generator of 1 MW. The following results were obtained:

- The total value of the on-board generation over a 1-year period is $\$ 273,000$. This is achieved by operating $20 \mathrm{MW}$ at $4.5[\mathrm{c} / \mathrm{kWh}$ ] for 469 hours and $15 \mathrm{MW}$ at 9.0 $[\phi / \mathrm{kWh}]$ for 78 hours.

- A realistic time window for the implementation of this program is the 9-5 time block. The total potential value is then reduced to $\$ 123,000$ with 159 hours of reciprocating engine operation and 39 ho urs of the gas turbine generator operation.

- By limiting the curtailment program to a 9-5 schedule, more than $50 \%$ of the total potential value was reduced. This is predominantly because the high price hours persisted during the early evening hours past $5 \mathrm{pm}$

- The average economic incentive for this program during the 9-5 schedule was 34 $[\$ / \mathrm{MWh}]$ or $3.4[\phi / \mathrm{kWh}]$. This translates into an economic incentive of $\$ 34$ per hour for each ship that operates its 1-MW generator. 


\subsection{Capacity-Based Load Reduction Program}

This program capitalizes on the market value of the load curtailment capabilities of the ship generators as seen at the Navy's electric meters. The appropriate market for the load curtailment capabilities is the replacement reserve market, which is one of the ancillary service markets conducted by the CAISO. The analysis evaluated the market value of 35 MW (20 MW reciprocating engines and 15 MW gas turbines) participating in the replacement reserve markets for a 1-year period (November 1998 through October 1999). The results are summarized below:

- There are two revenue streams available: (1) a capacity and (2) an energy payment. The maximal combined value of these payments is $\$ 1,499,000$ for the 24 -hour availability of $35 \mathrm{MW}$ of ship generator capacity. When reduced to a limited 9 am to $5 \mathrm{pm}$ schedule, the maximal combined value is $\$ 786,000$.

- The capacity-based program requires a bidding strategy and constant attention by monitoring the bidding performance. There are two major parameters that determine the revenue streams resulting from this program. The Navy needs to determine the hours and capacity to be bid into the replacement reserve pool first. If bid is accepted, the Navy will receive payments for being in the reserve pool with the commitment to be available for load curtailment dispatch by the CAISO. The frequency of the actual load curtailment dispatch is influenced by the energy bid. A high energy bid will reduce the probability, a low bid will increase the probability of dispatch. The CAISO determines dispatch based on the need for replacement reserves for maintaining safety and reliability of the California electric grid.

- The notification period for replacement reserves is 60 minutes. Within 60 minutes, the contracted load reduction must be achieved. In case of non-compliance, the CAISO imposes penalties.

\subsection{Demand Relief for Summer 2000 Program}

This program is part of the CAISO Summer 2000 Market Participation Load Trial Programs. It is designed for single or aggregated loads with relaxed telemetry requirements. It is only in effect for the summer season (June 15 through October 15, 2000) and limits the maximal load dispatch up to 30 hours per month. The CAISO will call participating loads just before or concurrent with a stage 2 emergency call. Participation in this program requires a successful bid to CAISO. The successful bidder will receive a capacity reservation payment independent of curtailment frequency and an energy payment based on the real-time energy markets for the period of load curtailment.

The capacity reservation payments are proprietary information and not disclosed by the CAISO. For the value estimates of this program, we used some unofficial estimates by a market expert of Newenergy, Inc. and bracketed the per kWh capacity payment into a low and high estimate. The energy payments are reliably estimated because they are based on the real-time energy markets. The hourly prices per MWh are published by the CAISO. So are the dispatch periods for the demand relief program. The value estimates 
are based on the scenario that $35 \mathrm{MW}$ of capacity be part of the demand relief program. The results are summarized below:

- Low capacity value is estimated to be $\$ 3,500,000$. High estimate is $\$ 5,600,000$.

- Energy payments using historic data for the period June 15 through August 31, 2000 are $\$ 877,600$. The project energy payments including the remainder of the trial program (September 1 through October 15, 2000) are $\$ 1,132,800$. During the load dispatch periods, the real-time energy markets were at their price caps.

- Total values for the low and high capacity estimates are $\$ 4,632,800$ and $\$ 6,732,800$ for a total projected dispatch period of 98 hours during the period of June 15 through Oct $15,2000$.

- The incremental or per-MWh value are high. They were evaluated to be $\$ 1,351 / \mathrm{MWh}$ and $\$ 1,963 / \mathrm{MWh}$ for the low and high capacity value estimates, respectively.

\subsection{Coincident On-Peak Demand Reduction}

The cost savings estimates for this program are based on the opportunity of reducing the coincident on-peak demand charge billed by SDG\&E. Included in the assessment are the cost impacts of displacing the utility delivered electric energy by on-board generation. The results of value estimation of this program are summarized below:

- Coincident on-peak demand charge reduction during the summer period (May 1 through September 30) is $\$ 1,433,250$.

- Net energy benefits were slightly negative meaning that the on-board generation is more expensive than the utility delivered electric energy.

\subsection{Volatility Analysis}

The report also presented the results of a volatility analysis. The volatility analysis was designed to provide insights into the magnitude of random load occurrences that may pose challenges in achieving CAISO compliance for a contracted load reduction target. The report presented a guideline for protecting against random load spikes.

\subsection{Block Forward Contracts}

The report evaluated the cost savings opportunities using block forward contracts to reduce the volatility exposure in the CALPX day-ahead prices. An optimal procurement portfolio was designed consisting of block forward contracts and spot market procurement. The cost of this optimal portfolio was compared to that of a pure spot market price portfolio for a 7 months period (June 99 through December 99). The savings potential using the optimal portfolio was estimated to be $7 \%$ over a 7 -month period with a total amount of $\$ 560,000$ in savings. 


\subsection{Comparison of Programs}

Table 11 below provides a summary of the assessed programs.

Table 11: Summary of Assessed Programs

\begin{tabular}{|c|c|c|c|c|}
\hline $\begin{array}{l}\text { Program } \\
\text { (Timeframe for value } \\
\text { estimate) } \\
\end{array}$ & Assumption & Total Value & $\begin{array}{l}\text { Total Run } \\
\text { Hours }\end{array}$ & $\begin{array}{c}\text { Normalized } \\
\text { Total Value } \\
{[\$ / \mathrm{MWh}]} \\
\end{array}$ \\
\hline \multirow{2}{*}{$\begin{array}{l}\text { Energy-based curtailment } \\
\text { program }\end{array}$} & $24 \mathrm{~h}$ availability & $\$ 217,000$ & $547 \mathrm{~h}$ & 11 \\
\hline & 9-5 availability & $\$ 125,000$ & $198 \mathrm{~h}$ & 18 \\
\hline \multirow{2}{*}{$\begin{array}{l}\text { Capacity-based curtailment } \\
\text { program }\end{array}$} & $24 \mathrm{~h}$ availability & $\$ 1,499,00$ & $320 \mathrm{~h}$ & 134 \\
\hline & 9-5 availability & $\$ 786,000$ & $148 \mathrm{~h}$ & 152 \\
\hline \multirow[b]{2}{*}{ Demand relief program } & Low estimate & $\$ 4,632,000$ & \multirow[b]{2}{*}{$98 \mathrm{~h}$ (projected) } & 1,351 \\
\hline & High estimate & $\$ 6,732,000$ & & 1,963 \\
\hline \multirow{2}{*}{$\begin{array}{l}\text { Demand charge reduction } \\
\text { program (SDG\&E) }\end{array}$} & Optimistic & \multirow[b]{2}{*}{$\$ 1,430,000$} & $15 \mathrm{~h}$ & 2,724 \\
\hline & Pessimistic & & $60 \mathrm{~h}$ & $\$ 659$ \\
\hline
\end{tabular}

The following general qualitative differences noticeable:

- The energy-based curtailment program exhibits the lowest value. It requires the longest run time of the ship generators and, thus, the longest commitment by the ship staff. As a result of the lowest total value and the greatest run time of ship generators the per MWh value is the lowest.

- The capacity-based curtailment program capitalizes on the capacity and energy value the power markets. It achieves a per MWh value by an order of magnitude greater than that for the energy-based curtailment program

- The demand relief program exhibits the highest total value and an order of magnitude improvement of the per MWh value compared to the capacity-based curtailment program. This result is attributable to the overall high prices during the summer of 2000, which may or may not be representative for the future. However, the capitalization of only the highest priced periods for only a few hours during the summer months makes this program attractive on a per MWh basis.

- The coincident on-peak demand charge reduction is valued at a fixed demand charge rate set by the SDG\&E rate schedule $(\$ 8.19 / \mathrm{kW})$. The per MWh value can be the highest of all program analyzed under optimistic assumptions. However, under more realistic assumptions (see Table 7) the value may be comparable to that of the demand relief program. 


\section{References}

A6-TOU, 1999. Schedule A6-TOU, General Service - Very Large - Time metered. Revised Cal. P.U.C. Sheet No. 12873-E. Date filed: June 29, 1999. Date effective: July 1, 1999. San Diego Gas \& Electric Company, San Diego, CA.

AB 1890, 1996. Assembly Bill 1890. Sponsored by Assemblyman Jim Brulte. Signed into law on September 23, 1996 by Governor Pete Wilson. Available at the web-site: http://www.leginfo.ca.gov/pub/95-96/bill/asm/ab_18511900/ab_1890_bill_960924_chaptered.html

CAISO BID, 1999. Schedule and Bids Protocol. ISO Tariff. California Independent System Operator, December 23, 1997.

CAISO CAP1, 2000. California ISO Board of Governors approves lowering price caps temporarily. News Release. California ISO. June 29, 2000. Downloaded on July 3, 2000 from website: http://www.caiso.com/docs/09003a6080/06/59/09003a6080065963.pdf

CAISO DR, 2000. Exhibit B, Pro Forma Demand Relief Agreement. California Independent System Operator, Downloads on March 24, 2000. http://www.caiso.com/docs/2000/03/24/200003241659376362.doc.

CAISO PL, 2000. Market Participating Load. Technical Standards for Summer 2000. . California Independent System Operator, March 1, 2000.

CAISO, 2000. Summer 2000 Demand Relief Program. Table of Times and Dates for Compliance Calculation. California Independent System Operator. Downloads from CAISO website on September 14, 2000. http://www.caiso.com/docs/2000/08/28/2000082809431728046.pdf

CALPX BF, 1999. CalPX Trading Services Block Forwards Market Background Information. California Power Exchange, Downloads on May 15, 2000. http://www.calpx.com/news/blockforwards/index.htm

CALPX PRIMER, 1999. California's New Energy Market. The Basics: How the California Power Exchange Works, California Power Exchange, December 1999. Pasadena, CA. Downloaded from CALPX website: http://www.calpx.com/news/publications

CALPX, 1999. The PX Market Experience. Becky Kilbourne, California Power $\begin{array}{llll}\text { Exchange. } & \text { Downloaded } & \text { October }\end{array}$ http://www.calpx.com/news/presentations/Infocast-Jan\%2099\%20new.ppt

CEC, 1999. California Energy Commission, High Temperature \& Electricity Demand. An Assessment of Supply Adequacy in California. Trend \& Outlook. California Energy Commission, Sacramento, CA. July 1999. 
CEC CAP, 2000. Wholesales Electricity Price Review, August 2000. California Energy Commission, Monthly review, Downloaded on September 11, 2000. http://www.energy.ca.gov/electricity/wepr/2000-08/index.html.

EOB 2000. M. Kahn, L. Lynch. California's Electricity Options and Challenges. Report to Governor Gray Davis. Electricity Oversight Board and California Public Utilities Commission. August 2, 2000. Available at CPUC website at:

http://www.cpuc.ca.gov/published/report/Table\%20of\%20Contents.htm

Gomez, Tomas, Chris Marnay, Afzal Siddiqui, Lucy Liew, and Mark Khavkin, 1999. Ancillary Services Markets in California. LBNL-43986. Ernest Orlando Lawrence Berkeley National Laboratory, Berkeley, California 94720.

Minos, 1993. Minos 5.4, User's Guide. Technical Report SOL 83-20R, B. A. Murtagh, M. Saunders. System Optimization Laboratory, Department of Operations Research, Stanford University, Stanford, CA. March 1993. 


\section{Appendix A: Load Profiles for Selected Navy Accounts}

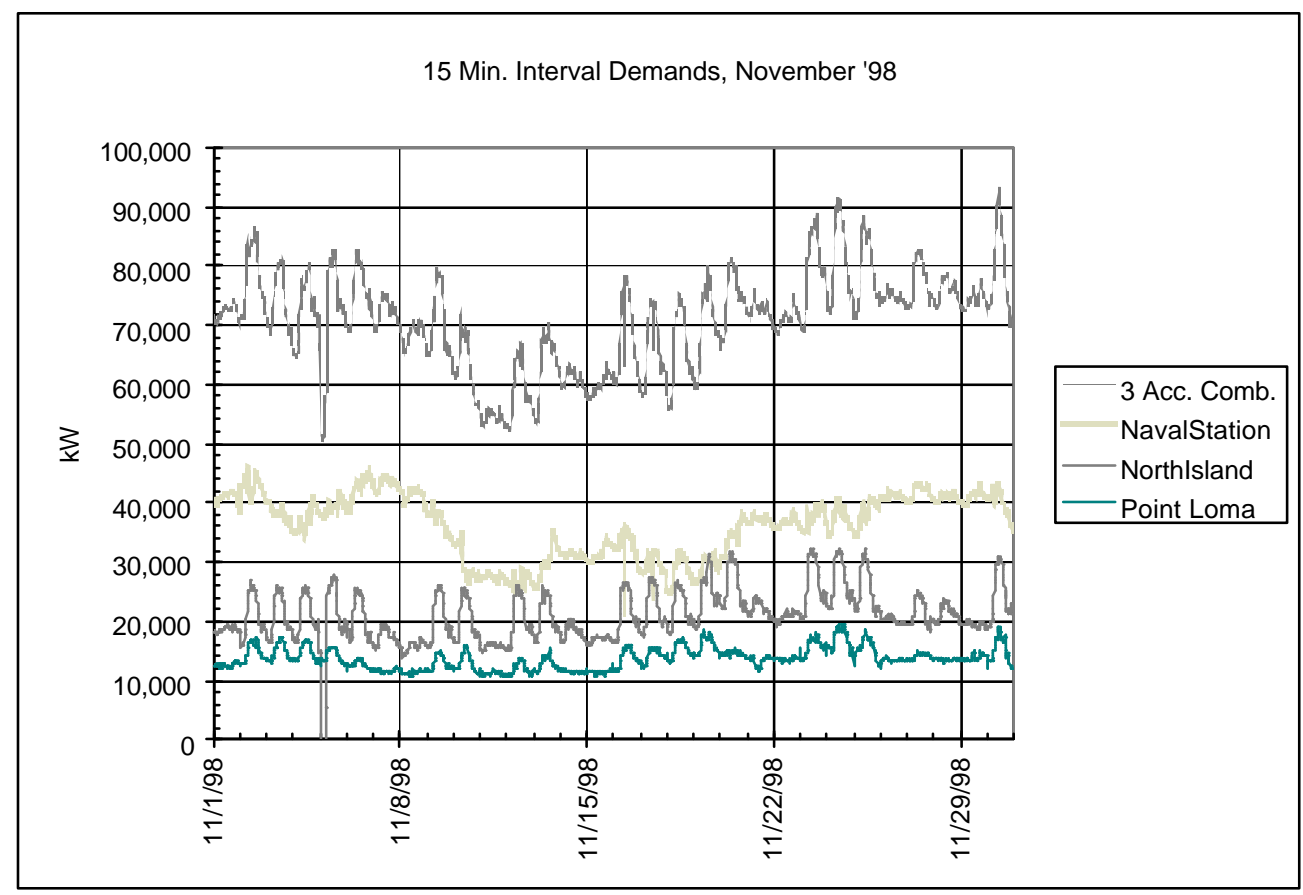

Figure A-1: 15 Min. Interval Demands, November 1998

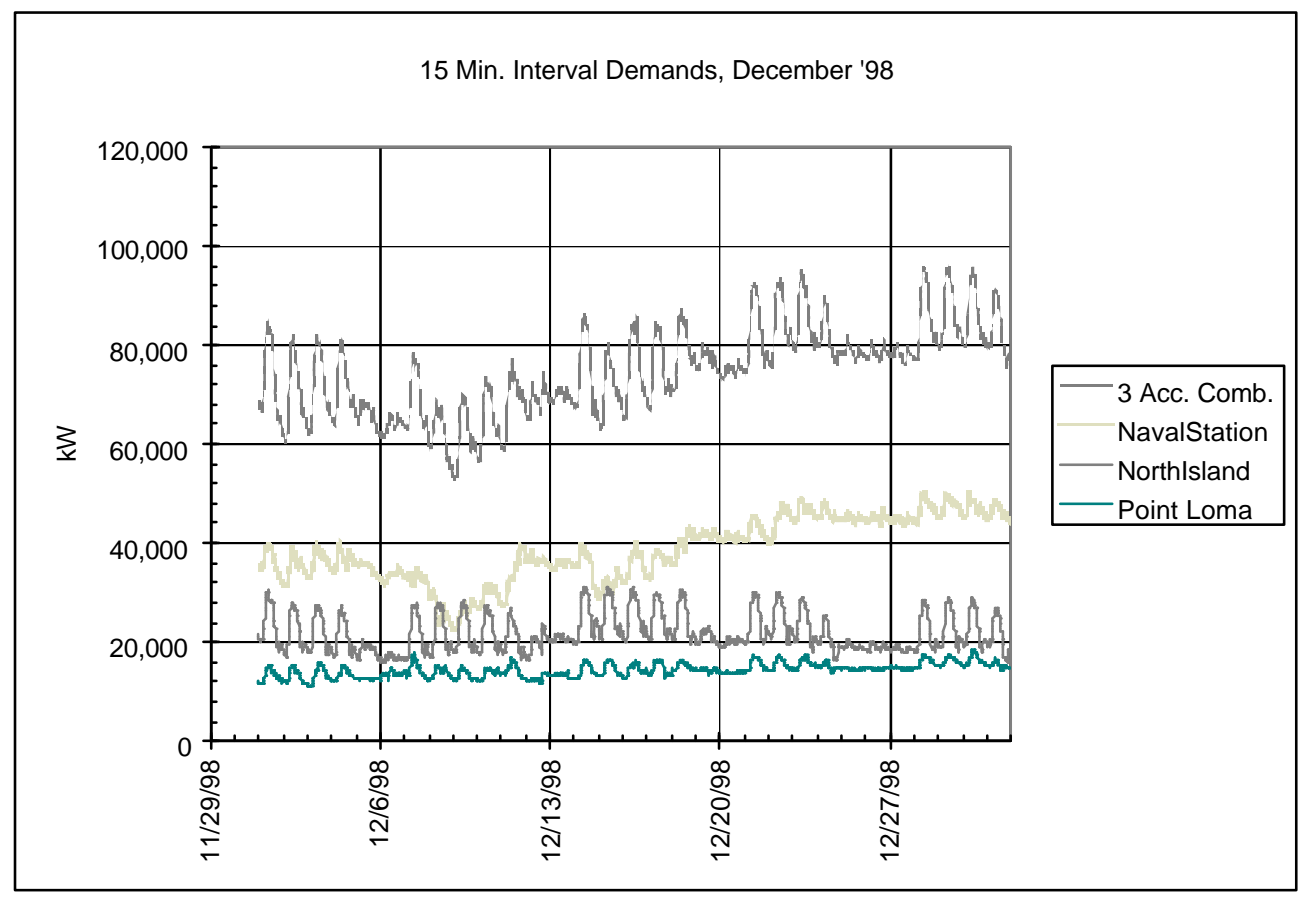

Figure A-2: 15 Min. Interval Demands, December 1998 


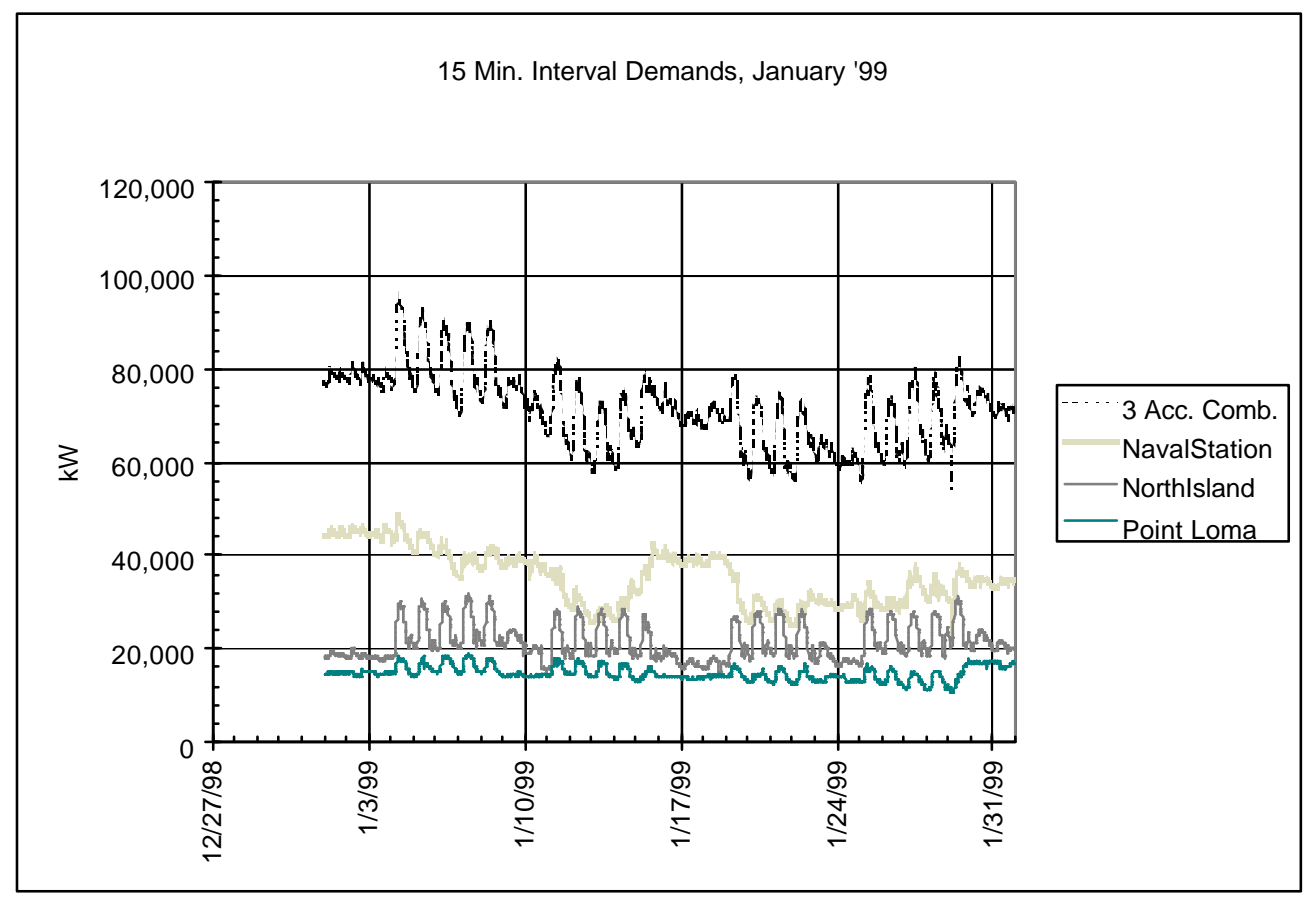

Figure A-3: 15 Min. Interval Demands, January 1999

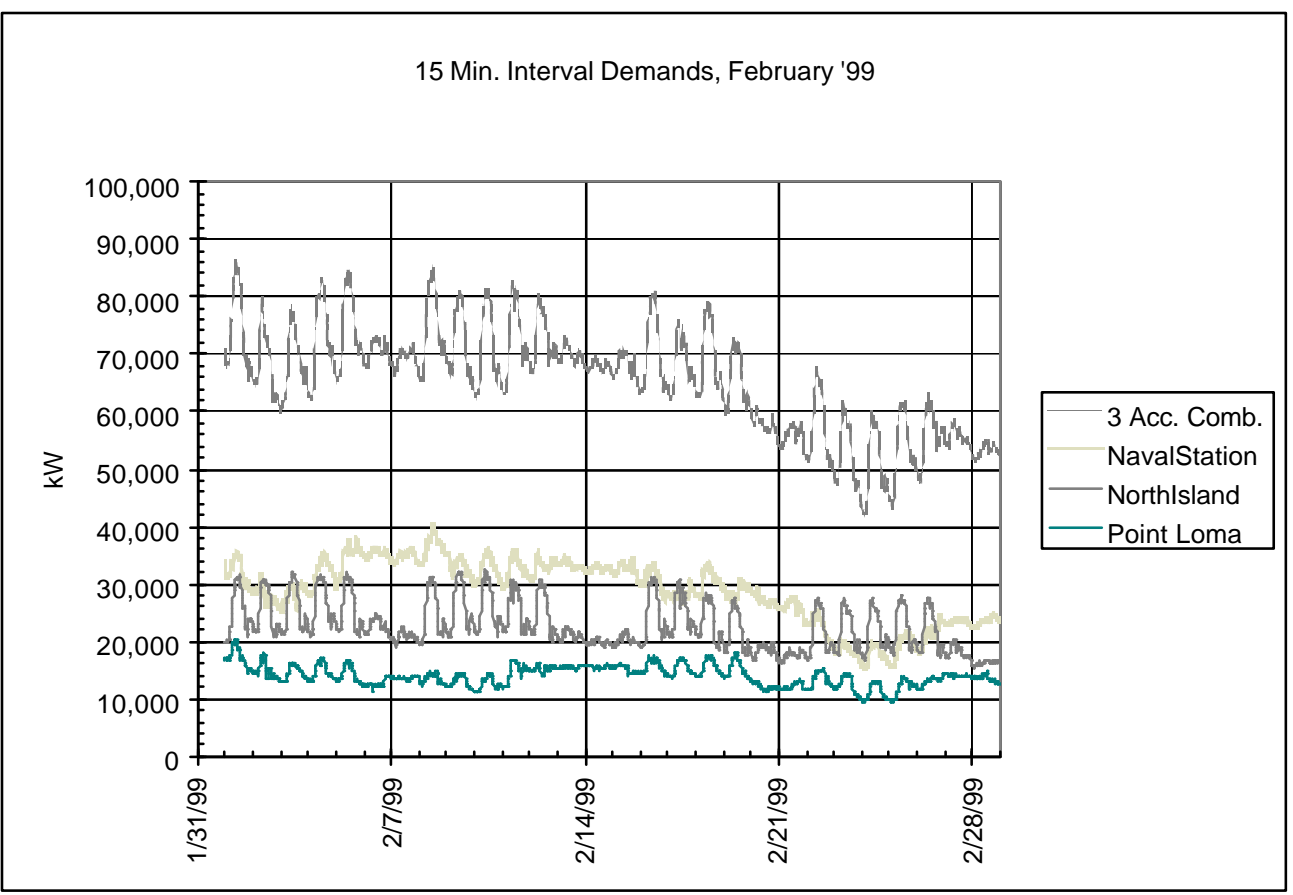

Figure A-4: 15 Min. Interval Demands, February 1999 


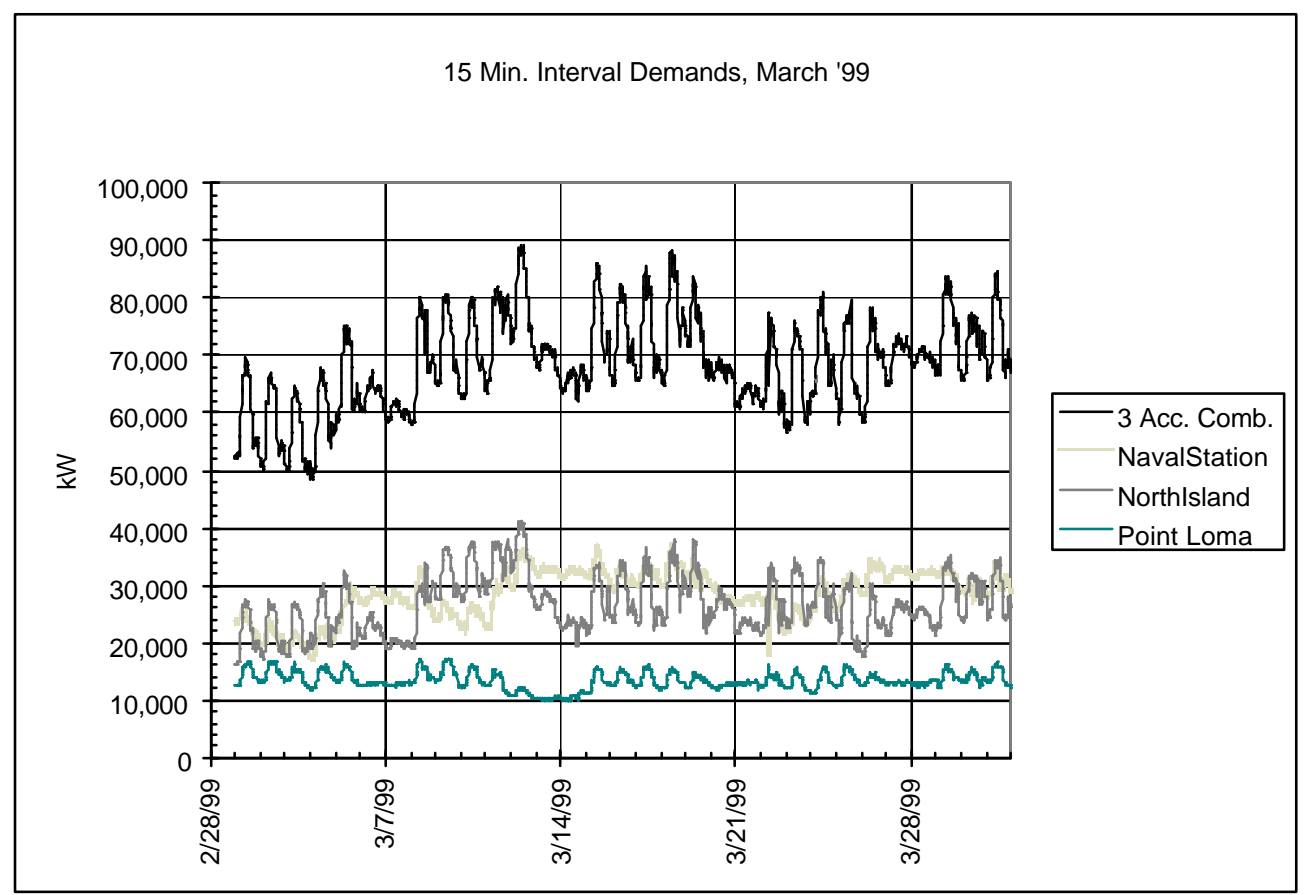

Figure A-5: 15 Min. Interval Demands, March 1999

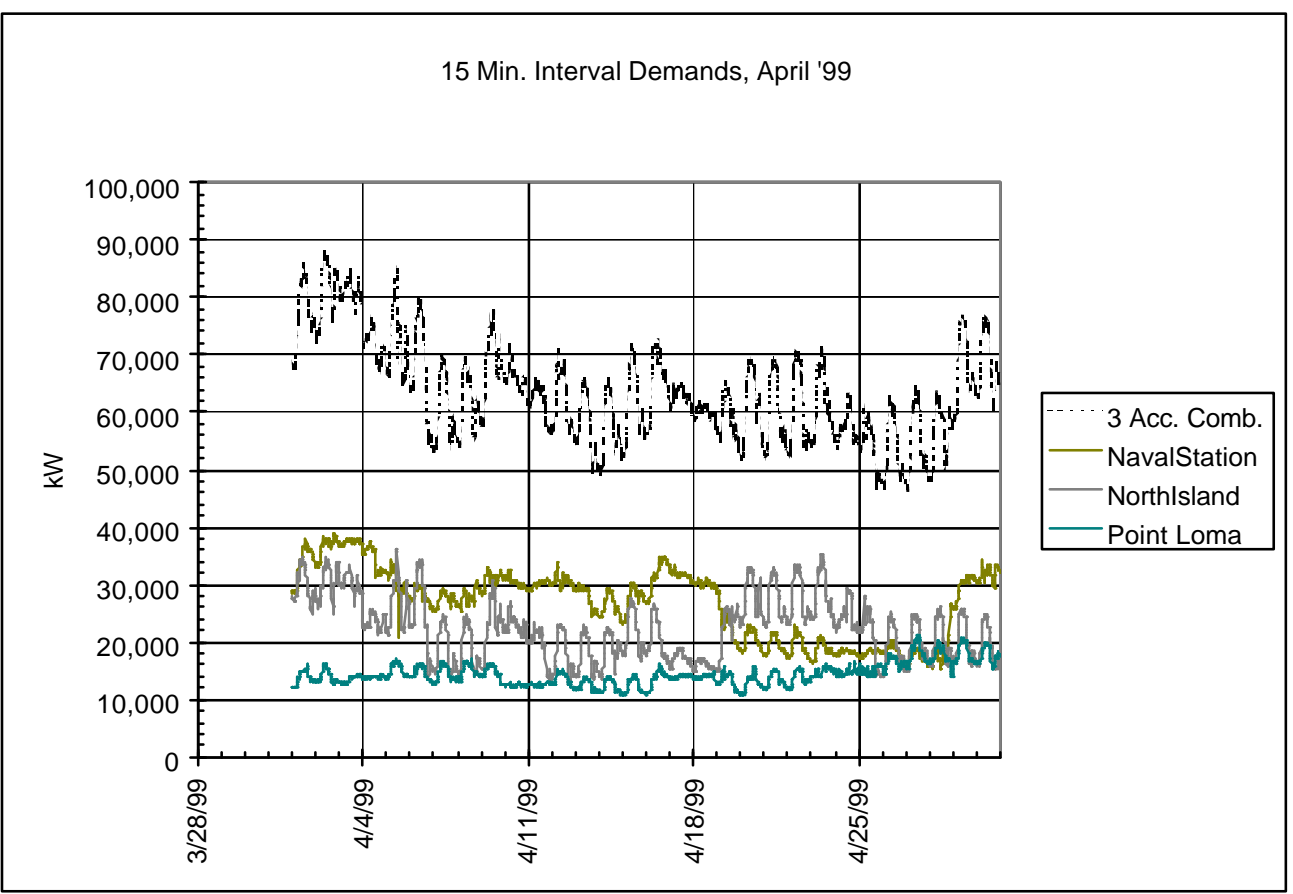

Figure A-6: 15 Min. Interval Demands, April 1999 


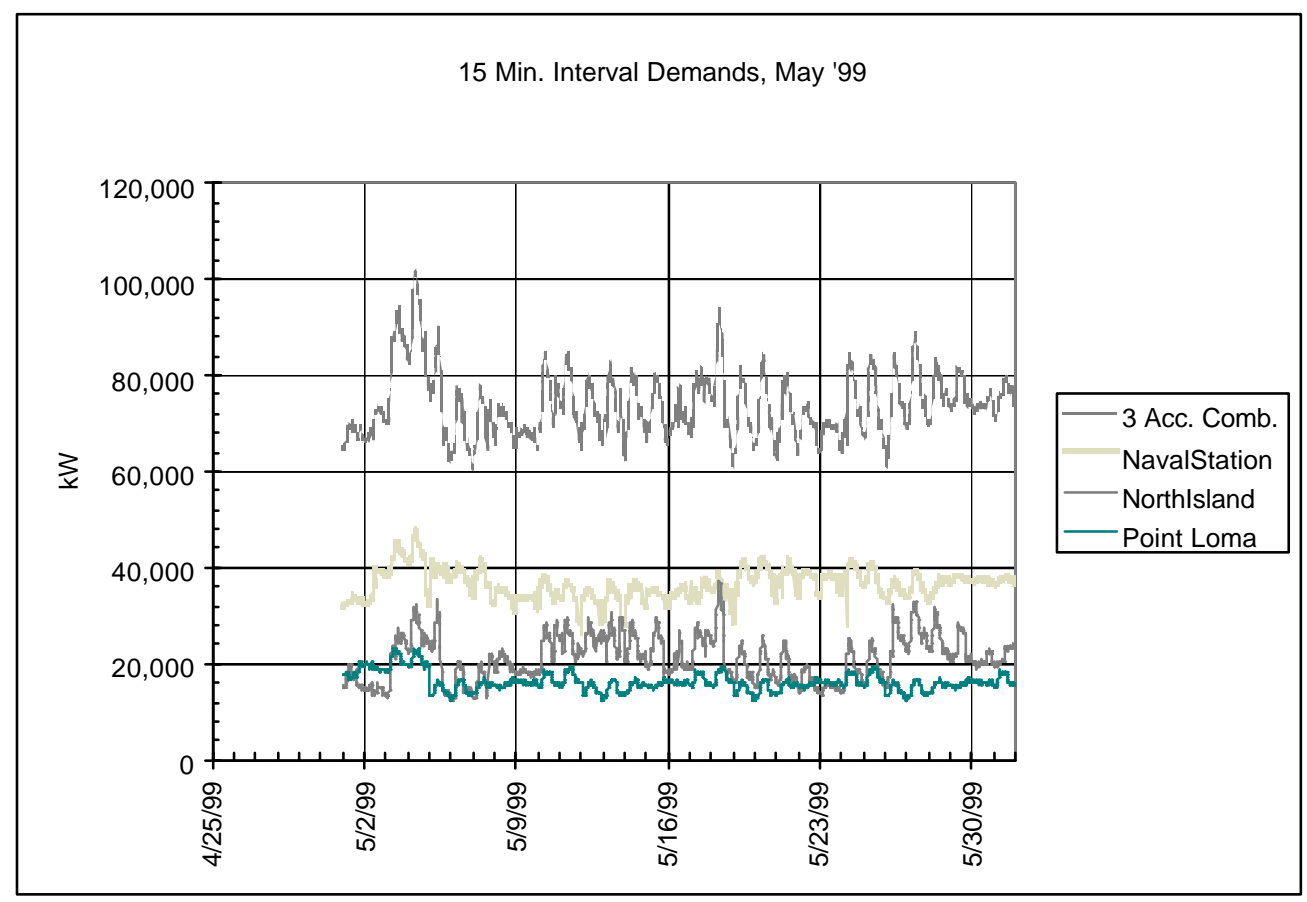

Figure A-7: 15 Min. Interval Demands, May 1999

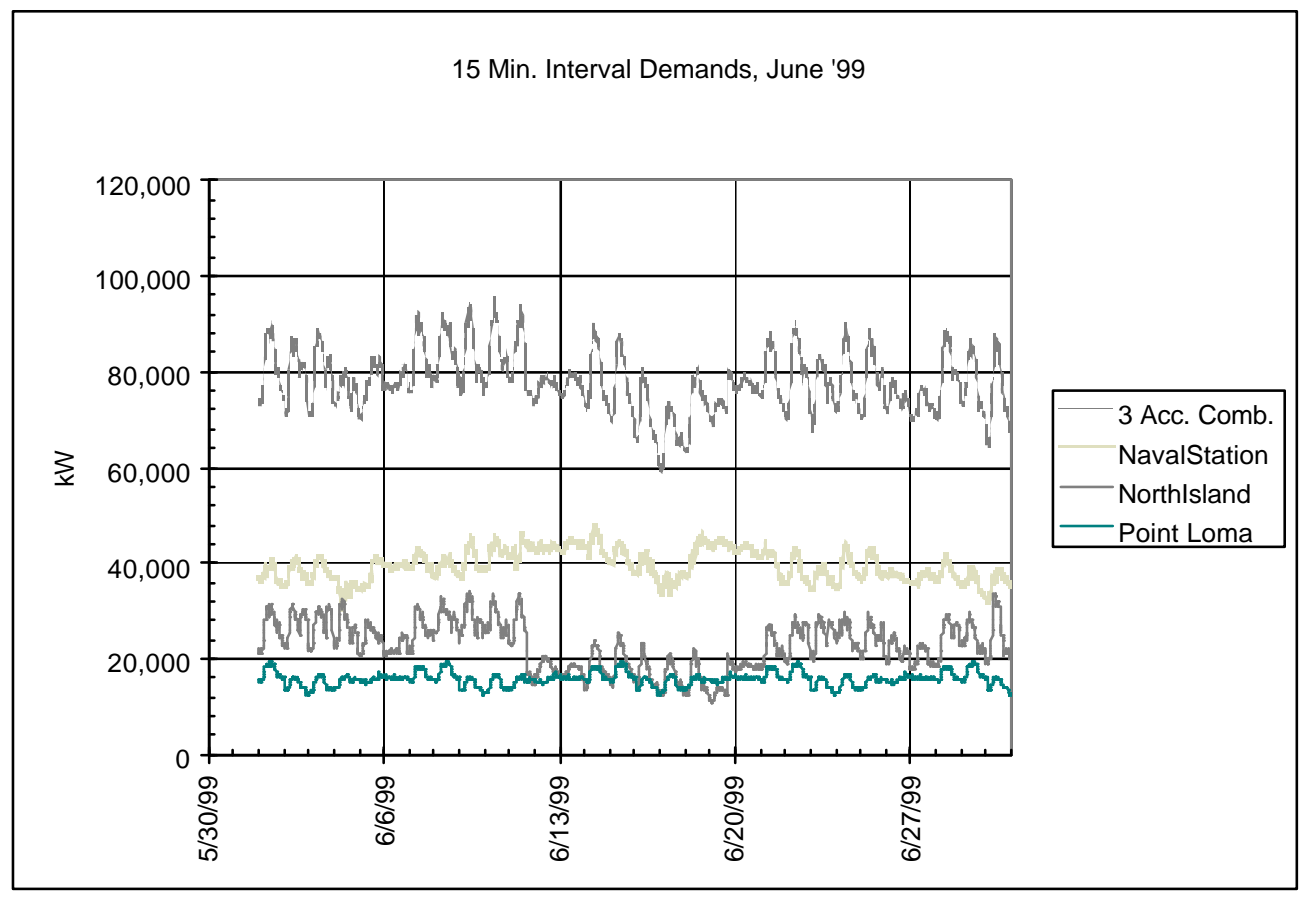

Figure A-8: 15 Min. Interval Demands, June 1999 
15 Min. Interval Demands, July '99

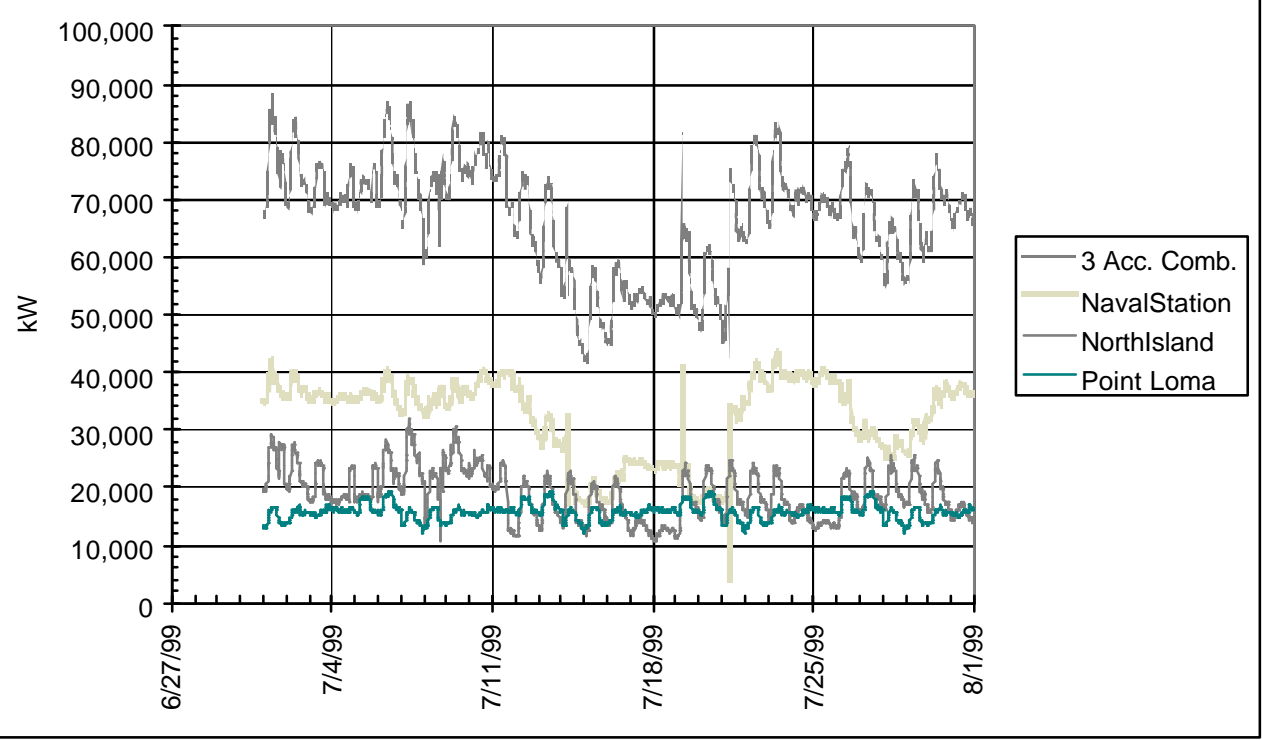

Figure A-9: 15 Min. Interval Demands, July 1999

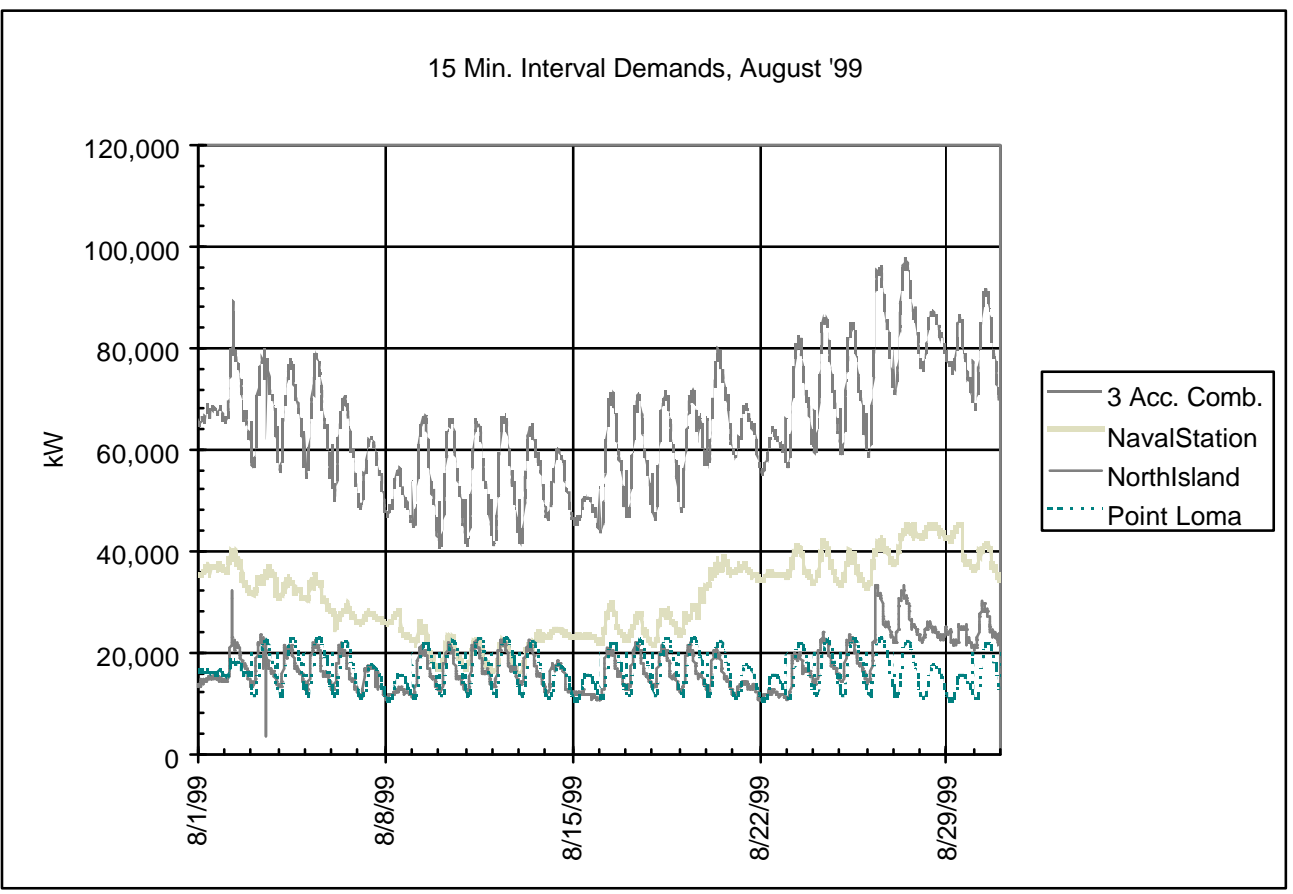

Figure A-10: 15 Min. Interval Demands, August 1999 


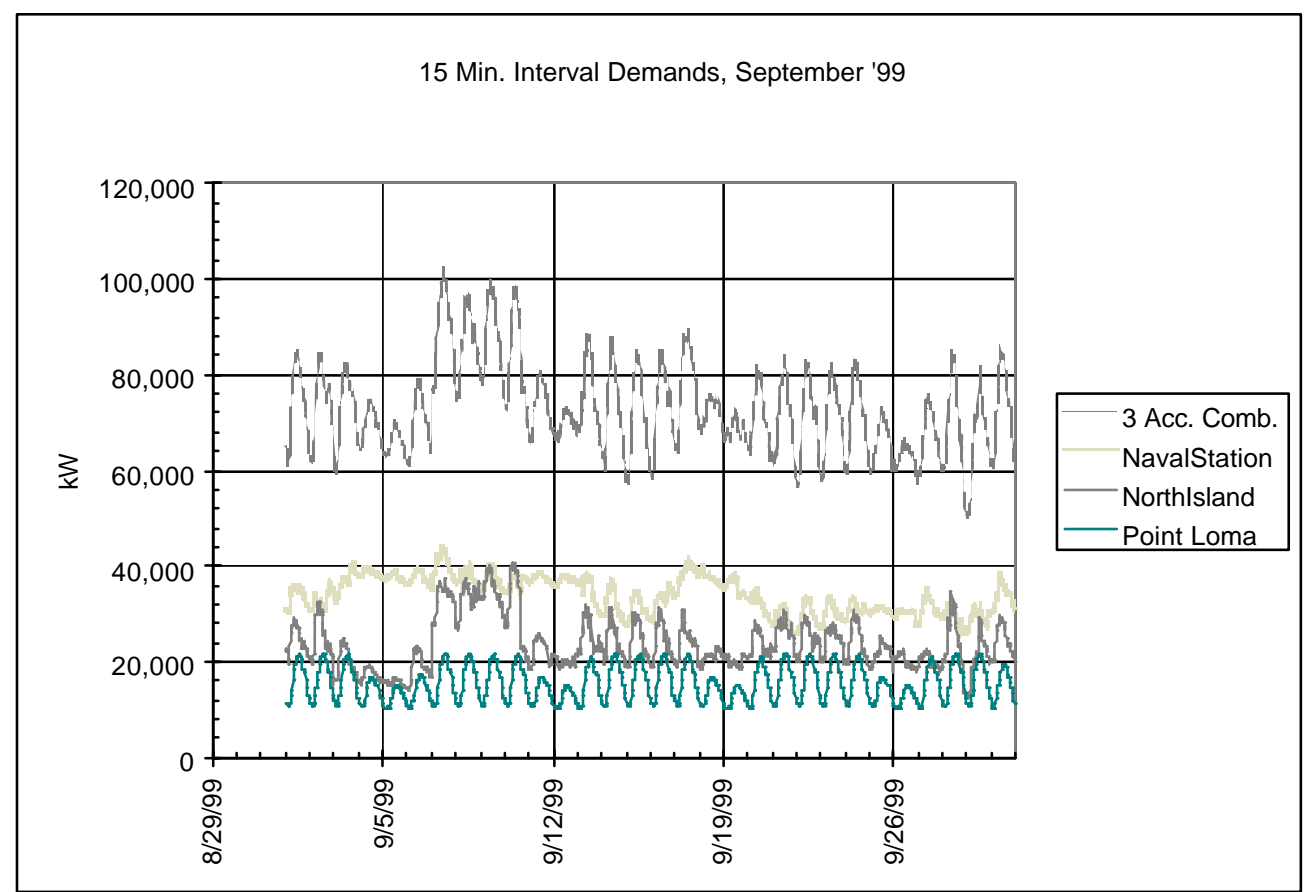

Figure A-11: 15 Min. Interval Demands, September 1999

15 Min. Interval Demands, October '99
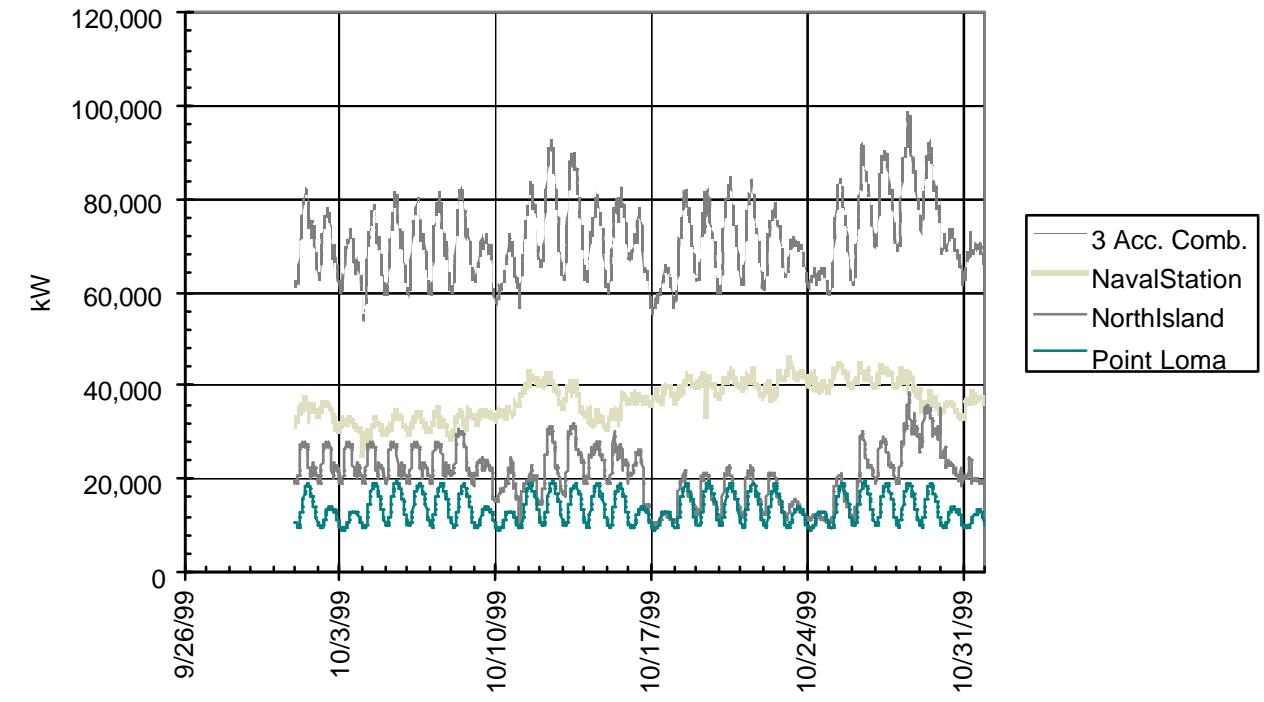

Figure A-12: 15 Min. Interval Demands, October 1999 


\section{Appendix B: Statistics of 15 Minute Interval Meter Readings by Day-of-the-Week}

\begin{tabular}{|c|c|c|c|c|c|c|c|c|c|}
\hline & Parameter & Sun & Mon & Tue & Wed & Thu & Fri & Sat & All \\
\hline \multirow{4}{*}{ RHM } & Low & 32886 & 29904 & 29148 & 29400 & 28524 & 17886 & 34398 & 17886 \\
\hline & Mean & 60213 & 63918 & 62857 & 61834 & 62828 & 64392 & 62328 & 62623 \\
\hline & High & 80128 & 99248 & 101456 & 95460 & 91904 & 93178 & 84312 & 101456 \\
\hline & STDev & 10259 & 12634 & 12644 & 12011 & 12041 & 11912 & 10500 & 11812 \\
\hline \multirow[t]{4}{*}{$\Delta \mathrm{RHM}$} & Low & -4872 & -18648 & -14952 & -19312 & -21680 & -14448 & -10248 & -21680 \\
\hline & Mean & -8 & -4 & -23 & 7 & 18 & 31 & -15 & 1 \\
\hline & High & 5488 & 17976 & 15792 & 26376 & 37296 & 31664 & 11592 & 37296 \\
\hline & STDev & 549 & 982 & 868 & 959 & 1129 & 920 & 625 & 882 \\
\hline \multirow[t]{4}{*}{$\Delta \mathrm{E} 15$} & Low & -2058 & -4284 & -4494 & -5564 & -15120 & -5304 & -2576 & -15120 \\
\hline & Mean & -9 & -1 & -23 & 7 & 18 & 29 & -15 & 1 \\
\hline & High & 1806 & 5670 & 4452 & 7938 & 13136 & 13026 & 3654 & 13136 \\
\hline & STDev & 268 & 542 & 543 & 561 & 706 & 593 & 320 & 525 \\
\hline \multirow[t]{4}{*}{$\Delta \mathrm{E} 60$} & Low & -8232 & -17136 & -17976 & -22256 & -60480 & -21216 & -10304 & -60480 \\
\hline & Mean & -38 & -4 & -91 & 28 & 71 & 118 & -61 & 3 \\
\hline & High & 7224 & 22680 & 17808 & 31752 & 52544 & 52104 & 14616 & 52544 \\
\hline & STDev & 1072 & 2169 & 2170 & 2245 & 2825 & 2372 & 1280 & 2099 \\
\hline
\end{tabular}

Where:

-RHM: Means of a rolling window of 1 hour,

- $\triangle$ RHM: Difference of RHM over a 15 Min. time step,

$-\Delta \mathrm{E}_{15}$ : Difference in electric energy $(\mathrm{kWh})$ over a 15 -minute time step,

$-\Delta \mathrm{E}_{60}$ : Difference in electric energy $(\mathrm{kWh})$ over a 415 -minutes time steps 